\title{
Roadmap for Development of Natural Gas Vehicle Fueling Infrastructure And Analysis of Vehicular Natural Gas Consumption by Niche Sector
}

\author{
Prepared for \\ National Energy Technology Laboratories (NETL) \\ U.S Department of Energy \\ Cooperative Agreement No DE-FC26-05NT42609
}

By

Clean Vehicle Education Foundation

Atlanta, Georgia

Principal Author

Stephen C. Yborra

Director of Market Analysis, Education \& Communications 


\section{DISCLAIMER}

This report was prepared as an account of work sponsored by an agency of the United States Government. Neither the United States Government nor any agency thereof, nor any of their employees, makes any warranty, express or implied, or assumes any legal liability or responsibility for the accuracy, completeness, or usefulness of any information, apparatus, product, or process disclosed, or represents that its use would not infringe privately owned rights. Reference herein to any specific commercial product, process, or service by trade name, trademark, manufacturer, or otherwise does not necessarily constitute or imply its endorsement, recommendation, or favoring by the United States Government or any agency thereof. The views and opinions of authors expressed herein do not necessarily state or reflect those of the United States Government or any agency thereof. 


\section{EXECUTIVE SUMMARY}

America's dependence on petroleum-based fuels for the transportation sector creates serious energy security, economic, air quality and other environmental challenges. Greater use of alternative fuel vehicles (AFV) is part of the solution to these challenges and natural gas vehicles (NGV) are an AFV option that offers substantial environmental, economic and energy security benefits. Despite these advantages, after more than forty years of industry and government investment in NGV and fueling infrastructure technology research and development (R\&D), NGVs still account for only a very small percentage of the total U.S. vehicle inventory and transportation fuel use.

For NGVs to make a greater contribution, there must be an acceleration of vehicle deployment and, critical to achieving that goal, greater infrastructure development. The U.S Department of Energy, through it's National Energy Technology Laboratory, tasked the Clean Vehicle Education Foundation (CVEF) with assessing the current status of NGV fueling infrastructure and vehicular natural gas consumption in order to evaluate successes and failures, the market factors that impacted these outcomes and what steps should be taken next to facilitate further station development. While the task statement placed particular emphasis on heavy-duty niche markets where vehicle deployment and fuel consumption have been greatest, it also directed that the report address public NGV fueling infrastructure as natural gas fueling technology and standards are viewed by many as the logical pathway or bridge to future hydrogen infrastructure market development.

NGV fueling infrastructure development cannot be viewed in a vacuum absent the influences of vehicle availability, government policy, market sales and service support, economic incentives and other market drivers. Individual favorable market drivers all existed at one point or another over the past forty years but were rarely in place at the same time. This directly impacted the type and amount of fuel station development, the level of station utilization and which stakeholders participated.

Historically, the NGV market - and its fueling infrastructure development - went through three general "phases" between 1965-2005. The first phase (1965-1990) was a period of slow growth, driven mostly by utilities and primarily for their own use although outreach to customers gradually built a customer base. The second phase (1990-1996) was a boom period of vehicle sales, station installation and ever-increasing fuel throughput, driven by a combination of government policy, increasing utility interest in developing an NGV market and the major auto companies' engagement of the technology and its potential. During the third phase (1997-2005), NGV market development was derailed, as many utilities’ NGV market development programs were decimated by gas utility deregulation and auto manufacturers introduced their factory-built NGVs then discontinued them (except Honda) when federal fleet mandate policies were circumvented or never materialized and vehicles sales fell far short of expectations. The unfulfilled expectations of the LDV market were somewhat offset by growing sales to operators of heavy-duty fleets, especially transit agencies and - to a lesser degree - airports, school districts and refuse companies.

By year-end 2005 (the reference point for CVEF's data collection efforts), the nation's estimated 92,000 NGVs consumed nearly 200 million GGEs, fueling at approximately 1100 stations. Of the 189.5 million GGEs allocated in CVEF's survey of 2005 data, 39.5 million GGEs was LNG and the rest was CNG. The transit sector accounted for the largest throughput (68.3\%) followed by airports (8.1\%), refuse (7.6\%), government (4.9\%), short-haul (3.0\%), utilities (2.7\%), schools (2.5\%) and "other" (2.6\%). Geographically, the Western region accounted for the highest fuel throughput (65.3\%), followed by the Mid-Atlantic region - including New York (15.4\%), the South Central region (7.3\%), the Southeast region (4.5\%), the Northeast (3.3), the Midwest region (2.2\%) and Rocky Mountain region (2.0\%). Throughput by niche sector varied from one region to the next; transit dominated in five of the seven regions. 
Of the 1100 stations, roughly $16 \%$ are operated by independent (non-utility) fuel providers, $27 \%$ are operated by utilities, another $37 \%$ are operated by federal, state or local governments and quasigovernment entities (e.g., transit, school, airport), 17\% percent are operated by private businesses (e.g., linen services, package companies, building trades contractors), and the remaining $3 \%$ percent are operated by individual consumers. Furthermore, $15 \%$ of the CNG stations accounted for roughly $65 \%$ percent of total U.S vehicular CNG throughput. Another 75\% of CNG stations accounted for the $35 \%$ of CNG fuel throughput. The remaining $10 \%$ percent of CNG stations were dormant or dispensed negligible amounts of fuel, amounting to less than 1\% percent of the U.S total. Many of the dormant or underutilized CNG stations are government- or utility-owned-and-operated and, most, only for their own CNG fleets, which are dwindling. Others allow public access but do not conduct market outreach to build load. Many of these stations are in need of repairs and/or upgrades to make them viable regardless of who owns and or operates them. Undoubtedly, there will be further attrition in the station counts as underutilized stations that are not upgraded by the present owner-operators, or purchased by independent fuel providers, are eventually decommissioned. Knowledgeable NGV industry analysts view this is a continuation of the infrastructure "market correction."

The NGV market is poised for growth but additional help from the federal government is needed and warranted. This includes public statements from the President and other high-level policymakers in the Executive Branch concerning the benefits of NGVs and their role in helping the nation meet its air quality and transportation energy portfolio diversification goals. Congress should extend the vehicle, station equipment and motor fuels excise tax credits far enough out (at least 10 years) so that the marketplace is assured that inclusion of these credits in their life-cycle cost analyses for these investments is a valid assumption. Also, funding for NGV RD\&D needs to be restored, at least to its previous level - if not higher. These funds are needed so that further emissions, efficiency and performance improvements to vehicles and engines can be made, new fuel storage materials and systems can be developed, and manufacturer's introduction of new NGVs may be accelerated, among other goals. Positive Executive Branch statements about NGVs' role in the nation's alternative fuel strategy and allocation of funding for NGV RD\&D initiatives - like those that have been made for biofuels - will encourage private industry investment in the NGV market and also go a long way in prompting GM, Ford, DaimlerChrysler, Toyota, Nissan and other major automotive manufacturers all of whom offer NGV models elsewhere in the world - to develop and market NGVs here in the U.S.

Government action must be accompanied by greater NGV industry action. Most important, it must increase its market presence through enhanced sales, marketing and communications activities. For example, utilities that suspended or eliminated their NGV market development efforts must be reengaged and shown how NGV programs can benefit their communities and their organization's bottom line. Their involvement at the local level, often with existing customers, will raise awareness and generate additional leads for suppliers to pursue. Station development/O\&M companies and equipment suppliers that are not doing so already, need to invest more resources in sales and marketing and/or provide greater support to their dealers to amplify their voice in the marketplace. NGV industry stakeholders also need to engage others outside their traditional circle of advocate-allies who may benefit from advancing the NGV market. These include petroleum retailers who increasingly market other alternative fuels like biodiesel and E85. It also includes fleet sales, lease and finance companies that can benefit from offering their clients additional "green" options that improve the bottom line. Last, but certainly not least, NGV advocates need to garner greater national media attention for the technology's many benefits by showcasing successful applications. These communications need to be targeted to fleets in their trade publications and also to the general public via mass communications to raise awareness and seed the market for future consumer market growth.

Today’s NGV industry sales and marketing efforts tend to focus on opposite extremes of the market. 
At one end are the very-high fuel use accounts that require the design and construction of large sophisticated fueling stations and - in many cases - desire operation and maintenance services. These high-profile accounts generate revenue streams necessary to attract the interest of national station developer/O\&M companies. At the opposite end are very low volume accounts that need relatively inexpensive and easily maintained fueling packages that fleets own and operate, typically. Small CNG equipment package manufacturers' generally rely on their dealer/representatives to prospect for and close the sales on these accounts. Both are important to the continued growth of the industry. In addition, there are literally thousands of potential prospects that have fueling needs that fall below the volumes necessary to attract station development/O\&M companies for an on-site station but for whom multiple small equipment packages is not a practical solution. Generally, these stations require the services of an engineering firm that can help the client determine needs, then design the installation and select the appropriate equipment. Equipment that meets these needs is available but the companies that produce it have few sales-marketing resources plying the market, relying instead on a limited number of experienced engineering and/or general contracting firms initiate the sale. As a result, many prospects located in regions other than the "usual hot spots" (e.g., California, New York, Texas) are largely ignored, yet they present a good economic case for fleet owned-and-operated CNG stations.

One of the barriers to developing a more robust retail CNG station infrastructure has been lack of resources. Fuel providers need to recoup their substantial investment in property, equipment, design, construction, maintenance and operations and marketing by growing fuel throughput quickly. Amoco pursued this path in 1995-1998 but exited the market when BP bought the company and slower-thanprojected sales growth did not meet the new owners' expectations. One approach to retail station development that appears to be working well and shows promise for future growth is to co-locate retail fueling capability at a host fleet's depot with "outside-the-fence” public access. The incremental cost of extra compression and storage capacity is less than if building from scratch and the added investment for the retail-side dispenser(s) and payment processing hardware is reasonable. A possible downside to this approach is that many fleets' depots are located in undesirable or inconvenient areas (e.g., industrial parks, warehouse districts). This type of "add-on" retail fueling capability should be given grant priority, especially in areas lacking existing public infrastructure.

Another approach to developing retail fueling infrastructure is to pool the fueling needs of one or more anchor fleets at an independent location that is convenient to the anchor fleet(s) and also to miscellaneous CNG vehicle operators (e.g., consumers, small business with one or two vehicles). Identifying this perfect mix of anchor customer(s) need, main thoroughfare proximity and access and real estate availability is easier said than done. These station development projects seem to work best when there are local government policies in place that promote NGV deployment either through mandates and/or economic incentives.

Several independent and utility fuel providers have had success in installing CNG fueling equipment at existing traditional retail petroleum site where gasoline and/or diesel is sold. Typically, a lease agreement is signed where the CNG fuel provider owns, operates (monitors) and maintains the equipment and the retailer gets a royalty on the natural gas as well as the added profitable in-store traffic. The upside to this approach is that retail gas stations are typically sited at prime high-visibility locations where there is convenient access and an established customer base. The only downside is that retail gas station/mini-marts are typically not configured for larger vehicles. NGV industry stakeholders may be well advised to pursue "big box" retailers (e.g., Costco, Wal-Mart) to include CNG as an option at fuel retailing store locations. Multi-site "truck stop" developers, which have many of the right characteristics for CNG station co-development (large footprint, easy on/off highway access, retail and fleet fueling islands, experience/familiarity with branded fuel card systems, existing natural gas service), may be another avenue worth pursuing more aggressively. 


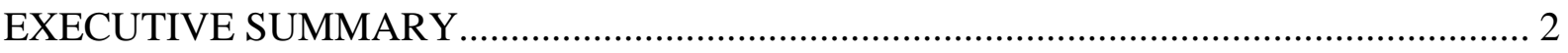

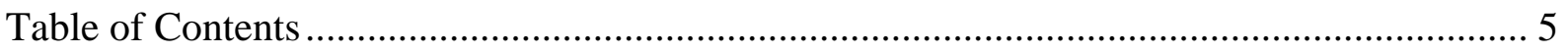

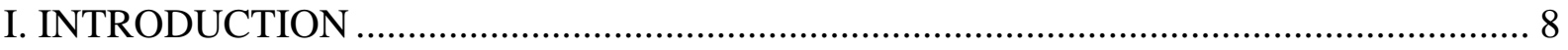

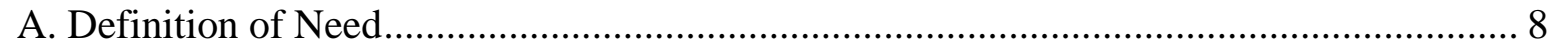

B. Scope of Work .................................................................................................. 9

II. ROADMAP FOR DEVELOPMENT OF NGV FUELING INFRASTRUCTURE ........... 10

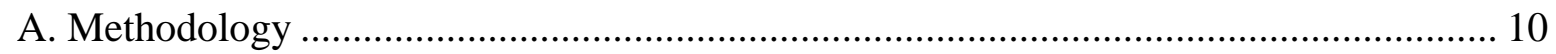

B. Historical Review of NGV Market and Supporting Infrastructure Development.......... 10

C. Types of Stations, Access and Development, Ownership and Operations Options........ 13

D. Factors Affecting NGV Fueling Infrastructure Development..................................... 16

E. Status of Current Natural Gas Fueling Infrastructure............................................... 29

F. Recent Trends in CNG Station Development, Ownership and Operations .................... 31

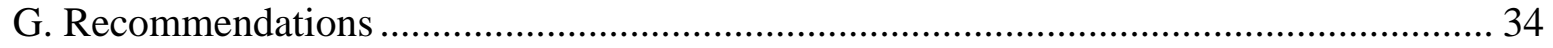

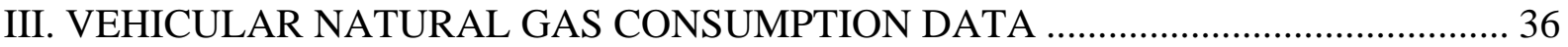

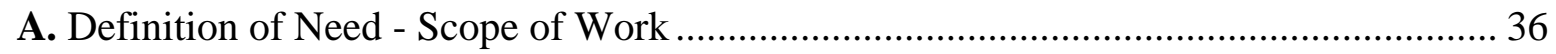

B. Assessing Past and Present NGV Data Collection Program ........................................ 36

C. Investigation of Data Availability and Collection Methodologies............................... 38

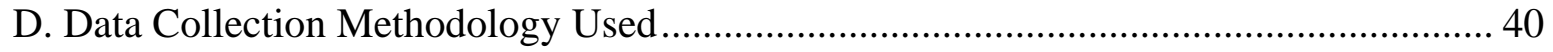

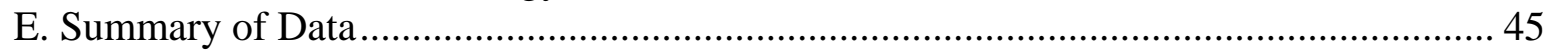

F. Recommendations For Future Vehicular Natural Gas Data Collection and Tracking .... 55

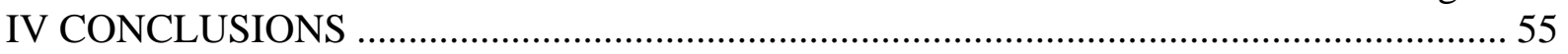

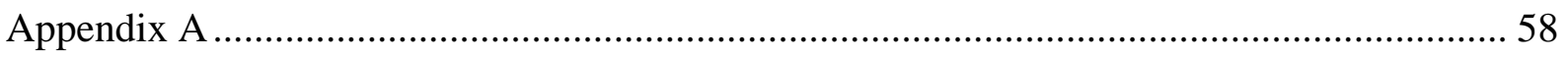

Summary of NGV Market and Fueling Infrastructure Development .................................... 58

I. 1965-1990: Gas Utilities Slowly Build An NGV Market From the Ground Up................. 58

A. Pioneering Utilities Demonstrate The Technology's Potential.................................. 58

B. Utility Interest Grows and An Industry is Spawned................................................ 58

C. Maturing NGV Industry Focuses on Technology Improvement................................... 58

D. Market Dominated by LDVs Operated by Few Early Adopter Utilities....................... 59

E. Early NGV Infrastructure Development and Operations ........................................... 59

F. Snapshot 1990: The NGV Market After First Quarter Century ................................... 60

II. 1990-1996: Boom Times For NGV Market Development ............................................ 60

A. Government Policy Energizes the Alt Fuel Vehicle Market........................................ 60

B. Major Vehicle OEMs Finally Engage, Market Takes Notice ..................................... 61

C. Early LNG Market Developments....................................................................... 62

D. NGV Market Experiences Sustained Double-Digit Vehicle Sales Growth ................... 62

E. Market Growth Leads to Station Development Frenzy, Trips and Pitfalls .................... 63

F. Snapshot 1996: A Market Positioned For Continued Expansion .................................. 63

III. 1997-2005: Utility Deregulation, Unfulfilled Expectations Derail NGV Momentum ...... 64

A. Deregulation Leads Many Formerly Active Utilities To Disengage From NGVs ........ 64

B. OEMs’ Vehicles Arrive as Many Utilities Exit, Price Premiums Are An Obstacle ....... 65

C. SVM Network and Vehicle Choices Dwindle as Regulation Takes its Toll.................. 65

D. Unfulfilled Expectations Lead All But One LDV OEM to Exit Market ........................ 66

E. As LDV Sales Falter, Steady Gains in HDV Niche Sectors Sustain Market ................. 67

F. Fueling Infrastructure Experiences Market Correction For Excesses of 1990s ............. 67

G. As NGV Inventory Peaks, Then Declines, Vehicular Natural Gas Use Climbs ............. 67

H. Snapshot 2005: Amid Mixed Market Signals, Industry Prepares to Redouble Efforts... 68 
IV. 2006-2007: Tax Credits, Emissions Advantages, Petroleum Prices Energize NGV Market

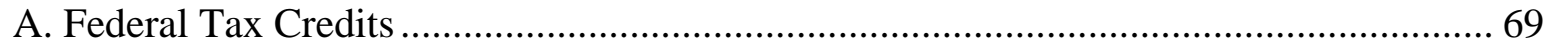

B. EPA Heavy-Duty Engine Emissions Requirements Take Effect......................................69

C. Current LDV Options Are Limited But Remaining OEM, SVMs Are Optimistic .......... 70

D. Price Differential Between Natural Gas and Petroleum Fuels Grows ............................. 70

E. Vehicle Counts Drop, Fueling Infrastructure Remains Flat, Throughput Continues to Grow 70

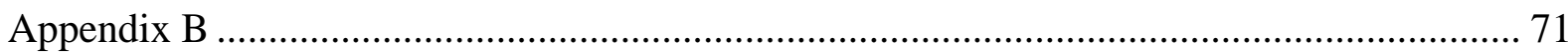

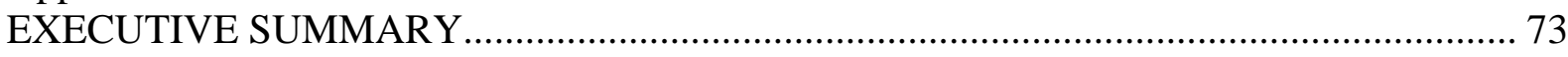

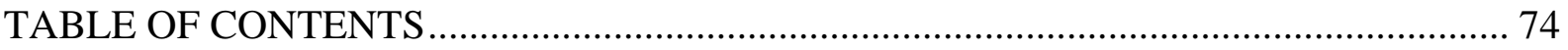

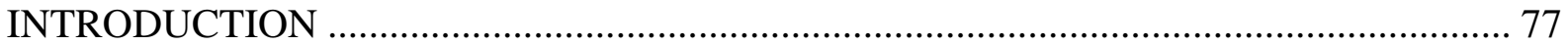

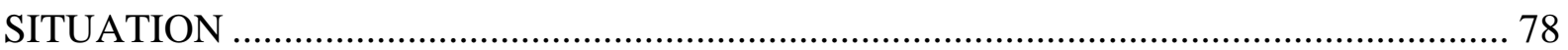

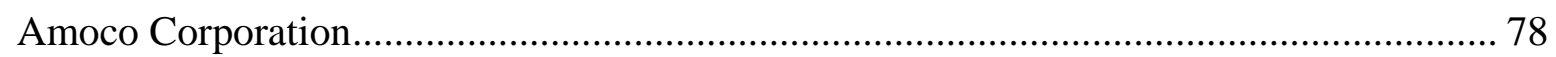

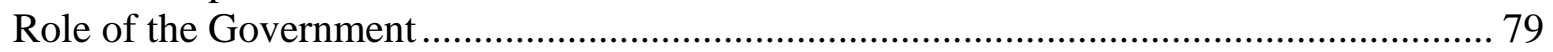

PART I - AMOCO's CNG REFUELING INFRASTRUCTURE STRATEGY 1992-1997 .. 80

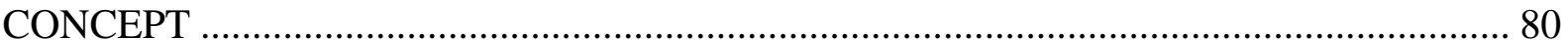

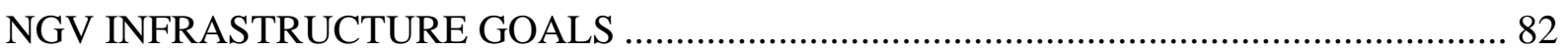

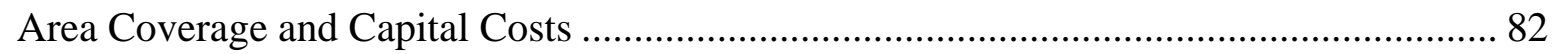

Refueling Transparency and Operating Costs................................................................ 83

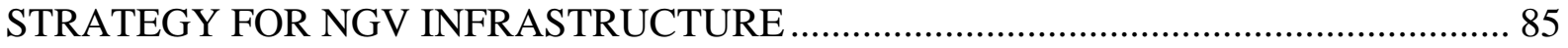

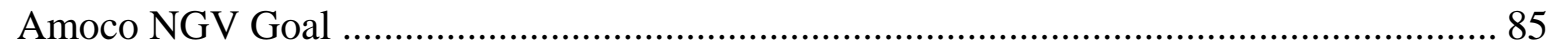

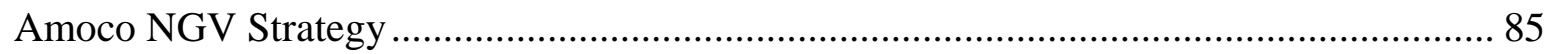

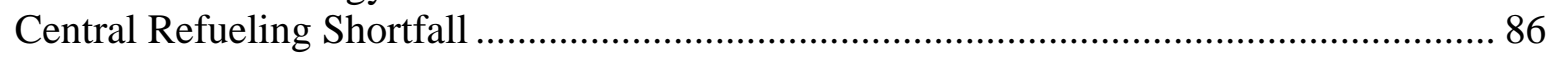

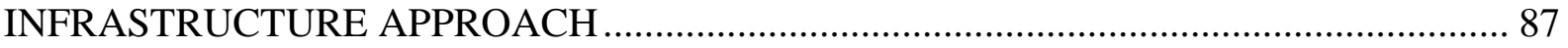

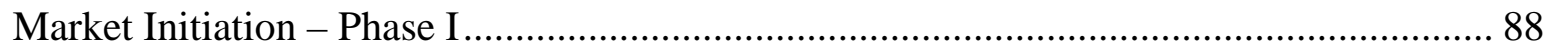

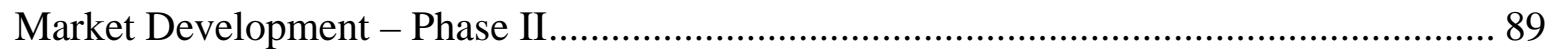

Growth and Profitability - Phase III ..................................................................................... 90

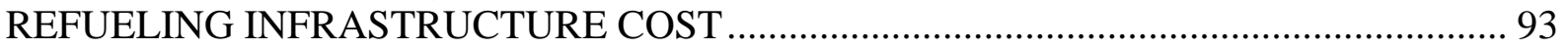

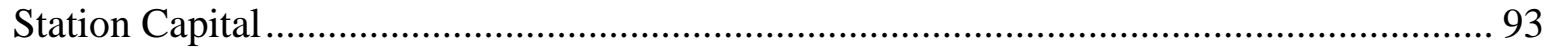

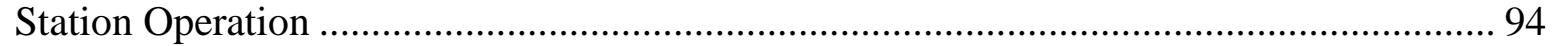

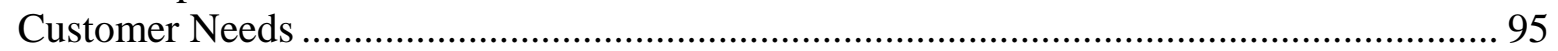

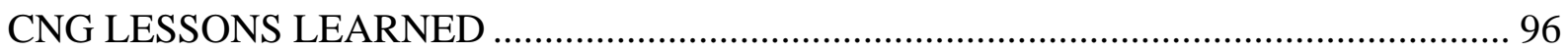

PART II - IMPLEMENTING LNG REFUELING INTO THE INFRASTRUCTURE

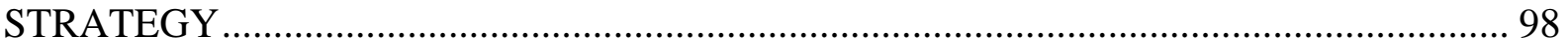

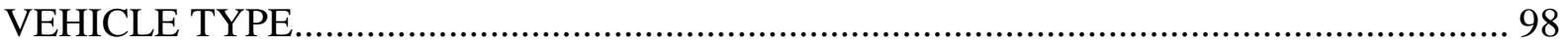

LNG IN THE CNG REFUELING INFRASTRUCTURE .................................................... 99

PART III - STARTING OVER and BUILDING A NGV REFUELING INFRASTRUCTURE

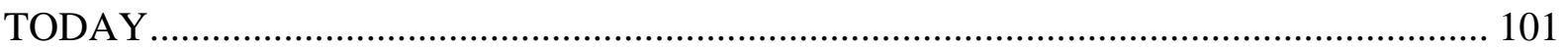

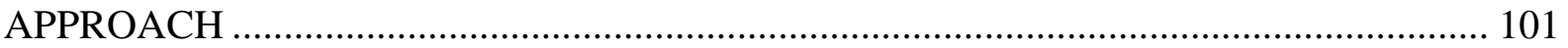

CONCEPT - REFUELING OPTIONS \& STATIONS LOCATIONS ................................... 102

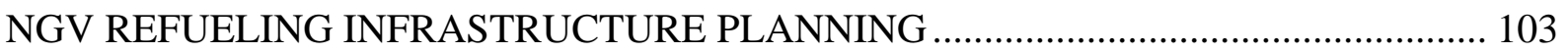

Step 1 - Identify customer fleet fuel requirements............................................................... 103

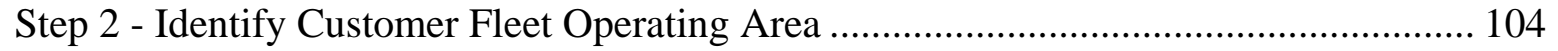

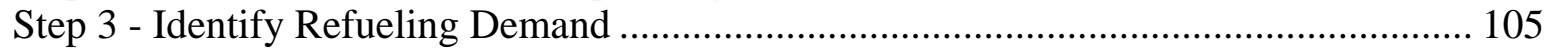

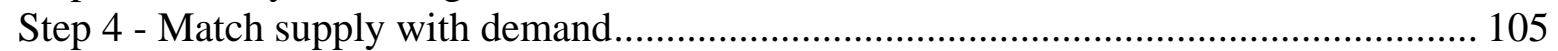

Step 5 - Match infrastructure development with NGV growth.......................................... 107 


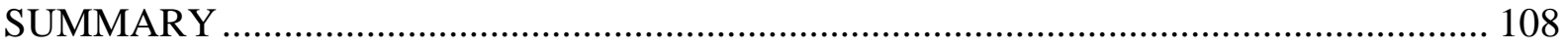

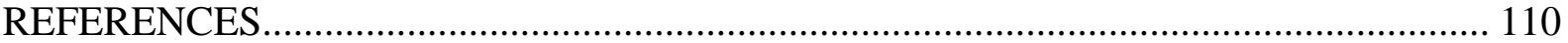




\section{INTRODUCTION}

\section{A. Definition of Need}

America's dependence on petroleum-based fuels for the transportation sector creates serious energy security, economic, air quality and other environmental challenges. The U.S. represents about five percent of the world's population but consumes twenty-five percent of the world's oil. Since 1985, worldwide oil production has lagged behind consumption, creating competition for a dwindling resource. U.S. dependence on oil - some call it addiction - long ago exceeded domestic production capacity and forced the nation to increasingly rely on imports, primarily from unstable regions of the world, making the U.S. economy vulnerable to unfriendly political regimes and - potentially - terrorists. And, despite improvements in fuel refining, engine efficiency and emissions control technology, gasoline and diesel emissions continue to degrade air quality in many urban areas, exacting social and economic tolls, as evidenced by diminished quality of life, lost productivity and increased healthcare costs. In addition, concerns about the relative impacts of different carbon-based fuels on greenhouse gas production have heightened awareness of the need to diversify our transportation energy portfolio.

Greater use of alternative fuel vehicles (AFV) is part of the solution to these challenges. A variety of AFV options - each with their own relative advantages and disadvantages - have been developed and marketed to American consumers and businesses. Natural gas vehicles (NGVs) are an AFV option that offers substantial environmental, economic and energy security benefits. Natural gas is an abundant domestically produced fuel, NGVs emit far less pollutants than their gasoline- and diesel-fueled counterparts, and they have demonstrated proven performance in all vehicle sizes and duty-cycles. Despite these advantages, after more than forty years of industry and government investment in NGV and fueling infrastructure technology research and development (R\&D), NGVs still account for only a miniscule percentage of the total transportation market. Today, NGVs account for less than one-fifth percent of the nation's vehicle inventory and natural gas accounts for less than one-half percent of on-road transportation fuel use.

There are several underlying reasons for the slow market acceptance and penetration of NGV technology. The biggest challenge for much of the past forty years has been that, by their very nature, gaseous fuel NGVs and fueling infrastructure are different than gasoline and diesel vehicles and stations, and people tend to resist change. In addition, despite their lower operating costs, NGVs' higher purchase price than comparable gasoline or diesel vehicles is still a market entry obstacle. The fact that hybrid vehicles, which cost more than their gasoline counterparts, have achieved considerable market acceptance and sales is a good indication that attitudes about "new and different" technology and paying a premium for a more environmentally favorable vehicle are changing. An important distinction between hybrids and NGVs is that buying a hybrid does not require switching to a new fuel and changing fueling habits. Hybrids run on the same gasoline or diesel available at thousands of retail fuel stations that have become part of American's day-to-day driving routine.

Given that NGVs' environmental, economic, energy security and performance attributes are on par with or better than gasoline and diesel vehicles, the lack of vehicle availability, the NGV price premium and less-than-ubiquitous fueling infrastructure would appear to be the primary hurdles left to overcome. These challenges are interwoven. New federal tax credits for vehicles and fuel have reduced purchase costs and strengthened the economic case for NGVs, shortening the simple payback period and further improving life-cycle cost savings. Increasing 
demand will likely re-engage the non-participating major auto and truck manufacturers to offer more vehicles and, as sales grow, lower the premium for NGVs. More NGVs in need of fuel will create market-driven demand and investment in fueling infrastructure and, through economies of scale, reduce fueling station costs. Conversely, installation of a more ubiquitous and more convenient NGV fueling infrastructure will elevate confidence in the consumer and business sectors that NGVs are a good investment and spur sales. While increasing auto and truck manufacturers' participation in the NGV market is an important step that must be addressed, the primary focus of this report is NGV fueling infrastructure.

While comprehensive statistical data about the NGV market is lacking, the Clean Vehicle Education Foundation (CVEF) estimates that there are 1050-1100 existing natural gas fueling locations - down from a high of nearly 1300 in 1998, and there are 85,000-90,000 NGVs on the road - down from an estimated peak of 105,000-110,000 in 2003. These seemingly downward trends are counter-indicative of the future, however, as market forces are converging to create an environment very favorable to growth. In fact, growth is already occurring in several niche sectors, as discussed later in this report.

For NGVs and vehicular natural gas to make a greater contribution to diversifying the nation's transportation energy portfolio, there must be an acceleration of vehicle deployment and, critical to achieving that goal, greater infrastructure development.

\section{B. Scope of Work}

It is against this background that the U.S. DOE contracted CVEF to develop "a comprehensive roadmap for targeted development of natural gas refueling infrastructure projects (Compressed Natural Gas -CNG, Liquefied Natural Gas - LNG and/or a combination of the two) to support successful deployments of light- and heavy-duty vehicles in niche markets.” Furthermore, the contract work scope statement says that the roadmap should "address the drivers and barriers to the successful deployment of natural gas vehicles, research and document the lessons learned from existing projects, and develop criteria that allow decision-makers to focus limited resources." Also included is "the development and implementation of a plan for the collection of natural gas (CNG and LNG) vehicle fuel sales information with emphasis on high-fuel use fleets in the transit, refuse, airport/taxi, school bus and short-haul niche sectors."

Further guidance and direction provided in subsequent supporting documents and discussions with U.S. DOE program managers identified the need for the report to address development of public refueling capability, which is projected to serve as the foundation for support of future hydrogen infrastructure. While focusing on fleets generates the highest vehicular natural gas throughout, it does not necessarily facilitate public fueling infrastructure for reasons that will be discussed in more detail later in this report. However, there has been success in melding the two interests in limited circumstances and these successes are explored further as are potential ways to build on this experience.

Part II of this report reviews the evolution of natural gas vehicle market and supporting fueling infrastructure, the past, present and potential future roles of utilities, independent NGV station developers and traditional petroleum retailers and lessons learned along the way. It examines critical financial and logistical factors affecting development of fueling infrastructure. It highlights similarities and dissimilarities between public and private station development, ownership and operation, offering best practices culled from operators that have successfully melded the two. Furthermore, while not a policy paper per se, this report addresses the important role that public policy plays in spurring - or deterring - natural gas vehicle and 
refueling infrastructure development.

Part III summarizes U.S. vehicular natural gas consumption by region and by niche sector. It also identifies some of the shortcomings and potential improvements that must be made in the NGV and vehicular natural gas consumption data collection and reporting process for it to be useful in helping government policymakers and industry stakeholders direct resources effectively.

\section{ROADMAP FOR DEVELOPMENT OF NGV FUELING INFRASTRUCTURE}

\section{A. Methodology}

In preparing Part II, CVEF referenced materials published over the last twenty years addressing the NGV industry's development. These include directories of existing and planned CNG and LNG fuel stations, utility company annual reports and numerous NGV stakeholder- and government-underwritten white papers addressing NGV market and technology development. Using these documents as background, CVEF conducted dozens of interviews with the following types of stakeholders:

1. Utility representatives at companies that are still active in NGV market development and those at previously active companies that have since suspended their programs

2. Independent NGV station development and operations and maintenance companies

3. Station engineering design consultants, equipment suppliers and general contractors

4. Staff at national, state and regional NGV associations, gas associations, energy consulting firms and media knowledgeable about NGV issues

5. CNG and LNG fleet managers from targeted niche sectors, including those who:

a) own and operate their fueling facilities,

b) own their fueling stations but contract out their operations,

c) purchase their vehicular natural gas fuel from a station developer-operator at a complete "bundled" price.

B. Historical Review of NGV Market and Supporting Infrastructure Development

NGV fueling infrastructure development cannot be viewed in a vacuum, as it is driven by many market factors. For this reason, it is helpful to understand how these factors have affected NGV market and infrastructure growth as the industry has matured. Despite major advances in vehicle, fuel storage and station technology over the past forty years, market penetration of NGVs is still far below its full potential. Key components necessary to successful development of the NGV market, including reliable vehicle and station technology, favorable environmental policy, adequate marketing resources and economic incentives have all existed at one point or another but have rarely been in place at the same time. The result is that the industry has been in a constant state of metamorphosis, undergoing periods of growth and contraction, sometimes simultaneously in different regions. 
The following review of the major developments and trends provides a context within which to view the current market, glean insights into lessons learned and shape future efforts. As a summary, it does not attempt to document every market event or regional nuance. A more detailed summary of the history of NGV market growth and infrastructure development is attached (Appendix A).

\section{1965-1990: Gas Utilities Slowly Build An NGV Market From the Ground Up}

The was a period of slow, gradual growth that started with a few pioneering utilities and eventually comprised about fifty utilities and a large assortment of national, regional and local vehicle conversion and station equipment vendors. The focus of the fledgling industry was internal, but gradually grew to include a small customer base more and more utilities became interested in the technology and its potential to meet national air quality and transportation energy goals. These early adopter utilities shared information about NGV technologies and applications and eventually, after formation of the Gas Research Institute (GRI) created a more formal RD\&D funding process, invested in improvements to vehicle, engine system, on-board fuel cylinder and fuel station technologies and development of national codes and standards.

By 1990, CVEF estimates that there were about 10,000 NGVs fueling at slightly less than four hundred CNG stations and consuming eight million gasoline-gallon-equivalents (GGE) of vehicular natural gas. While a few were dedicated vehicles, most were bi-fuel vehicles that were operated on natural gas most of the time, a reasonable assumption given that nearly ninety-five percent of these vehicles were LDVs and most of them were in utilities' own fleets. Of the 500 heavy-duty vehicles on the road, all were field conversions done by utilities for their own trucks and/or customers' vehicles or by the major engine OEMs, which had field demonstrations underway to test the technology.

All but a few dozen of the NGV stations were operated by LDCs or their affiliates and about eighty percent of them were operated by just ten LDCs. The rest were owned and operated by non-utility fleets or, in a very few cases, by local/regional independent station operators. Time-fill technology was still predominant although interest in, and experimentation with, fast-fill technology was underway at utilities own depots and some customer locations. Because the industry was still developing fuel container, nozzle and dispenser standards, the national CNG fueling infrastructure comprised a rather disorganized mix of different technologies and equipment from one utility service area to the next. It was possible to navigate large sections of the U.S. without getting "stranded" by moving from one utility network to the next, as long as you had the appropriate adaptors and gas cards for each utility.

\section{1990-1996: Boom Times For NGV Market Development}

This was a period of dramatic NGV market growth, as measured by number of parameters: yearly increases in the number of NGVs deployed, the expanding list of utilities actively engaged in NGV marketing and, most relevant to this report, the number of new CNG stations added and the amount of vehicular natural gas fuel consumed. This boom was driven, in part, by federal (and some states') government policies to address air quality and energy diversity goals including the Energy Policy Act (EPAct) of 1992 and the Congestion Mitigation and Air Quality (CMAQ) program initiated under the Intermodal Surface Transportation Efficiency Act (ISTEA) of 1991. EPAct 1992 included AFV purchase mandates for federal, state and fuel provider fleets and the potential to 
mandate private and local government fleets if national energy diversification goals were not met. The CMAQ program provided substantial grants to help fleets switch to cleaner fuels. Another important driver was the major automotive manufacturers' pronouncements that they would develop NGVs for market entry by mid-late decade. For the first time, a major petroleum marketer, Amoco, entered the market installing retail CNG station "test" networks in several metro areas and establishing an LNG business unit developed a limited customer base in Texas and, a bit later, California and Arizona.

By 1996, there were nearly 55,000 NGVs on the road fueling at more than 1250 CNG stations dispensing almost 50 million GGEs. This was five times the number of vehicles, three times the number of stations and more than a six times the throughput volume as compared to 1990, and double-digit growth was projected for the next several years. LDVs now accounted for eighty-four percent of the vehicle inventory as advances in natural gas heavy-duty engines spurred sales, especially to the transit industry as CMAQ funds were largely directed to this segment. Some of the station development that occurred during this period was ill conceived and/or poorly executed as some utilities built facilities based more on overly optimistic expectations than economic fundamentals. This over-development later contributed to some utilities' diminishing of enthusiasm for - and support of - NGV market development. As discussed further below, several hundred of these underutilized stations would eventually be decommissioned over the next decade as the market went through a "correction."

\section{1997-2005: Utility Deregulation, Unfulfilled Expectations Derail NGV Momentum}

During this phase, a long and painful gas utility deregulation process of mergers, acquisitions and cost cutting wiped out many NGV marketing staffs and programs and, in some cases, idled their CNG station operations, just as the major automotive manufacturers were launching their limited number of CNG models. During this period, several independent fuel providers interested in developing, owning and/or operating other's stations entered the market, often by buying the NGV assets of gas utility companies that were exiting the market either voluntarily or by PUC decree.

The federal government's decision to not mandate that local governments and private fleets purchase AFVs eliminated one of the market drivers that many had counted on to launch NGV market development to the next level. Furthermore, lax enforcement of EPAct AFV purchase and fuel use guidelines allowed mandated fleets to skirt the intent by buying Flex-Fuel Vehicles (FFV) without using the alternative fuel. Projected lightduty NGV sales did not materialize and, by year-end 2005, all the major automotive companies except Honda had either left the market entirely or were about to leave.

Small Volume Manufacturers (SVM) of engine conversion-retrofit components and systems, who had been the NGV industry's primary suppliers of gaseous fuel technology, came under increasing EPA regulatory pressure to document that there equipment was keeping up with emissions advances of the major auto manufacturers. New testing, documentation and certification requirements forced many without the technical or financial resources to exit the market. For those few SVMs that remained, substantially increased certification costs forced them to eliminate some vehicle models and increase their costs. This exiting of many SVMs and the eventual departure of all but one OEM left the market with limited LDV options to offer customers. This has had a direct impact on the number of station development projects that move forward. 
The number of NGVs on-road in 2003 peaked between 105,000 and 110,000 and then declined to about 92,000 by 2005, due to more vehicles being taken out of service than new ones being added. During this period, there also was net attrition in the total NGV station count as installation of new stations lagged closures of older underutilized stations. By year-end 2005, CVEF estimates that there were 1050-1100 stations in operation. On the positive note, continued sales successes in the heavy-duty niche markets, especially the transit sector, generated ever-larger fuel throughputs. Total vehicular natural gas consumption in 2005 was approximately 200 million GGE, comprising 39.5 million GGE of LNG (roughly 60 million LNG gallons) and 159 million GGE of CNG.

\section{2006-2007: Tax Credits, Emissions Advantages, Petroleum Prices Energize NGV Market}

The fourth phase, which began in 2006 and continues today, is witnessing a reinvigoration of the NGV market. The factors that slowed market acceptance and penetration all have been - or are - being addressed. General lack of familiarity and comfort with gaseous fuel vehicle and station technology probably is still the greatest challenge, although businesses and consumers are beginning to embrace the fact that alternative technologies and fuels are essential to our nation's goals of improved air quality and reduced reliance on imported oil. The technical hurdles the industry faced early on - like those endured by any new or emerging industry - have been overcome through constant improvement to the point that NGV performance is now equal, if not better than, gasoline and diesel vehicles. New federal tax credits for NGVs and motor fuels excise taxes have substantially lowered NGVs' initial purchase price premium and further improved life-cycle cost savings, making them the better buy for many fleets and some consumers.

While light-duty vehicle (LDV) availability from the major auto manufacturers remains a hurdle, Honda remains committed to the market with the Civic GX and several conversion-retrofit systems manufacturers remain with products that pass the same stringent emissions testing protocols as the OEMs. Heavy-duty natural gas engines' advantages over diesel engines, already recognized by the transit industry, continue to open new niche markets for natural gas, which is garnering the attention of truck chassis manufacturers, several who now offer natural gas as a factory-built option in select models

In terms of station counts, CVEF estimates that the number of new stations added has been offset by closures of smaller underutilized stations so the net count remains at 10501100 stations. However, independent developer/O\&M company purchases, upgrades and re-launching of previously utility- and municipal-owned-and-operated stations (usually as public access locations) has added value to the fueling infrastructure. When combined with increase in consumption by existing and new high-fuel use accounts (both CNG and LNG), CVEF estimates that total vehicular natural gas consumption at year-end 2006 was approximately 205 million GGEs.

\section{Types of Stations, Access and Development, Ownership and Operations Options}

For the discussions and recommendations that follow, the following definitions are used with respect to station types, access options and various development, ownership and operation models. The relative merits of each are discussed further below under Fueling Station Trends.

\section{Access Options}

a) Private Access 
Access is provided only to the owner's vehicle(s). Typically, fueling equipment is located at central fleet depot, often in secure area and/or requiring access code or key to activate dispensing equipment. No other private or public accounts have access. Examples: utility, transit and government public works depots where public fueling is not allowed.

b) Public Access

(1) Limited Public Access

Access to fueling capability is limited by physical barrier, e.g. the dispenser is located in secure area open during limited hours of operation and/or requiring preapproved access key or gate code, or by administrative requirement, e.g., dispenser requires pre-approved fuel card or billing code to activate. Generally, transient customers are prohibited and cash and/or credit card sales are not available. Examples: Utility or government public works fleet yards where a limited number of pre-approved "guest" fleets are authorized to use "host" fueling site.

(2) Full Public Access

Comparable to using a traditional retail gasoline or diesel station, site access is unencumbered and fueling capability is open to all via use of proprietary fueling cards, major credit cards and/or cash (if station is manned). Examples include dedicated public retail natural gas stations (e.g., those operated by Clean Energy, Pinnacle, Trillium, AVSG), CNG dispensers located at traditional petroleum locations, and CNG dispensers installed adjacent to typically-private-access-only fleet yards (e.g., at a transit agency or government public works depot that agrees to provide public access "outside the fence").

\section{Station Types}

a) Time-Fill

Fueling is accomplished over extended period of time, typically overnight or during lulls in daily operating hours, using time-fill posts. Gas is compressed and gradually delivered directly to vehicle fuel cylinders. No significant (if any) on-site fuel storage is included and there's no fast-fill capability. Because of the need to park vehicles for long periods of time, this type of fueling capability is most common at fleet owneroperator sites such as utility yards, school bus depots and government public works yards. However, there are still cases where utilities own and maintain these stations on their customers' sites for their customers' use.

\section{b) Fast-Fill}

Fueling is accomplished in relatively the same time as liquid fuels (e.g., several minutes). Gas is compressed and stored in on-site fuel storage containers at elevated pressures (typically 4500-5000psi), from which CNG is transferred to the vehicle fuel cylinders through fast-fill dispensers. This type of fueling capability is used anywhere that vehicles need to fuel quickly, including all public access sites and many private 
access locations where time-fill fueling capability does not meet operational needs.

c) Combination-Fill

This type of station includes both time-fill and fast-fill dispensing capability. These types of stations are often found on fleet owner-operator sites where mid-day fueling capability is needed to meet public access needs and/or to supplement the fleet's timefill capability.

\section{Station Ownership and Operations Options}

There are several basic models of station development, ownership and operations. Each has its own associated risks and benefits and none is the "right" approach for all circumstances. Within each of the options outlined below, there are further iterations that are beyond the immediate scope of this report, such as the type and level of detail in the bid specification, (e.g., performance- versus design-specification).

\section{a) Fleet Owner-Operator}

In this scenario, a public or private fleet operator elects to build a station and operate it. Scheduled preventative maintenance and/or emergency repairs may be performed either by in-house staff or contracted service provider. This type of station is nearly always located at the fleet's base site or, in some cases (e.g., a government-owned site for multiple departments) nearby. The station may include time-fill, fast-fill or both fueling capabilities. The station may or may not offer some level of public access and, if it does, the fleet owner-operator sets the fuel price.

b) Independent Owner-Operator

In this scenario, a utility or independent fuel provider that is not the fleet operator owns and operates a station. The fuel price is established by the fuel provider, which in the case of the utility, may be regulated by the PUC. The fuel provider or their contracted agents handle all operations and maintenance (O\&M). In the best-case scenario, the station will be built at a location that is easily accessible to the public and near or adjacent to an anchor fleet. The owner-operator may elect to purchase property or lease it, as is the case with some utility owned-and-operated stations installed at retail petroleum fuel stations in Utah and some larger stations installed on airport property.

The station may also be located "inside the fence" on a fleet operator's property under a capital lease or an operating lease agreement with option to buy clause, typically after five-to-seven years. The price of the fuel to the host fleet is negotiated for the life of the agreement and, if the station also includes "outside the fence" public access, the station developer-operator typically sets the retail price. Upon conclusion of the lease, ownership of the equipment usually transfers to the host fleet, which then may elect to (1) take over O\&M or, as discussed next, (2) contract with the original station developer to provide these services, usually on a fee-per-gallon basis, or (3) shop the O\&M contract to multiple bidders.

c) Outsourced Operations and Maintenance 
Regardless of who owns the station equipment and/or land, operations and maintenance may be outsourced to an independent contractor who may or may not be the original builder of the station. In most of these cases, the O\&M contractor charges the station owner (usually a fleet operator) on a fee-per-gallon basis. The amount of the fee is negotiated based on factors such as length of contract, total yearly and contract projected throughput, gas and electric utilities and who pays them, 24/7 monitoring of equipment operations, scheduled preventative maintenance and related parts replacement (e.g., labor, filters, compressor oil), emergency repair services and rate schedules and other O\&M costs. The contract may or may not include procurement of the gas commodity, either from the local utility, a gas brokerage or other source. Bids for O\&M contracted services may be requested by the station owner as part of the station construction agreement or entered into later under separate negotiation, (e.g. in cases where an existing station owner-operator elects to forego handling these responsibilities in-house and opens station O\&M to competitive bid).

As discussed in more detail in the historical summary of NGV market development (Appendix A), CNG station design and construction has similarities to other compressed air and gas applications but there are differences that can be troublesome for those not familiar with engineering these systems. There are literally thousands of small- and medium-sized fleet operations across the country that are well positioned to use NGVs but do not have existing fueling infrastructure conveniently available. Many can make a good economic case to develop an on-site fueling station for their own use (and potential use by other area fleets and consumers) but not generate enough fuel throughput to meet the economic hurdle that might attract an independent fuel provider willing to build, own and operate a station for them. If serving as the anchor fleet at an independent fuel provider's off-site fueling location is not an acceptable option, then these fleets are best served by contracting the services of a knowledgeable CNG station design firm that can help them determine current and future fueling station needs, design a station and prepare a construction bid request that makes the most of equipment and system efficiencies.

Once built, proper station operations and maintenance assure that performance and savings goals will be realized. A poorly run station likely will cost more to operate, incur unscheduled station downtime and result in missed or delayed deployment of fleet. For large fleets, the trade-off between the added cost of paying for these services versus taking responsibility - and risk - in-house will depend on the individual operation.

\section{Factors Affecting NGV Fueling Infrastructure Development}

Multiple factors influence the practicality and economic viability of a vehicular natural gas fueling station. For purposes of this review, these have been loosely categorized below into three areas: policy, financial and logistical/operational and general.

\section{Policy}

Successful development of a sustainable market for alternative fuel vehicles and fueling infrastructure requires that governments enact, enforce and clearly communicate longterm policies favorable to market introduction and encouraging of private industry investment. The areas of policy most relevant to the development of the NGV and fueling infrastructure market are those that address improvement of air quality (including greenhouse gases) and diversification of our transportation energy portfolio for improved national energy security. State PUC regulatory policies also have proved to be important 
to the development of the NGV industry as most natural gas used in the U.S. still flows through a regulated delivery system. These are addressed further below.

a) Air Quality, NAAQS, Local and Regional Clean Air Policies and Programs

Research has documented the negative impacts of poor ambient air quality on health and the economic toll in worker absenteeism, lost productivity and lower crop output. Transportation energy use produces tons of carbon monoxide (CO), particulate matter (PM), ozone from nitrogen oxide (NOx) and volatile organic compound (VOCs) emissions. Ozone and PM are regulated by EPA as criteria pollutants and carbon dioxide (CO2) is a greenhouse gas. EPA's National Ambient Air Quality Standards (NAAQS) mechanism requires that the nation's large metropolitan areas monitor criteria pollutants in their area and, depending on the quality of that air, take steps to improve it over a defined period of time. Generally, for each criteria pollutant, a metropolitan area may be defined as "in attainment," "near attainment" or various progressively worse states of "non-attainment." Currently, there are nearly 400 counties in metropolitan areas across the country in non-attainment with one or more of the criteria pollutants. Over 149 million people live in these polluted areas.

Metropolitan planning organizations (MPOs) representing areas designated as nearattainment or non-attainment, and areas of attainment that were formerly near- or nonattainment, are required to implement plans to reduce those pollutants. These emission reduction plans typically address both stationary sources, e.g. industrial facilities and power plants, and mobile sources. Examples of mobile source strategies include mandatory vehicle emission inspection programs, traffic mitigation measures (such as HOV lanes) and, most pertinent to this report, fleet emissions reductions programs. MPOs often target local government, school district, transit agency and other "public" fleets first because of their high visibility and the expectation that "government" should lead by example.

Fleet emissions reduction plans often include mandates and/or incentives for fleet operators to equip their vehicles with emission reduction devices and/or use alternative fuels, including the retrofit or replacement of their current vehicles with alternative fuel vehicles and installing fueling infrastructure.

(1) Mandates

Mandates are a double-edge sword. While they accelerate market penetration of NGV and other AFV technologies, they also can create market animosity or resentment toward these technologies. Some argue that mandates are only needed for technologies that can't capture market based on their own merits. Others counter that government should help commercialize technologies that provide societal benefits (e.g., clean air, lower healthcare costs). The best known example of an air quality-driven fleet mandate program is in California's South Coast Air Quality Management District (AQMD), where the “1100 Series Fleet Rules” require that street sweepers, school buses, refuse trucks and other vehicles operated by municipalities or their contracted service providers run on cleaner fuels. AQMD's application of these mandates to private fleets were challenged in court and initially struck down. 
(2) Incentives

As discussed further below in the section on "Available Grants," state air quality authorities may use incentives, usually in the form of grants, to facilitate public and private fleets' use of alternative fuels and vehicles. Funding for these state vehicle emissions reduction activities varies across the board. Some states rely entirely on what funds they receive from the federal government through the CMAQ program while others use vehicle registration fees, bonds and other mechanisms to raise additional funds for these projects. The most significant state and local air quality authority-driven fleet emission reduction programs are in California, where Carl Moyer Program grants and regional AQMD grants reduce the cost of NGVs and related fueling infrastructure. California's progressive and aggressive programs to curb vehicle emissions and improve air quality have provided more funding over the last fifteen years than all other states combined. Other important state initiatives include Texas' Emission Reduction Program (TERP) and several New York programs implemented by the State Energy Research \& Development Authority (NYSERDA).

b) Diversification of National Transportation Energy Portfolio

(1) Federal Energy Policies and Programs

Since the 1970's, the federal government has implemented a number of initiatives to reduce the transportation sector's reliance on petroleum motor fuels. These initiatives have included: mandatory increases in fuel economy for motor vehicles; production incentives for alternative fuels; reduced excise tax rates for alternative fuels; funding mass transit; mandating the acquisition of alternative fuel vehicles; tax incentives for advanced vehicle technologies; funding for advanced fuels and vehicles RDD\&D, among other things. Some of these initiatives benefited development of the NGV market either directly or indirectly. Most of the federal government initiatives and funding have been directed at biofuels. Unfortunately, the overall net effect of these policies on reducing reliance on petroleum has been, at best, to slow the increased rate of petroleum use. A thorough review of all the initiatives and their impact, while a worthwhile endeavor, is beyond the scope of this report. Following is a short summary of the initiatives that most directly affected NGV market development.

(a) CAFÉ

The Corporate Average Fuel Economy (CAFÉ) requirements created under the Energy Policy and Conservation Act of 1975 and since modified several times not only slowed down the growth in oil demand by increasing the fuel efficiency of new motor vehicles, it encouraged production of AFVs. Enactment of the Alternative Motor Fuels Act (AMFA) in 1988 created valuable CAFÉ credits for auto manufacturers. This helped engage the major auto manufacturers to allocate more resources to AFV options including NGVs. Unfortunately, the relative value of NGVs' CAFÉ credits to most of the major automakers became negligible over time as government policy leaned ever more strongly toward ethanol fuels and manufacturers geared most of their efforts toward development of Flex-Fuel Vehicles (FFVs). FFVs earned CAFE credits and, due to their lower relative cost and ability to run on 
regular gasoline (instead of the intended E85), were an easier AFV option for consumers and EPAct-governed fleets to choose.

\section{(b) CMAQ Program}

One of the most important federal initiatives to NGV market development has been the CMAQ program initiated under the Intermodal Surface Transportation Efficiency Act of 1991. It has provided billions in federal funding to help local authorities address transportation related emissions, including a significant level of funding for alternative fuel projects. This funding has been particularly important in encouraging increased use of alternative fuels in the transit bus sector, where natural gas powered buses and fueling infrastructure have been one of the primary beneficiaries of the program. CMAQ funding also has been an important source of co-funding for many smaller public and private NGV deployment projects. While wellfunded, competition at the local level for CMAQ program grants is fierce and political; alternative fuel projects must receive priority if they are to successfully vie against other projects for funding.

\section{(c) Energy Policy Act (EPAct) 1992}

EPAct 92 established aggressive national goals for replacing petroleum motor fuels with alternative and replacement. To stimulate demand for alternative fuel vehicles and alternative fuels, the law required the federal government first and, then later, state government and fuel provider fleets to acquire lightduty AFVs. The acquisition requirements were phased in over time so that an increasingly larger percentage of new light-duty acquisitions must be alternatively fueled. An amendment made several years later modified the programs to allow fleets to satisfy up to 50 percent of their annual AFV acquisition requirements by using biodiesel blends of at least 20 percent. Additional discretionary rulemaking authority was provided with respect to private and local government fleets but, in a rulemaking in 2004, DOE determined that such a rulemaking was not "necessary" based on its consideration of a number of factors required in the law. Other than the fleet mandates, EPAct focuses mainly on voluntary efforts (forming the basis for the National Clean Cities Program) and the law strictly limits DOE authority to require fuel retailers or vehicle manufacturers to produce or sell alternative fuel vehicles or alternative fuels. The law also provided a number of tax incentives, including tax deductions for qualified clean fuel vehicles and infrastructure. As discussed in more detail below in "Financial," tax deductions have little impact for most fleets.

EPAct 1992 was intended to spur sales of AFVs and did create some demand for NGVs by the mandated fleets. However, as detailed more thoroughly in the historical review (Appendix A), the 2004 decision not to promulgate private and local government fleets rules "took the wind out of the sails". The introduction of FFVs, with their ability to more easily satisfy EPAct's requirements (if not its intent), and the biodiesel credit provisions further negated the impact of EPAct 1992 on NGV market development. 
(d) EPAct 2005

EPAct 2005 included several provisions of importance to NGV market development. These include small changes to the fleet acquisition program that should improve its implementation and market impact, authorization of significant funding for demonstration programs involving AFVs and fuelefficient vehicles to be administered through DOE's Clean Cities Program and, most important, two new tax credit provisions - one for alternative fuel vehicles and the other for alternative fueling infrastructure investment. The law also contained a significant section on hydrogen, authorizing the development of hydrogen-fueled vehicles. While the implementation of the hydrogen initiatives is still in progress, the NGV market could benefit from this program as gaseous-fueled NGVs and fueling infrastructure technologies are the precursor - sometimes referred to as the "bridge" or "pathway" technologies - to hydrogen. Finally, EPAct 2005 included a mandate called the Renewable Fuels Standard (RFS) for the fuels industry to include renewable fuels in the nation's transportation energy portfolio. Much of the focus of this program is on blending alternative fuels with petroleum fuels (e.g., ethanol, biodiesel) but methane from biomass may be able play a role. This remains to be seen as the RFS is in development at the time this report was being written.

The most significant changes to the fleet acquisition mandate program are the requirement that federal agency fleets use alternative fuels in dual-fuel vehicles, and the directive to the General Services Administration to equally allocate the purchase price premium for AFVs across requisitioning agencies' entire new fleet purchases, thus eliminating the cost differential.

The funding authorization for AFV demonstrations could be beneficial to NGV market development if (1) authorized funds are appropriated by Congress, (2) funds are directed to NGV and fueling infrastructure programs.

By far, the most important NGV-related measures of EPAct 2005 are the tax credits for buyers of alternative fuel vehicles and fueling equipment. The tax credits, which apply only to dedicated natural gas-, propane- and hydrogenpowered vehicles, go to the buyer and are available for fifty to eighty percent of the incremental cost of the vehicle. These credits, which range from \$2,500-\$32,000 depending vehicle GVWR, significantly reduce NGVs’ price premium, thus shortening the payback period and further improving life-cycle savings. The fueling equipment credit also goes to the buyer and is equal to thirty percent of the cost of equipment placed in service that year with a credit cap of $\$ 30,000$. In cases where the buyer is tax exempt, vehicle and fuel equipment tax credits may be taken by the seller(s). When combined with the motor fuels excise tax credit included in the SAFETEA-LU (Transportation Act) of 2005, the vehicle and fueling equipment tax credits, effective January 1, 2006, are proving to be a catalyst to NGV market development.

\section{(e) Federal Investment in NGV Infrastructure R\&D}

In the 1990's and up to FY 2003 the Federal Government through the Department of Energy and its national laboratories invested up to 20\% of their 
NGV R\&D budget in development of CNG, LNG and L/CNG fueling infrastructure technologies. These funds (max amount of \$1.96 million in 2002) were part of a larger cooperative $R \& D$ program that included cofunding from the industry primarily through the Gas Research Institute-GRI (now Gas Technology Institute - GTI) and the Institute of Gas Technology (now part of GTI). This cooperative R\&D program covered all aspects of fueling infrastructure design including but not limited to dispensing, metering, gas conditioning (dryers and oil recovery), gas composition analysis, optimization of operational protocols, fueling connector development and support for codes and standards. During the last few years of the DOE R\&D program, funding was directed specifically to research on small scale liquefiers for LNG from pipelines and biomethane from landfills and other sources and to develop processes for generating CNG from LNG storage systems. In 2004, DOE zeroed out their support for NGV R\&D for both vehicle engine development and NGV infrastructure. The NGV industry has proposed to Congress that DOE reinstate their NGV R\&D program to meet the goals of the nation in increasing the utilization of alternative fuels.

(2) State Policies to Reduce Petroleum Use

In recent years, a number of states have adopted policies to reduce petroleum demand. Many of these policies have been implemented to further environmental objectives such as clean air and reducing greenhouse gas (GHG) emissions. Some states are driven primarily by the promise of developing a domestic market for home-grown fuels, such as ethanol or biodiesel. These policies and incentives include tax incentives for AFVs, high occupancy lane exemptions for fuel efficient and alternative fueled vehicles, sales tax exemptions for certain types of vehicles, lower fuel tax rates for alternative fuels, investment tax credits for ethanol production facilities, and grants for fueling infrastructure. Many state governors have adopted executive orders that require state government fleets to acquire AFVs and use alternative fuels when such fuels are available. Several states require government fleets to exceed the acquisition requirements contained in EPAct 1992. Of the tax incentives, the most important seem to be production tax credits and reduced fuel taxes.

It is difficult to determine what impact initiatives adopted by states will have, as many are relatively new. Moreover, many state measures have the effect of supporting or contributing to the achievement of existing federal initiatives rather than necessarily generating additional demand for alternative or replacement fuels.

Potentially one of the most significant state actions is California's adoption of greenhouse gas emission reductions for new automobiles. The regulations could significantly increase the fuel efficiency of motor vehicles in California and other states that have moved to adopt it. However, the provision is currently being challenge in court and it is not certain whether the regulations will take effect as planned in 2009.

c) State Public Utility Commission Regulatory Policies

State PUC regulatory policies can facilitate or hinder development of vehicular natural 
gas fueling infrastructure in several ways. For example, several states' PUCs allow LDCs to rate-base CNG station capital investment and operating expenses on the basis that these expenditures facilitate the utilities' own fleet operations while also providing ratepayers access to lower cost transportation fuel. Other PUCs take the view that not all ratepayers are NGV operators and therefore CNG station investments should not be rate-based, at least not fully rate-based. The arguments for and against hinge on the value the PUC places on the greater societal benefit to all ratepayers that a more roust NGV fueling infrastructure provides (e.g., improved air quality, diversified energy portfolio).

A developing trend in state utility regulation that can have positive or negative impacts on LDC involvement in NGV fueling (depending on how it is implemented) is "decoupling," which deals with how PUC rates are structured. Customers' gas rates are divided into two parts - the commodity charge and the demand charge. The commodity cost is the price the LDC pays for the natural gas itself. LDCs do not "mark up" the price they pay for gas. Rather, it is a pass through - i.e., customers pay what the LDC pays. The demand cost comprises all the other costs that the LDC incurs to provide gas service - including the LDC's profit. Under a decoupled rate structure, the commodity charge includes just the commodity costs, and all the demand costs are included in the demand charge. Under this rate structure, the LDC is economically indifferent to how much gas a customer uses. Customers pay $1 / 12^{\text {th }}$ of all the approved non-gas costs for the year (the demand charge) in monthly installments plus the actual cost of any gas they use.

To better understand this concept, consider the way cable TV charges for service. The commodity charge for a cable company is zero. In other words, it costs no more for the company to provide service to someone who watches TV all day than to someone who never watches. All their costs (including shareholder profit) are recovered in the demand charge, which is their standard monthly fee. They are economically indifferent to how much TV customers watch. A decoupled rate for gas would be similar except that in addition to the standard monthly demand charge, the customer would also get charged for the actual gas used.

Unfortunately, today, most PUC-approved rates are hybrid rates, where some of the demand costs is collected as part of the commodity charge. In these cases, the LDCs' shareholders do benefit economically when customers consume more gas, and consequently, the LDCs have little incentive to promote gas conservation or energy efficiency.

To address this situation, some PUCs now are implementing or considering implementing decoupled rates. Further, some PUCs don't just want LDCs to be indifferent about how much gas customers consume; they want them to be to be advocates for conservation and energy efficiency. To do this, some PUCs are providing incentives, whereby the LDC's shareholders get a better rate of return if the LDC successfully implements conservation and energy efficiency programs.

How could these decoupled/incentive rates affect an LDC's interest in pursuing NGVs? If implemented poorly, it could severely dampen interest. For example, if the LDC just focuses on volume reductions, they would have no incentive to promote NGVs. If implemented well (such as in California), NGV use could be encouraged. In fact, PUCs could provide specific incentives for the growth of natural gas use in 
NGVs.

\section{Financial}

In researching station development and operations for this report, there was surprisingly little consistency in station costs, regardless of the measure used (e.g. cost per GGE, cost per scfm, cost by region, etc) as site-specific variables, including those outlined below, weighed heavily.

\section{a) Station Development}

(1) Land Purchase Cost or Lease Expense

Unless sufficient land is already available at an existing location owned by the station owner and/or made available at a favorable lease rate to the developeroperator (e.g., at an existing fleet yard or fuel depot/station), the cost of land is usually a major contributor to an NGV fueling facility site cost and the resulting price per GGE. Following is a brief summary of factors affecting land cost.

(a) Location: Stating the obvious, one of the biggest factors affecting real estate cost is location, location, location. The closer a prospective site is to other residential and commercial development and traffic patterns, the more desirable the site is to competing interests and, thus, commands a higher price. Generally, the more urban the location, the higher the price. In addition, regional variations in land cost are substantial. Land costs for an urban site in the Los Angeles, New York or Washington D.C. metro areas may be as much as three times that of a similar site in St. Louis or Indianapolis, for example. Proximity to major highways or thoroughfares, an important consideration in facilitating public and private fleets' access and use, also increases land cost.

(b) Size of property: Considerations include the footprint of the compression and storage equipment that will be needed to meet the expected fuel throughput rates; the number of fueling islands and types of dispensers, e.g., low-volume versus high-volume dispensers and whether there is inside- and/or outsidethe-fence fueling planned; necessary clearances and/or setbacks from adjacent properties; the types and sizes of vehicles expected to fuel at the property and their traffic access and maneuvering space requirements (e.g., refuse trucks need greater turning space and prefer unidirectional entrance-exit routes to avoid the need to back-up).

(c) Availability of utility services: If electric, natural gas and telecommunication utilities are not readily accessible or insufficient to meet station equipment needs (e.g., inlet gas pressures, electric service voltage/amperage), they will have to be brought in or upgraded, adding expense. Property adjacent to existing utilities commands a higher premium than those more distant from these services.

As mentioned above, a more favorable option to buying land may be to lease it. For example, a western utility has successfully expanded its network of utilityowned-and-operated stations by leasing a small footprint of an existing traditional fuel retail location at a favorable rate in exchange for paying the retailer a royalty 
on the natural gas in addition to the traffic building benefits the station may generate. Another example is a transit or refuse operation that out-sources its onsite fuel station development and operations needs to an independent party that leases the land for a minimal fee as part of fuel pricing structure.

(2) Site Development, Construction and Permitting Costs

Site development requirements and costs can vary widely. If a new station is to be built at an existing fuel station, for example, there may be equipment removal or remediation requirements (e.g., underground gasoline or diesel fuel tanks). Depending on projected changes to traffic in and out of the site, local jurisdictions may impose road access improvement requirements (e.g., turning lanes, traffic signals, etc). In addition, despite the existence of model building codes (including NFPA 52) covering NGV station construction, code requirements differ from one location to another and can have a significant impact on station cost. Lighting, signage and security fencing requirements are other considerations that factor into total site cost. Construction labor rates also vary widely from one region or jurisdiction to another depending on general economic health of the construction trades and availability of union versus non-union labor. Depending on jurisdiction, site development, construction and occupancy permit fees can be quite substantial.

(3) Fueling Equipment Cost

Each fuel station design and operations differs. Generally, a natural gas station's equipment needs and costs will be based on the type of fuel to be dispensed (CNG, LNG or L/CNG), number of vehicles projected to fuel there, the total daily throughput estimates and, in some cases, whether nearby back-up fueling capability is available.

A CNG station's fueling equipment needs and costs will be based on compression, storage, dispensing, fuel-metering/management and redundancy requirements. Available utility services also impact station design, equipment selection and operational strategy.

(a) Compressors - Compressor sizing and cost factors include: total fuel throughput and peak flow needs, inlet gas pressure and its impact on horsepower requirements to achieve the desired flow rates; the need for - and amount of - redundancy required and how this may affect compressor(s) sizing; electric-drive versus gas engine-drive prime mover(s); incremental cost per added scfm (i.e. different compressor packages have different "sweet spots”); type and sophistication of the controller; remote monitoring capabilities.

(b) Gas Dryers - Dryer sizing and cost factors include: volume and flow rates of fuel to be processed; inlet gas pressure and moisture content; automated or manual regeneration capability.

(c) Storage - Factors affecting storage equipment sizing and cost include: whether any storage is needed; the type of system (e.g., buffer versus cascade); amount and pressure of total storage needed to help meet peak 
demand periods; type of storage container selected (ASME, DOT, etc); controls.

(d) Number and Type of Dispensers - Factors to consider include whether to use time-fill posts, fast-fill dispensers or both; the pressure, flow rate and types of nozzle(s); number of fueling dispensers needed to meet peak demand.

(e) Fuel Metering / Transaction Recording / Payment Processing Capability Factors affecting equipment selection and costs include: whether a card reader system is necessary (i.e., will the station offer public access); the sophistication of the card reader system (e.g., California requires a video screen for first-time fueler training); modem systems.

As is the case with a petroleum fuel station, an LNG station's equipment needs and costs will depend primarily on the distance to the nearest supply and transportations costs, the amount of fuel storage needed to meet needs between deliveries, and the number of dispensers. Of course there are fuel metering and data recording system requirements but LNG stations do not usually include the more sophisticated (and more expensive) card reader systems that are required for public access CNG locations.

b) Differential Between Natural Gas and Petroleum Fuel Prices

One of the key economic drivers of NGV sales and related infrastructure development is the cost differential between natural gas and gasoline or diesel fuel. Favorable fuel price advantages translate into shorter payback periods and lower life-cycle cost. On a national average, natural gas historically has maintained a significant cost advantage as compared to both gasoline and diesel fuel, and that favorable differential is projected to increase even more over the next decade according to EIA forecasts. General factors affecting the amount of differential include: crude oil prices; regional availability/distance from petroleum refining capacity; whether the fuel is for internal fleet operations or sold to the public and, if the latter, whether the operator is a forprofit business or a not-for-profit organization (e.g. government agency, transit fleet, school district); state and federal taxes. Additional factors include: for LNG, availability of supply and distance to fueling location; for CNG, regional gas commodity and pipeline transportation costs, and prevailing natural gas and electric utility tariffs.

\section{c) Availability of Grants}

Other than in rare cases where a mandated NGV fleet is forced to build fueling infrastructure regardless of cost, NGV fuel station development is driven by economics. In some high-fuel use fleet applications, such as refuse or transit, an initial deployment of NGVs may be sufficient to meet the economic "tipping point" required by the station operator. In most cases, however, the initial projected fuel throughput of a station is insufficient to justify investment, especially by the private sector. Federal DOT, EPA and DOE grants and those offered through state and local energy, environment and economic development agencies have been instrumental in reducing costs enough to move many projects forward. Conversely, lack of grants has stopped projects from progressing. 
While federal, state and local grants likely will continue to play a critical role in improving project economics, the total available funds are far less than the current demand and the shortfall will undoubtedly increase as market interest in NGVs and other alternative fuel technologies grows, creating even greater demand. This point is illustrated by the number of applications received versus those funded under DOT's CMAQ, DOE’s State Energy Projects and EPA's Supplemental Environmental Projects, Clean School Bus and Diesel Emission Reduction programs.

d) Availability of Tax Deductions and Credits

(1) Tax deductions

EPAct 1992 included a package of tax incentives to encourage the purchase of alternative fuel vehicles (AFVs) and installation of alternative fueling stations. The size and incremental cost of AFVs were two primary factors in determining the tax deduction amount for AFVs. They ranged from tax deduction of $\$ 2,000$ per passenger car or light truck up to $\$ 50,000$ for on-road vehicles with a gross vehicle weight rating of more than 26,000 pounds. The tax deductions could be taken for new original equipment vehicles or newly installed aftermarket conversion equipment. Furthermore, only the initial purchaser of the equipment qualified for the tax incentive. A \$100,000 tax deduction was also made available for businesses that installed fueling equipment for dispensing alternative fuels. The tax incentives in EPAct 1992 were scheduled to originally expire after 2004.

The incentives in EPAct 1992 ultimately did not have much impact on the market for alternative fuel vehicles. Part of the reason is that tax deductions are not much of an incentive for private businesses, which already are permitted to depreciate the cost of capital equipment. Tax deductions simply allow companies to accelerate the depreciation of their equipment, taking a larger upfront deduction in the first year of owning a new alternative fuel vehicle or fueling station. Thus, the overall benefit is small. The benefit to consumers that are not able to depreciate property is more significant but still not large enough to offset the initial higher cost of most alternative fuel equipment. And because the incentives in EPAct 1992 were tax deductions and not tax credits they only had the affect of lowering taxable income by a certain amount. Tax credits, on the other hand, are much more valuable because they reduce a person's tax obligation on a dollar-for-dollar basis whereas a dollar of tax deduction is only worth about $\$ 0.15$ - $\$ 0.30$ depending on the applicable tax bracket.

(2) Tax credits

As noted above, EPAct 2005 included new federal tax credits for investment in natural gas vehicles, fueling equipment and motor fuels excise taxes, effective in 2006. A number of states also offer tax credits, as do some local jurisdictions. The federal vehicle and station equipment purchase credits are income tax credits as are most of the available state and local tax credits. The motor fuels tax credit is an excise tax credit.

Income tax credits can be an effective way to improve NGV economics if the entities involved have tax liabilities or, if not, the value of these credits may be captured through other marketplace mechanisms. 
Income tax credits only have negotiating value to tax-exempt entities such as governments, school districts, transit agencies and airport authorities if their suppliers have sufficient tax liability to take them. Thus far, tax-exempt organizations experience with auto, bus and truck dealers and NGV fuel station developers and equipment suppliers has been mixed as these suppliers have had limited tax liabilities. Furthermore, the larger the order, the less likely any one supplier has been able to absorb the full value of the credits and pass them back in the form of lower price or improved contract terms. Another way tax-exempt entities may indirectly capture the value of these income tax credits is to acquire vehicles and fueling station equipment through a capital lease arrangement with a municipal finance-lease company or other third-party. Under this type of acquisition scenario, the leasing company takes the full tax credit then reduces the basis of the vehicle cost in their calculation of lease payments and fees.

Motor fuels excise tax credits improve NGV economics regardless of whether the fuel seller is tax-exempt or not and experience thus far with the new federal tax credits has been very positive.

In preparing this report, NGV industry stakeholders and fleet operators alike noted that decisions about vehicle and station economics are based on minimum vehicle and station life (e.g., five-eight years minimum for vehicles and up to ten years for fueling station equipment). Uncertainty about continuation of motor fuels excise tax credits and vehicle tax credits beyond the current expiration dates, September 30, 2009 and December 31, 2010, respectively, is making some fleet operators hesitant to move forward with their vehicle deployment and station development projects. CVEF recommends that these credits be extended far enough into the future to eliminate uncertainty and facilitate long-term decision-making.

\section{Logistical/Operational}

Although presented last, the logistical and operational needs and concerns of customers are paramount. For a fleet manager considering installation of their own fueling site, the economic, emission reduction and other operational benefits of NGVs may appear - on paper - to be overwhelming but, unless he/she has already had positive experience and is familiar with using NGVs and fueling infrastructure, implementing this option is counterintuitive. Following are some of the logistical and operational concerns that factor into the potential viability of a fuel station project moving forward.

\section{a) Projected Fuel Throughput, Flow Rates and Storage Needs}

The most obvious criteria to be evaluated in deciding whether and how a station is to be developed is the volume of fuel to be dispensed, either to the single fleet proposed to have access (i.e. private access-only station), or to the anchor fleet(s) and transient customer base that will use the public station. As discussed in more detail above under Station Development Costs, volume needs to be assessed in terms of total daily throughput, peak hourly throughput, flow rates and storage needs.

b) Fueling Reliability

Fleet operations are supportive of, or secondary to, the core product or service of any 
business. A fleet management team's job is to be invisible, delivering seamless reliability day-in and day-out. Those that choose to use NGVs must be able to rely on their vehicles and know that their fueling capability is guaranteed because, in most areas of the country, there is insufficient "back-up” fueling via nearby CNG stations to provide fueling if a station goes down.

\section{c) Fueling Convenience}

If a proposed station is to rely on transient customers to meet all or, most likely, part of its required throughput goal, it has to be conveniently located. For a fleet operator, the time spent fueling a vehicle is unproductive. Every minute a vehicle travels out of its way to or from a fuel station, it is not performing its primary task (e.g., delivering something or someone from point A to point B), and it is costing additional labor. For example, assuming that, on average, traveling out of the way just four miles off a planned suburban route adds twelve minutes (roundtrip) to the bakery truck driver's schedule and the driver has a fully-loaded hourly labor rate of $\$ 42.00$ costs an extra $\$ 8.40$ per tank fill or $\$ .34$ per gallon (based on 25GGE tank). In a business that counts profitability in the pennies, this added time and cost is substantial. It may, however, be within reason if the overall savings on the fuel warrants the added time. For larger fleets, fuel stations, if not located on-site, must be conveniently located on or near a main thoroughfare close to their business or along their normal route of travel.

Another aspect of fueling convenience is accessibility, especially if the station is offsite and allows public access. This includes traffic lanes and signals, the number of vehicles expected to be in and around a station and their expected fueling patterns, and the footprint and layout of the space. Vehicles that have to negotiate heavy traffic, endure extra traffic light stops then wait for access to a dispenser log additional time, i.e. cost. Large vehicles need to be able to enter a fueling station and exit without the need to turn around or maneuver in tight side- and overhead-clearances, especially if the station allows public access and there may be additional smaller vehicles moving about. Concern about accident liability is one of the main reasons cited by current private-access-only station operators for not allowing public fueling at their location.

\section{d) Payment Processing and Tax Administration}

When natural gas is dispensed into an NGV owned and operated by a taxable entity, it incurs a federal motor fuels excise tax obligation and, in most states, a state motor fuels excise tax as well. Independent CNG and LNG fuel providers expect to deal with payment processing hardware and software and the related collection and payment of various local, state and federal taxes on taxable sales; it is part of their core business fuel delivery. For fleet operators who are asked to consider allowing public access to their private CNG or LNG fueling site (e.g., "outside the fence”), this creates additional cost and administrative burdens. Fleets that install on-site fueling capability for their own NGVs can use a far simpler and less expensive fuel metering and data recording system than that required for a station that will dispense to other public and private accounts. In addition to citing other concerns outlined above (e.g., space availability, liability, fuel capacity), many fleets are reluctant to take on these extra burdens, as they are not a part of their core business.

The simplest way around this hurdle is to engage the services of a fuel metering and payment processor that monitors the dispensing equipment card readers, records each 
fueling transaction, applies the appropriate taxes, invoices, collects payment and provides detailed reports back to the station owner. This is usually done a monthly fee-plus-GGE surcharge basis. Some fuel providers use these services and many private fleets use similar but less sophisticated hardware and software to record their own fleet vehicle fuel use; upgrading to a full public access payment processing system (e.g., those that accept major credit cards and branded fuel cards) adds cost but is essentially an extension of that capability.

e) Availability and Skill Level of Station Operations and Maintenance Personnel

Proper operation and maintenance of a CNG or LNG fueling station requires skilled technicians familiar with the respective technologies. On a day-to-day basis, critical equipment performance parameters (e.g., oil temperatures, flow rates, storage pressures) should be monitored for anomalies and addressed before damage or failure occurs. Regular scheduled preventative maintenance is also imperative and, in the unfortunate case of equipment failure, repairs need to be made immediately.

Attracting and retaining skilled mechanics is already a difficult task for many fleet operators; finding technicians with the added knowledge and/or experience with gas compressor systems, dryers, CNG or LNG fuel storage hardware and controls is even more difficult.

The time resources and cost of skilled personnel may be spread across multiple locations, as is the case with most independent fuel providers and O\&M companies. In some large fleet operations, these costs are absorbed in-house. For example, several large natural gas fleets (e.g., Metropolitan Atlanta Rapid Transit Authority) have accomplished these tasks using skilled in-house mechanics trained in equipment PM and repair. Other large fleets have outsourced these via station O\&M contractors (e.g. Los Angeles Metropolitan Transit Authority).

\section{E. Status of Current Natural Gas Fueling Infrastructure}

The limited number of vehicular LNG installations in the U.S. (estimated at 40-45) primarily is a function of economics determined, in large part, by availability of - and distance from LNG supply. As more LNG import terminals are approved and brought on line and new smallscale liquefaction technologies are commercialized and placed, supply options will increase, as will the applicability and financial viability of LNG fueling on a greater scale. While CNG and LNG station development project dynamics share some similarities, there are far more differences in the technologies, the applications, the supplies and other key factors involved in the sale and post-sale support. The discussion that follows focuses primarily on CNG fueling infrastructure.

Part III of this report provides more detail about vehicular natural gas consumption by niche sector and regional. Interviews with station owners and operators conducted in preparation of that section, including those operated by utilities, independent fuel providers and fleet operators, revealed much about the current inventory of CNG fueling infrastructure. It comprises a mix that runs the gamut from large to small and from modern well-utilized publicand private-access stations, to those that are grossly underutilized either because the customer base never materialized or the original throughput dwindled through attrition of bi-fuel and dedicated CNG vehicles and little was done to generate new load. Generally, the more recent the station was built or upgraded, the better it is utilized because, as note earlier, most of the 
investments in CNG stations over the last several years were undertaken based on confirmed or soon-to-be-added load.

\section{Who's Operating Existing CNG Stations}

Of the approximate 1100 CNG stations in operation, CVEF estimates that sixteen percent are operated by independent (non-utility) fuel providers, twenty-seven percent are operated by utilities, another thirty-seven percent are operated by federal, state or local governments and quasi-government entities (e.g., transit, school, airport), seventeen percent are operated by private businesses (e.g., linen services, package companies, building trades contractors), and the remaining three percent are operated by individual consumers.

\section{CNG Station Utilization}

Based on 2005 throughput data collected and analyzed for Part III of this report, CVEF estimates that about fifteen percent of the CNG stations accounted for roughly sixty-five percent of total U.S vehicular CNG throughput. Seventy-five percent of CNG stations accounted for the other thirty-five percent of CNG fuel throughput and the remaining ten percent of CNG stations were dormant or dispensed negligible amounts of fuel, amounting to less than one percent of the U.S total.

Furthermore, based on installed fueling capacity, CVEF estimates that approximately thirty percent of CNG stations are grossly underutilized, defined as stations that dispensed, on average, no more than fifteen percent of their capacity in 2005. Many of the CNG stations contacted by CVEF dispensed as little as one percent of their capacity.

There were wide regional variances in this data. When transit accounts were taken out of the data set (because of their high-utilization factors and the fact that transit accounted for approximately fifty percent of total U.S. CNG throughput), western state CNG stations had higher utilization factors than anywhere else in the nation with California having the highest utilization.

\section{Dormant and Underutilized CNG Stations Need Investment to Be Viable}

Many of the dormant or underutilized CNG stations are government- or utility-ownedand-operated and, most, only for their own CNG fleets, which are dwindling. Others allow public access but do not conduct market outreach to build load. Based on interviews with station operators, many of these stations are in need of repairs and/or upgrades to make them viable - regardless of who owns and or operates them. One factor that will affect this decision is the level and cost of upgrading the facility. Some stations basically are intact but out of commission for one reason or another and repairable at relatively low cost. Other stations need significant investment to upgrade them from their current 2400psi or 3000psi fuel dispensing capability to 3600psi and/or to replace or repair dryers, controls and other critical components. Investments in these stations must be offset through increased fuel throughput. Whether these investments are made or not will depend, in part, on the outlook for potential load growth, available funds and the current station owner's interest and commitment to the CNG station. In many cases, the investment likely will not occur and the station will eventually close. This may be viewed as continuation of the "market correction" discussed above and should not be perceived as indicative of NGV market health. 


\section{F. Recent Trends in CNG Station Development, Ownership and Operations}

1. Summary of New Capacity Added in 2004-2007

The CNG refueling capacity added over the last several years may be divided into two general categories: capacity installed at a new location; capacity added at an existing location to meet projected demand growth.

a) New CNG Station Development

CVEF estimates that between 90-110 completely new CNG stations were added to the CNG fueling infrastructure during the 2004-2007 period. This estimate does not count upgrades and "re-launching" of existing underutilized stations, as discussed below, nor does it include installations serving forklifts, ice resurfacing machines and other off-road applications. About eighty percent of these new stations were small-capacity stations (less than 50scfm), five percent were medium-capacity stations (50-400scfm) and fifteen percent were large capacity stations (over $400 \mathrm{scfm}$ ). When measured in terms of throughput, large-capacity high fuel use stations have definitely had the biggest impact. This is where most of the sales and marketing efforts of the independent fuel retailers and station development/O\&M companies is directed because of station economics

About twenty-five percent of the new stations were installed at new locations for existing CNG clients (e.g., LA MTA, Arlington County Public Works, City of Fresno Rural Transit), another sixty percent were installed for new NGV clients (e.g., numerous small towns and school districts in CA, Long Beach Public Schools, Portland ME Transit). The remaining fifteen percent were brand new retail locations developed by independent fuel providers.

b) Investments in Existing CNG Station Infrastructure

Like any other infrastructure, investments need to be made periodically to replace parts and, on occasion, to change out worn or spent critical components. For active well-utilized stations, this process is ongoing and is not the focus of the comments that follow.

\section{(1) Added Capacity to Existing CNG Sites}

Several large and high-profile CNG station projects completed between 20042007 occurred at existing sites and involved the addition of compression, storage and dispensing equipment to serve the added load of additional vehicles (e.g., DFW Airport, New York MTA). On a station count basis, these were few in number but they added significantly to U.S. vehicular CNG throughput. In addition, dozens of operators of existing small-capacity stations (e.g., a school district with several buses, towns with a small CNG fleet) added fueling capacity, although these projects' net increase to the total U.S. fueling capacity is minimal.

(2) Reinvigoration of Underutilized Stations 
In addition to developing new projects from the ground up, a few independent fuel providers are purchasing existing dormant or underutilized stations from utilities, states and municipalities, making upgrades to compression and storage and installing credit card payment processing systems to make the locations "retail ready." These projects sometimes require site development work to create public accessibility, including creation of "outside the fence" dispensing capability. If needed, property lease agreements are signed in cases where the equipment is located on utility, state or municipal property. Because these investments are justified by - and are driven by - additional load, the independent fuel companies are directing considerable sales efforts at simultaneously securing one or more local NGV anchor fleets. The net effect is that existing CNG capacity is reinvigorated (and often enlarged), access is opened to the public and throughput is increased.

2. Increasingly, Independent Station Developers and Equipment Vendors Take The Lead

LDCs that actively engage in NGV market development, either directly or working with trade allies to support sales and marketing activities, now numbers less than a dozen. Most other LDCs, including many previously engaged in NGV market development, now either devote little resources to the effort or have neither NGV marketing nor technical staff to respond to customer queries. Increasingly, independent fuel providers, station development/O\&M companies and equipment vendors and their dealers are taking the lead in developing new projects. Collectively, however, the number of companies and the amount of sale and marketing resources they're able to devote to developing the NGV market is far less than when more utilities were active. In addition, the geographic coverage is spotty.

There are less than ten non-utility station development/O\&M companies in the market. Of those companies, only one is well resourced enough to establish sales teams in multiple markets, and several target only the largest station development/O\&M projects with a few regional sales people. The remaining three or four companies are local or regional and have limited sales-marketing resources deployed on the street. About a half-dozen compressor package manufacturers rely heavily on a few select active dealers and/or design consultants to develop leads to which they respond with bids but these manufacturers conduct very little direct marketing outreach to customers. In addition, the few heavy-duty engine manufacturers, one major automotive OEM and two SVMs occasionally generate new station development leads from their sales efforts but they're not able to execute these fueling facilities without getting station developers or equipment packagers involved. This lack of "feet on the street" is a major obstacle to more robust NGV market development. Interest in NGVs and fueling infrastructure that is created through presence at fleet trade shows, conferences and web casts and/or through media coverage is not always supported at the local level due to gaps in the local/regional salesservice network.

\section{Heavy-Duty Fleets and Larger Stations Receive Greatest Effort}

Heavy-duty fleet applications and larger stations have become the primary focus of most market development activities. This focus on heavy-duty fleets and larger stations does not diminish the importance or value of market development initiatives taken by small fueling packagers, Honda or the SVMs. As noted above, all but one major automotive LDV OEM (Honda) left the market by mid-year 2006 and most other LDV OEM vehicle 
model options were gone before then unless the prospective fleet customer was amenable to purchasing through the SVM channel. Many states' general services administrations and some local government jurisdictions will not allow or shy away from purchasing through SVMs. Government fleets, which until recently accounted for a large percentage of the small fueling equipment package purchases, no longer have an OEM option for pick-up trucks and cargo vans. Consequently, sales of small fueling equipment packages have dropped off significantly in the last two years. Meanwhile, sales of heavy-duty engines to manufacturers of transit-style and school buses, refuse trucks and other vocational work trucks (e.g., sweepers) have been growing. For reasons of vehicle availability and station economics, independent fuel providers and station development/ O\&M companies have focused much of their efforts on these types of accounts.

4. Pooling CNG Throughput: Retail Stations, Anchor Fleets and Outside-The-Fence Sites

Generally, stations need to generate enough fuel sales to justify the investment, especially if the station is to be owned and operated by a fuel retailer. To achieve this critical economic benchmark, it may be necessary to "pool” the needs of multiple customers through the development of a retail fuel site.

One option is to build a CNG station on developer-owned property at a location that is near to one or more local "anchor" fleets and which also is convenient and attractive enough to grow additional customer load. Identifying this perfect mix of anchor customer need, main thoroughfare proximity and access and real estate availability is easier said than done. These station development projects seem to work best when there are local government policies in place that promote NGV deployment either through mandates and/or economic incentives. An example is a retail station developed at an airport that has policies that mandate or provide incentives for taxis and other private shuttle fleets to use NGVs.

Another option that is occurring more frequently is the co-location of retail fueling capability adjacent to an anchor fleet's own depot or yard by extending fuel lines and installing dispensing equipment outside the fence of the host fleet. The compressor equipment, dryers and storage are sized to serve both the host's fueling facility and the retail island(s), thereby achieving the best economies of scale. The station may be located on or adjacent to the host fleet's property and it may be owned by the host fleet or, more typically, by the independent fuel provider who handles all the fuel transactions and related administrative burdens. Some public and private fleet operators have established outside the fence public accessibility on their own but this is more the exception and almost always involves the awarding of grants and other incentives to offset the added equipment expense.

Another option that utilities and independent natural gas station developers have used is to partner with petroleum fuel retailers to install natural gas on leased space at existing gasoline and diesel stations. Typically, the natural gas fuel provider retains ownership of the CNG equipment and handles O\&M while the gas station owner handles transactions and related administrative burdens for a cut of the proceeds (e.g., royalties, transaction fees). This option also has it own challenges including whether there is enough available space for the additional compression, storage and dispensing equipment and, if expected to handle large vehicles, whether the station is designed and sited appropriately (e.g., traffic access and clearances, canopy height). 


\section{G. Recommendations}

The following recommendations are intended to help spur NGV market growth and, consequently, fueling infrastructure growth. Some require direct involvement of government, either through the implementation of alt fuel vehicle policies and programs (e.g., in support of air quality and energy diversification goals) and/or tax policies. Others are the primary responsibility of the present and potential NGV industry stakeholders.

1. At the highest federal level, (e.g., President and Executive Branch Secretaries and senior managers), communicate publicly the importance of NGVs and NGV fueling infrastructure in helping our nation meets its transportation energy diversification and air quality improvement goals. This will establish clearly the role that NGVs can and should play, as has been communicated about other alternative fuels and vehicles.

2. Issue private fleet and local government fleet AFV purchase requirements as authorized, but not yet promulgated, under EPAct 1992. Furthermore, enforce existing requirements governing federal fleets' purchase of AFVs and use of alternative fuel in those vehicles.

3. Reinstate federal NGV RD\&D funds for:

a) Continued improvement and development of new, cleaner, more efficient light-, medium- and heavy-duty natural gas vehicle engines, the integration of those engines into natural gas vehicles for on-road and off-road applications, and the demonstration of the proper operation and use of NGVs This will accelerate the market introduction of improved factory-built vehicles and lower the OEMs engineering cost, thereby reducing the premium these companies must charge to recoup their engineering investment.

b) Expanded availability of NGVs by assisting manufacturers in the certification to EPA and/or CARB standards.

c) Development and improvement of codes and standards for the continued safe operation of NGVs, natural gas fueling infrastructure and their components

d) Improvement in the reliability and efficiency of natural gas fueling infrastructure and certification of natural gas fueling station infrastructure to national recognized industry safety standards

e) Improvement in the reliability and efficiency of onboard natural gas fuel storage systems, development of new natural gas fuel storage materials and certification of onboard natural gas fuel storage containers to nationally recognized industry safety standards

f) Development and demonstration of natural gas engines in hybrid vehicles

g) Development and improvement of biomethane recovery, processing and liquefaction technologies to expand the supply and availability of CNG and LNG.

4. Increase the grants made available for purchase of alternative fuel vehicles and fueling infrastructure through federal and state programs 
5. Revise current federal tax incentive legislation for vehicles and station investment to allow tax-exempt organizations to more-readily take advantage of these credits; options include allowing these tax exempt organizations to take the credits as payroll tax credits, or to make these credits available as direct grants.

6. Extend the federal vehicle, fuel equipment and motor fuels excise tax credits sufficiently beyond their current expiration date to instill confidence in public and private fleet operators that these incentives will remain in effect long enough for them to be fully applied through the life of the equipment, and better yet, long enough to have the desired effect of accelerating market adoption of the technology and the resulting manufacturing economies of scale.

7. Re-engage the major automotive OEMs to produce and market light- and medium-duty NGVs.

8. Create lead development and "soft-order" consortia to facilitate major truck chassis OEMs introduction of factory-built heavy-duty natural gas powered vehicles.

9. Continue to focus NGV fueling infrastructure development efforts on high-fuel use fleet locations where throughput justifies equipment investment (e.g., transit agencies, refuse operations, port transfer terminals, airports, food distribution terminals, beverage distributors, textiles services). Expand efforts targeting high fuel use accounts that fall below the throughput threshold that attracts the independent station development/O\&M firms as these prospects often have good economic payback and life-cycle cost characteristics that justify fleet ownership and operation of their stations.

10. Provide additional grants, tax credits and/or other incentives for fleet operators that include public access "outside the fence" dispensing capability from their stations, thereby furthering the goal of expanded public fueling infrastructure

11. Expand the outreach of the current NGV stakeholder network by:

a) Re-engaging natural gas utilities to once again become active in NGV issues including market development (either directly or indirectly through sales-marketing and technical support of local NGV industry trade allies) and public education about CNG vehicle and fueling infrastructure safety.

b) Station development/O\&M companies and equipment vendors that are not already doing so, allocating additional sales-marketing resources to pursue the market more aggressively, either directly or through support of their dealer networks (e.g., sales tools, mailing lists)

c) Engaging petroleum marketers including independents and major oil and gas companies regarding the value-added benefits of marketing vehicular natural gas fuel at their retail stations, just as many of them are beginning to market E85 and other alternative fuels.

d) Engaging commercial fleet lease-finance companies to communicate the benefits of NGVs to their clients and offer this option. 
e) Engaging municipal lease-finance companies to take advantage of the federal vehicle and fueling equipment tax credits, thus lowering the basis of the their vehicle acquisition cost and thus lowering the capital lease fees to their government fleet accounts.

f) Garnering greater national media attention for NGV benefits and successful applications through trade press and business and mass communications channels

\section{VEHICULAR NATURAL GAS CONSUMPTION DATA}

\section{A. Definition of Need - Scope of Work}

U.S. DOE EERE program managers and NGV industry stakeholders agree that compiling an assessment of the total vehicular natural gas fuel consumption and allocating that fuel use by market niche will help guide U.S. government alternative fuel policies and natural gas vehicle (NGV) industry programs.

Toward that goal, the contract work scope statement calls for "the development and implementation of a plan for the collection of natural gas (CNG and LNG) vehicle fuel sales information that will add the most value by concentrating on fuel use data collection efforts for CNG/LNG niche markets (e.g. transit bus, school bus, airport taxis and shuttles, short-haul freight carriers, and refuse haulers) and aggregating and reporting the collected data at the State and National levels." It further stipulates that, "both retail and wholesale sales from private and public pumps will be included.”

Note: While Canadian and U.S. NGV markets are closely linked in terms of equipment and service suppliers, adherence to similar US EPA vehicle certification requirements and vehicle, station and fuel container codes and standards, only U.S data was requested and included in this report.

\section{B. Assessing Past and Present NGV Data Collection Program}

Examination of past efforts to measure vehicular natural gas fuel use over the past two decades provides useful insights about different data collection and extrapolation methodologies and their relative strengths and shortcomings.

\section{Early NGV Data Collection by Natural Gas Local Gas Distribution Companies}

From approximately 1982 until 1998, the American Gas Association (A.G.A.) surveyed its natural gas local distribution company (LDC) members concerning NGV inventories and vehicular natural gas fuel use in their respective service territories.

Most of A.G.A.'s early NGV-related data collection efforts emanated out of the Fleet Working Group, an ad-hoc subset of A.G.A.'s Operations Committee, working in conjunction with A.G.A.'s Technology Committee and the Gas Research Institute (GRI). At the time, these surveys provided the most comprehensive assessment of the NGV market, as most NGVs were either LDC-owned-and-operated or had been converted as part of the LDCs' NGV market development efforts. Furthermore, nearly all NGVs relied on LDC-owned-and-operated fueling stations or those installed at the host site by the LDC. 
In1988, as the NGV market gained momentum, A.G.A. members interested in enhancing NGV programs formed the independently funded and managed Natural Gas Vehicle Coalition (NGVC), which was later renamed NGVAmerica in 2006. NGVC continued to work with GRI and A.G.A.’s operations division to collect data on vehicles and fuel use. However, as the gas utility industry transitioned to a deregulated marketplace in the midto-late 1990s, many LDCs scaled back or discontinued their NGV market development activities. Eventually, A.G.A's Fleet Working Group dissolved, GRI’s end-use programs including its NGV programs were scaled back dramatically or discontinued and without the necessary resources, NGVC's surveys of utilities' NGV activity ceased in 2001.

Regarding validity and completeness of the data collected by the utility industry, it is important to note that not all LDCs with NGVs operating in their service territories were A.G.A. members nor did all A.G.A. member companies choose to participate in these surveys. Also, different LDCs used different methodologies to calculate vehicle inventories and fuel use estimates provided to A.G.A.

\section{AFVs' Role in National Energy Initiatives Drives DOE Need for Better Data}

The federal government became a more active and prominent player in the collection of NGV market data beginning in the early 1990s. Driving this data collection process was Congress's passage of the EPAact 1992, which mandated that federal, state and fuel provider fleets purchase alternative fuel vehicles (AFVs) - including NGVs - and that they report their purchases annually to the US DOE's Energy Information Agency (EIA) using Form DOT/OTT-101 “Annual AFV Acquisition Report for State and Alternative Fuel Provider Fleets” (DOT/OTT-101). It is important to note that local governments and private fleets were not similarly mandated, nor have they been since. Also important, EPACT ' 92 AFV purchase requirements for federal, state and fuel provider fleets includes exemptions for smaller fleets, vehicles not centrally fueled and vehicles used in critical services (e.g., security, emergency response). Most important, EPACT '92 does not require that mandated fleets use alternative fuel in the vehicles purchased. As such, data gleaned from DOT/OTT 101 submittals, while useful in measuring specific EPACT 92 objectives, does not provide a complete picture of the NGV market.

EPACT '92 also directed EIA to collect information about AFV manufacture, conversion and use in order to satisfy public inquiries and to provide Congress with a measure of the extent to which the objectives of EPACT '92 were being met. While EIA created a reporting mechanism that attempts to quantify all AFVs manufactured and/or converted as well as determine where they were in use and to what extent they used alternative fuel (EIA Form-886 “Annual Survey of Alternative Fueled Vehicle Suppliers \& Users”), the agency does not have the authority to mandate that local government fleets and private fleets respond to the survey. EIA eventually persevered in obtaining AFV manufacturing numbers from original equipment manufacturers (OEMs) and most small volume - i.e. conversion system - manufacturers (SVMs), but there is no in-place tracing mechanism to track where these vehicles are deployed once manufactured. With limited program resources and authority with which to create such a tracking mechanism, EIA, like A.G.A. and NGVC before it, increasingly has relied on miscellaneous information sources including aging AGA-NGVC database reports, press release searches and anecdotal accounts - to create the target list to which send the annual Form-886 survey. The effort, while commendable, is under-resourced and far from comprehensive.

An additional data source available to EIA program managers and statisticians comes 
from EIA-Form 176 (“Annual Report of Natural and Supplemental Gas Supply and Disposition”), which requires that utilities account for the disposition of natural gas passing through their distribution lines - including sales of vehicular natural gas.

Unfortunately, the accuracy of much of that utility-provided data is suspect because, unless specifically required by their state public service/utility commission (PSC) - often a function of whether an NGV-specific tariff is in place, few have formal tracking mechanisms for vehicular natural gas use or sales. A sample crosscheck of EIA-176 data against other information sources indicates inconsistent application of the form's data reporting guidelines, wide discrepancies and, generally, under-reporting of vehicular natural gas sales. For example, a utility in one southern state reported vehicular natural gas sales volumes that were nearly thirty percent lower than the amount of fuel used by just one transit system operating in its service territory, let alone the amounts used by additional known NGV customers in the area.

With these data source deficiency caveats noted, EIA produces the two most widely referenced reports regarding CNG and LNG vehicles in use and their related fuel use: the “Transportation Energy Data Book" and "Natural Gas Annual.” In recent years, however, it has become increasingly difficult for the agency to validate their NGV data. Given the uncertainty about data gleaned from EIA-Form 176, EIA's vehicular natural gas estimates rely heavily on extrapolations of estimated NGV inventories multiplied by typical fuel use per vehicle. Without more accurate vehicle tracking mechanisms, NGV inventory estimates must be extrapolated from years of aggregated OEM data, depleted by estimated vehicle life-cycle attrition rates, and cross-referenced against miscellaneous EIA-886 surveys and DOT/OTT-101 compliance reports, which - as noted earlier - account for only a portion of all NGVs in service. EIA analysts must then estimate average fuel consumed per AFV, factoring in assumptions about vehicle types, duty cycles and how often bi-fuel vehicles are fueled with alternative fuel. The results are coarse estimations based on extrapolations of outdated and incomplete sub-data sets, which EIA's own statistical professionals agree are questionable.

\section{Clean Cities Coalition Data Collection Efforts}

More recently, the US DOE Clean Cities Program has attempted to collect and aggregate alternative fuel vehicle counts and, by extrapolation, alternative fuel use by requiring that its coalitions provide annual reports for their respective areas (including CNG and LNG). Most coalition estimates are based on responses to surveys by member-stakeholders and other known fleets operating within their areas. While this data reporting process has proven to be useful in illustrating the impact of outreach and education programs in Clean Cities Coalition areas, there are significant numbers of NGVs operating in areas not designated as Clean Cities. Furthermore, there are no requirements that NGV operators be members of - or respond to - coalition surveys and fuel usage is not included in the reporting process.

It is against this background that US DOE Clean Cities Program managers requested that an independent effort be undertaken to assess available resources of accurate vehicular natural gas fuel use data and to implement a repeatable collection program, the results of which would be used to validate and/or fine-tune existing reports.

C. Investigation of Data Availability and Collection Methodologies

After preliminary interviews with representatives from A.G.A., EIA, NREL, multiple Clean 
Cities Coalitions and NGVAmerica's utility and equipment members, CVEF investigated multiple approaches to calculate CNG and LNG fuel usage to see which might be most fruitful and repeatable for future data collection efforts. These approaches are outlined below, as are summaries of the feasibility of each.

\section{Collection of Utility-Provided State Public Service/Utility Commission Data}

According to National Association of Regulatory Utility Commissioners (NARUC) staff, state PSC reporting requirements differ significantly and, while NARUC has mechanisms in place to survey their members concerning NGV-related tariffs and reporting requirements, no such NARUC survey has been conducted. Interviews with staff at a sampling of state utility service commissions and at NGVAmerica utility member companies highlighted the fact that only the states with NGV-related tariffs had any reporting requirements, and even then, the information required by the regulatory authority varied significantly. None required allocation of fuel use or sales by niche market sector.

For example, in Connecticut, the PSC requires reporting about vehicular natural gas fuel sales but not fuel used by utilities in their own fleets. In Utah, where the local distribution company (LDC), Questar, has an active NGV market development program complemented by a favorable PUC regulatory environment, vehicular natural gas is not required to be separately metered. Fortunately, in California, the state recognized as having the largest number of NGVs in service and the greatest vehicular natural gas sales, there is a comprehensive vehicular natural gas sales tracking and reporting program. However, as discussed further below, this fuel data is not allocated by niche market sector.

Even if more utilities were required to report their vehicular natural gas sales or volumes to state utility regulatory authorities, the veracity of the data in many utility areas would be suspect because, as noted above, their systems to monitor and track vehicular natural gas fuel sales and/or use are inadequate.

\section{Collection of Federal and State Motor Fuels Excise Tax Data}

When compressed for use in on-road vehicles, the seller of CNG - or the user of CNG in cases where there is no sale - incurs a federal motor fuels excise tax liability that is reportable to the IRS and, in many cases, to state tax assessment bureaus. The only exceptions to this federal tax liability are tax-exempt entities including most state and local government agencies, transit agencies, public school districts and some quasigovernment special districts and/or authorities (e.g., port and airport authorities).

In nearly every state, there is an additional state-levied motor fuels excise tax and/or special assessment fee and, in many of these states, these taxes and fees apply to federally tax-exempt entities. Given the existence of these motor fuels excise tax assessments and reporting requirements, state tax collection agencies/bureaus were contacted to investigate whether this data might be made available to the US DOE on a voluntary basis.

In discussions with tax assessment agencies in eleven states with known NGV fleets, CVEF found that less than one-half actively tracked this tax obligation for NGVs and, even in those states, between 20-50\% of the known NGV fleets obligated to file such information did not do so on a regular basis. Based on these preliminary contacts with state agencies, this data collection approach was determined to be unacceptable. 
Note: Later in the data collection process, the reports' author spoke with hundreds of station operators, most who did not know of the reporting requirement

\section{Extrapolation of NGV Fuel Use Based on State Vehicle Registration Data}

Another methodology investigated was the extrapolation of fuel use estimates based on NGV inventories as recorded in state motor vehicle registration Vehicle Identification Number (VIN) databases. Interviews conducted with representatives of the American Association of Motor Vehicle Administrators (AAMVA) and also with a sampling of state motor vehicle administrations revealed that there is no consistent protocol for states to follow regarding what data is recorded and reported, and few denote a vehicle's fuel type.

For example, while Alabama's motor vehicle administration does not have any information about AFVs operating within its borders, Arizona's vehicle registration records include the number of dedicated and bi-fuel NGVs on the road, but there's no cross-reference capability to identify the types or class of vehicles without writing a custom software program to pull this information from its VIN dataset. California's state motor vehicle registration database contains information on all vehicles applying for HOV status, including dedicated CNG vehicles.

CVEF contacted R.L. Polk \& Associates, an independent vendor that specializes in providing data storage, retrieval and search services for numerous state motor vehicle administrations. Given the VIN sequences to search for, company representatives indicated that they would be able to search state databases of registered vehicles for those operating on natural gas. This approach had several hurdles that ultimately made it unfeasible for CVEF to pursue but which may be fruitful for future DOE efforts if adequately funded. First, a comprehensive search would require OEM VIN sequences for each engine family and corresponding model for each model year, a request that has proven difficult for even EIA to obtain. Second, the estimated cost of this custom VIN data search and report exceeded the entire value of the current contract. Third, state VIN registration data would not capture vehicles converted, re-powered or retrofitted after leaving the OEMs' factories. Lastly, even if an accurate count of all NGVs registered were compiled, CVEF would still have to estimate average fuel use for each vehicle type and duty cycle, including estimations of fuel use by bi-fuel vehicles.

Note: Subsequently, NREL did purchase the R.L. Polk database and found that information about CNG and LNG vehicles was grossly deficient.

\section{Data Collection Methodology Used}

After evaluating the options discussed above, CVEF determined that none were likely to produce information at level that would meet the intended purpose of the report and decided upon the following course of action:

\section{Liquefied Natural Gas (LNG)}

The process of tracking total vehicular LNG use and allocation of that fuel by niche sector is far simpler than that for CNG because there are a limited number of plants producing vehicular LNG and an even smaller number of companies that market and sell this fuel to fleet customers. Vehicular LNG production and delivery volume data from plants in Wyoming, Texas, Arizona and Colorado was cross-referenced with customer data 
voluntarily provided by the primary suppliers, Clean Energy and Applied LNG Technologies (ALT). Apollo Energy (later renamed Earth LNG) provided additional data as it acquired ALT's LNG business in late 2005. All LNG vehicles identified in this report operate in Texas, Arizona or California.

Note: Additional LNG vehicles operate in Canada accounting for approximately 3.47 million LNG gallons (2.28 million GGE).

\section{Compressed Natural Gas (CNG)}

After assessing the options discussed above, CVEF determined that, in most states, existing CNG vehicle and fuel use tracking mechanisms were - and are - inadequate to create repeatable yearly estimates without substantial investment of resources each year. The most notable exception is California, where the major natural gas utilities are still actively engaged in NGV market development, NGVs play an important role in the state's energy and air quality policies and the PSC has fairly comprehensive reporting requirements in place. In states other than California, CVEF primarily relied on data collected through an exhaustive direct contact program to all known CNG stations and/or the utilities that serve them. This process is detailed further below.

a) California

According to California state vehicle registration records, supplemented by several independent publicly- and privately-underwritten reports, California's existing inservice NGV fleet exceeds 28,000 vehicles. In addition, the state has the greatest number of CNG stations, including "private access-only" and "limited public access" or "full public access" retail locations. California's PSC requires that regulated natural gas utilities meter and report all natural gas sold for vehicular use, either directly to the "captive" end-use fleet customer such as a transit agency or municipality that compresses the fuel for its own use, or to a "retailer" that sells CNG to others. For purposes of this report, CNG sales and use data was taken directly from the state PSCrequired reports.

However, California's PSC does not require that utility reports include allocation of vehicular natural gas sales by niche sector. This report's niche market allocation was accomplished by cross-referencing CNG fuel sales/use data extracted from PSC filings against California data gleaned from multiple NGV-related reports, surveys and databases published by niche market associations, federal and state government agencies and independent consulting firms, proprietary customer lists provided by independent station operators and interviews with California gas utility NGV account managers. The author's level of confidence in the California CNG allocations correlates to the level of detail available in these multiple information sources with the greatest confidence in the transit, refuse and school sectors and the least confidence in the government and short haul sectors.

b) States Other Than California

In states other than California, CVEF telephone surveyed LDCs and/or the stations they served to obtain 2005 calendar year utility meter data, then translate that into gasoline gallon equivalents (GGE). The National Renewable Energy Laboratory (NREL) Alternative Fuel Data Center (AFDC) database of known CNG stations was 
the primary source from which CNG stations were located. Additional sites not on the AFDC database were added based on information gathered during interviews conducted with LDC representatives, station operators and station service contractors.

For each LDC listed, the survey process entailed the following:

(1) The AFDC list of stations served by that LDC was reviewed to determine if the LDC had its own CNG station on utility property (e.g. "Piedmont Natural Gas Fleet Service Yard”). An introductory telephone call or e-mail was made to the AFDC database contact, who was often a fleet operations manager or service technician, to explain the data need and to determine awareness of and familiarity with the LDC's CNG stations and also with other stations on the LDC's distribution lines. This initial call inevitably led to additional calls to the LDC's fleet management, marketing, accounting and/or IT staff.

Once the initial contact was made and all the cognizant "data keepers" were identified, a follow-up introductory letter and data reporting guideline summary were forwarded along with a spreadsheet of all AFDC listed stations served by that LDC. The letter explicitly stated that submittal of data was voluntary and that all data submitted would be aggregated so as to protect confidentiality. The letter asked the LDC contacts to:

(a) Confirm the continued existence and service at the stations listed. If CNG service had been discontinued, CVEF asked that the date of discontinuance of service and the disposition of the equipment be provided (still in place, removed, etc).

(b) Provide basic contact information (general location, owner or operator, telephone or e-mail) for any other CNG station not listed on the AFDC list but served by that LDC, including LDC-owned-and-operated stations and those owned and operated by customers or third-party retailers. LDC fleet maintenance staff were often familiar with these additional locations because they either installed them and/or provided station maintenance services.

(c) Provide meter throughput information for the AFDC listed and additional CNG locations (therms, ccf, mcf, MMBtu). Accomplishing this task was either very simple (e.g., pulling fuel use records previously submitted to the accounting department for tax reporting purposes) or very difficult (e.g. additional letters/calls to the LDC's general counsel or management, identification of meter serial numbers to determine which meter served the compressor, searches of billing records, etc).

(d) Allocate fuel throughput by niche sector based on their knowledge of the station operation using the guidelines provided by CVEF. For private access stations, where all fuel use fell into one niche sector (e.g. an LDC's own internal-use-only site or a transit agency's private location), this task was easily accomplished. In cases where the LDC had no information about the customer's site other than throughput, follow-up calls to the station operator were necessary. 
In many cases where the LDC either would not or could not provide the data for customers' CNG stations, CVEF contacted those customers directly to ask if they would be willing to share this information with the same assurances of confidentiality. On a station-by-station interview basis, vehicular natural gas volumes were either compiled from utility bills or estimated based on vehicle counts and types provided by the interviewee. In most cases, these stations either were "private access only" stations that allowed fueling only for their own vehicles or "limited public access" stations that allowed fueling by a limited number of pre-approved fleet customers in the area. One example is a municipal fueling site on government property that only fuels the town's vehicles or - on occasion - other local or state government vehicles traveling through. For stations that offered "full public access," including petroleum fuel retailers with CNG stations on site, volumes were often provided in GGEs from billing records, which were also used to determine allocation by niche market.

In less than a dozen cases, LDCs refused to provide any data, never followed through on their agreement to supply the data despite CVEF's repeated attempts to collect it, and/or never returned calls or e-mail queries. Due to time and resource constraints, approximately twenty-five individual CNG stations listed on the AFDC database were never contacted nor were the LDCs that serve them. Most of these stations were small volume locations, based on AFDC database information about the size of the compressor and the fill rate (quick-fill versus time-fill).

\section{Cross-Referencing of Data Against Known Natural Gas Fleets}

To ensure that major natural gas fleets were not overlooked due to the absence of their fueling station on the AFDC database or to LDC non-responsiveness, CVEF crossreferenced its data collection summary against the following sources:

a) American Public Transportation Association (APTA) 2005 Annual Transit Survey

APTA's survey of 280+ major transit agencies accounts for approximately 82 percent of all public transit buses estimated to be in revenue service in the U.S. The report, which includes vehicle fuel type, includes responses from most of the major market transit agencies and thus captures most of the CNG and LNG transit fleets in existence. Through web searches, press releases and proprietary member information, NGVAmerica supplemented information culled from APTA's database and identified an additional 23 transit agencies that operate approximately 250 additional natural gas-powered buses or shuttles.

b) INFORM Inc.'s “Greening of Garbage Trucks,” published in 2003, updated in 2006

The original report evaluated the in-the-field experience of public and private refuse firms using natural gas powered vehicles and the opportunities and benefits for increased use. In preparing the report, the author created a database of all known U.S refuse operations (and some international operations). Lacking any government- or refuse association-compiled database of natural gas-powered refuse trucks in service, the report's author compiled his own conducting web searches, interviewing natural gas utilities, and obtaining lists from natural gas engine manufacturers and refuse truck OEMs. The list is widely considered the most comprehensive available for the 
refuse sector.

c) US DOE EPAct compliance reports

CVEF did not have direct access to these reports but, through NREL sources, was able to get total aggregated NGV counts for the largest state and alternative fuel providers and used this data to cross-check utility fleets and flag larger state university fleets, which often are "under the radar."

d) Other US DOE Studies, Reports, Tool Kits and documents

Over the past decade, U.S. DOE and/or its subcontractors have published numerous studies, reports, case studies and other reviews of NGVs (e.g. Clean Cities Program case studies; niche-specific transit, short-haul and other fleet performance evaluations, Clean Cities Coordinator Tool Kits).

e) California State School Bus Inventory database

CVEF searched this database of all California public school districts' bus fleets to flag NGV fleets that were not already on the list compiled by NGVAmerica, which is based on information from gas utility representative interviews, press releases, web searches and lists provided by John Deere, Thomas Bus and Blue Bird and their distributors.

f) State Agency reports

State agencies, most notably those in California, Texas and New York, have either published or funded independent reports addressing the role of NGVs in meeting air quality and energy independence goals. CVEF and its sub-contractor (CNGVC) reviewed these reports for reference to existing NGV fleets. Reports reviewed include (but were not limited to) those written by/for the California Energy Commission (CEC), California Air Resources Board (CARB), South Coast Air Quality Management District (SCAQMD), Texas Emission Reduction Program, New York State Energy Research \& Development Authority (NYSERDA) and New York State DOT.

\section{Data collection timeline}

The data collection and verification process described above was undertaken over a fourteen-month period with the initial investigation of possible resources occurring in the first six months and the station-by-station survey and cross-referencing taking another eight months.

Throughout the process, CVEF took the opportunity to interview station owners and operators about what factors affected the original development and ongoing viability of their NGV fueling station(s) and how these factors might affect future station development investments. This information was critical to development of the Natural Gas Fueling Infrastructure Roadmap. Interviews were conducted with "private-access only" station operators in each of the target niche sectors as well as both "limited public access" and "full public access" retail station operators. Discussion topics varied greatly depending on the interviewee. In some instances, macro issues were the focus such as how the role of 
political and/or regulatory drivers factored into the decision to build and/or operate stations, how early assessments of potential markets compared to actual throughput and market growth, and the evolution of business development strategies. Other interviews focused more on specific station development concerns including both economic and technical issues, e.g. fuel throughput thresholds, regional variability in labor, real estate and material costs; site permitting, codes and standards requirements and other station design and construction issues; station maintenance and operations; the role of grants and/or other financial incentives.

E. Summary of Data

1. Survey Response Rates, Estimations of Data Validity and Accuracy

CVEF was successful in compiling fuel use information from 892 CNG and LNG stations. This station count is "net," and includes 157 "new" stations not listed on the AFDC database and 51 stations listed on the AFDC database that were determined to be "out of service" either before or during 2005. Some of the 157 "new" stations were discovered via the contact/interview process with station operators in nearby or adjacent utility service territories. Given the fact that older U.S. DOE and NGV industry reports estimated total station counts well in excess of 1275 stations, it is reasonable to assume that the reduction in total station counts is not entirely due to attrition and that some stations were missed, especially those located in isolated markets. Without access to - and the resources to evaluate - historical AFDC data sets against current databases, it is impossible for CVEF to state with absolute certainty an accurate count of all vehicular natural gas stations in existence. However, it is equally reasonable to assume that, given the extensive crosscheck of available information noted above, stations missed in this process likely represent a very small portion of the total NGV inventory and - by extrapolation - an even smaller percentage of the total vehicular natural gas consumption.

CVEF estimates that the 892 stations represent a data collection success rate of eighty-two percent of all stations and, based on existing AFDC database station equipment logs and information culled from interviews with knowledgeable local area contacts, a ninety-five percent vehicular natural gas volume throughput capture rate. Although extremely labor intensive, this direct survey and cross-reference methodology proved very successful in collecting vehicular natural gas volumes data and reasonably successful in allocating fuel use by niche sector.

\section{Summary of Station Access Status}

An assessment of the "public accessibility" status of current inventory of CNG and LNG stations was not included in the work scope statement, but it is valuable to understanding the role public accessibility has in relation to developing additional infrastructure in the future. Due to the different data collection methodologies used in different states and, in some cases, between different utility service territories within the same state, CVEF did not attempt - nor was it able - to verify the "accessibility" status of all stations against the information contained in the AFDC database. However, based on the survey interview and online search process, CVEF makes the following observations about public accessibility:

Very few LNG stations offer public access. In fact, the few that do (whether they be L/CNG stations or LNG stations) offer limited "public" access to other area LNG or CNG 
fleets that have already pre-established accounts with the fuel site operator. One example is the L/CNG station operated by Southwestern Transportation Agency, an organization formed as a joint operating agreement between several adjacent school districts, which fuels its own school buses as well as several other non-school district accounts operating in the area.

All of the CNG stations located on military facilities and most located on non-military federal property ceased offering public access shortly after the events of September 11, 2001.

Other than in the California utility service territories (and a few other utility service territories - notably in Utah, Oklahoma and isolated markets within New York, Indiana and Michigan), most utility owned-and-operated CNG stations that did offer public access to their fueling facilities prior to September 11, 2001, eliminated public access shortly thereafter due to "safety" or "terrorism" concerns. In most cases (well over 80 percent), these stations offered only limited public access anyway (e.g., pre-approved accounts with fuel cards, etc) and their customer base typically included only a few small local government or private fleets comprised primarily of bi-fueled light-duty vehicles (LDVs). One example of a utility that closed public access after September 11, 2001 is Public Service Electric \& Gas (New Jersey), which eliminated access to all its stations but one and, even there, only allowed the local law enforcement agency continued access. Another example is Dominion Energy, which eliminated access to all of its Pennsylvania, Ohio and Virginia stations. This left most of its existing western Pennsylvania area NGV customers without refueling capability, so vehicles had to be prematurely retired or auctioned off to other markets.

Of the 51 CNG stations on the AFDC database that CVEF confirmed had closed prior to or in 2005, 35 offered private access only, twelve offered limited public access and only four offered full public access. Based on interviewee's responses, most fueled only a few NGVs and closed either due to the retiring of the station operator's own NGVs (e.g., a utility's station), dwindling external NGV customer base and throughput and/or a combination of both. As such, the closing of these stations had negligible impact on total U.S. vehicular natural gas throughput although they further exacerbated gaps in the NGV fueling infrastructure.

Of the 157 "new" stations, approximately fifty percent offer either limited public access or full public access, which is representative of more recent trends in station development and operation as public access facilitates better station utilization and higher fuel throughput. Of the "new" stations that do not offer public access, most are located at local government sites, refuse companies or transit agencies.

\section{Total Estimated 2005 NGV Inventory}

While it was not the scope of this contract to quantify current NGV inventories, the process yielded useful information that, at very least, suggests that current government and NGV industry estimates may be overstated. Utility company survey data collected biannually between 1992-1998 likely led to the overstated base counts that were later extrapolated by the NGV industry and US DOE to reach the 130,000 count that has been widely circulated and accepted for more than five years. Re-evaluation of that data, supplemented by recent interviews with federal, state and utility fleet providers about their NGV purchases and the disposition of many of those vehicles, indicates that, at the peak 
of LDC and government involvement in the NGV marketplace, there may have been 105,000-110,000 NGVs in service.

However, with the exit of most aftermarket retrofit system suppliers due to EPA and CARB implementation of stricter emission verification requirements in 2000-2004, and the withdrawal of three of the major LDV OEMs between 2000 and 2005, there have been very limited LDV choices to replace aging vehicles. While several SVMs invested the technical and financial resources to meet the tougher EPA and CARB certification requirements, most federal and state fleets (and many local government fleets) will not or cannot buy these systems. And while American Honda has remained steadfast in its commitment to supplying CNG vehicles, its Civic GX was not a direct on-par replacement for the Chevrolet bi-fuel Cavalier or Ford Contour used by many of these fleets and it was obviously not a suitable replacement for the other OEM's CNG pick-up trucks.

The result of this perceived dearth of LDV options was major attrition in LDV inventories between 2004-2006. CVEF estimates that total NGV inventory dropped to 92,000 in 2005 and is now between 85,000 and 90,000. Many of the retired vehicles were utility-owned and government-owned bi-fuel vehicles that used little or no CNG. Growth in the medium- and heavy-duty vehicle counts have not offset the dramatic attrition in LDV counts but CNG and LNG fuel use has more than offset the CNG throughput associated with the LDV decline.

\section{2005 National Vehicular Natural Gas Fuel Use}

While NGV inventory counts have dropped, CVEF estimates that fuel use has steadily risen. 2005 vehicular natural gas consumption at the 892 locations tallied 189,441,307 GGEs. CVEF estimates that, if all stations had provided data, total 2005 vehicular natural gas consumption would have been about five percent more, or approximately 200 million GGEs. Vehicular LNG consumption accounted for approximately 39,450,000 GGE of the total U.S. vehicular natural gas volumes (roughly 60 million LNG gallons); the remaining 150 million GGEs was CNG. The "missing” five percent (roughly 10 million GGEs) is all CNG.

\section{State and Regional Distribution of NGV Fuel Consumption}

Listed below are 2005 total state vehicular natural gas volumes (stated in GGEs), allocated regionally according to Petroleum Administration for Defense Districts (PADD). As noted above, the volumes listed reflect gas meter throughput and/or available vehicle-based estimates for the 892 stations reporting. In some states, noted by “*”, the totals are underreported although the missing amounts likely have a negligible impact on total U.S. volumes.

$\begin{array}{ll}\text { PADD IA (New England): } \\ \text { ME } & 0 \\ \text { VT } & 3,300 \\ \text { NH } & 0 * \\ \text { MA } & 5,438,000 \\ \text { RI } & 340,776 \\ \text { CT } & 537,458\end{array}$

$\begin{array}{ll}\text { PADD IB (Central Atlantic): } \\ \text { NY } & 21,165,586 \\ \text { NJ } & 412,711 \\ \text { PA } & 1,222,950 \\ \text { DE } & 1,460 \\ \text { MD } & 1,278,262 \\ \text { DC } & 5,155,200\end{array}$

$\begin{array}{ll}\text { PADD IC (Lower Atlantic): } \\ \text { WV } & 0 * \\ \text { VA } & 398,443 \\ \text { NC } & 171,169 \\ \text { SC } & 46,831 \\ \text { GA } & 7,563,623 \\ \text { FL } & 317,187\end{array}$

\section{PADD II (Midwest):}




\section{DRAFT}

\begin{tabular}{llll} 
OH & $42,000^{*}$ & TN & 78,101 \\
IL & 404,332 & KY & $0 *$ \\
IN & 178,814 & MI & 433,119 \\
IA & 0 & MN & 39,744 \\
KS & 42,761 & WI & 456,000 \\
\multicolumn{2}{l}{ PADD III (Gulf Coast): } & \multicolumn{2}{l}{ PADD IV (Rocky Mtn.): } \\
AL & 61,921 & CO & $1,574,255$ \\
AR & 29,391 & ID & 376,392 \\
LA & 92,001 & MT & 2,622 \\
TX & $12,212,636$ & WY & $19,244^{*}$ \\
NM & $1,387,457$ & UT & $1,794,720^{*}$ \\
MS & 0 & &
\end{tabular}

$\begin{array}{ll}\text { MO } & 1,281,150 \\ \text { NE } & 54,146 \\ \text { OK } & 1,065,618 \\ \text { SD } & 0 \\ \text { ND } & 3,411\end{array}$

PADD V (West Coast):

AK $\quad 0^{*}$

WA $1,111,093^{*}$

OR 935,865

CA $106,075,893$

AZ 15,133,558

NV $\quad 501,506$

HI 0

As expected, PADD V, comprising the western states, accounted for the greatest volume with nearly 123,758,000 GGEs or 65.33 percent of total U.S. vehicular natural gas sales. LNG accounted for over 27 percent of this region's total vehicular natural gas volumes. By far, the largest total volume was in California, which alone accounted for about 56 percent of total U.S. volume. While California's transit sector clearly surpasses all other niche sectors combined (approximately two-thirds of the state's total volume), all the major niche sectors were well represented. Also in PADD V is Arizona, which nationally ranks third in total vehicular natural gas volumes with more than 15.1 million GGEs or nearly eight percent of the national total. Like California, Arizona's top niche sector is transit (again, about two-thirds of the statewide total) with the airport and government sectors ranking a distant second and third in volumes. PADD V would dominate even more if data from the state of Washington were not under-reported.

PADD IB, comprising Mid-Atlantic states, accounted for the second largest volume with 29,236,169 GGEs or 15.43 percent of total U.S. vehicular natural gas volume. Most notable in this district is the contributions of New York with just over 21 million GGEs, the second highest volume state in the nation, representing 11.2 percent of the national total. Also notable in this region is the District of Columbia, which ranks seventh in the nation at just over five million gallons, over 99 percent of which is due to the capitol region's public transit system, WMATA-METRO. In both Pennsylvania and Maryland, which contributed about one million GGEs each, one or two customers accounted for the majority of the volume.

PADD III, comprising the gulf coast states, accounted for the third highest volume, 13,783,407 GGEs or 7.28 percent of total U.S. vehicular natural gas use. Leading the region is Texas, which ranks fourth among all states with 12.2 million GGEs. Several large transit, airport and government accounts in Texas' major metro areas accounted for more than seventy-five percent of the state's total vehicular natural gas volume. While only accounting for a small percentage of Texas' total volume, use by the short-haul sector ranks second only to California. New Mexico, a distant second to Texas in this region, ranks tenth among all states, primarily due to one transit customer.

PADD IC, comprising the southeast coastal states from Florida north to Virginia plus 
West Virginia, ranked fourth accounting for 8,497,253 GGEs or 4.49 percent of total U.S. volume. Georgia carried most of the region with over 7.5 million GGEs, most of which was used by just one account, Atlanta's transit system, MARTA. Other bright spots include pockets of activity in the Tidewater and suburban Washington, D.C. areas of Virginia. In addition, while there are few if any large accounts in North Carolina, a small network of independent (mostly municipal) stations remains in place. These could serve as a launching pad for additional growth if these local governments opt to encourage public fueling.

The next highest volume region, PADD IA, comprising the upper northeast states, accounted for 6,319,534 GGEs or 3.33 percent of the total U.S. vehicular natural gas volume. By far, the largest contributor to this tally is Massachusetts where 3 large stations serving MBTA, Boston's regional transit system, account for more than 4.5 million GGEs. The rest of the region's volume is dispersed among a fairly extensive and growing network of smaller stations, many located at and/or operated by state and local governments and open to the public. In addition, several new locations began operating in Maine, New Hampshire and Vermont after 2005 (not captured in this data set), which - if opened to public access fueling - could further expand the region's fueling infrastructure. When combined with New York (allocated under PADD IB), the expanding network of stations positions the greater northeast U.S. for growth.

PADD II, comprising 15 Midwest states, ranked sixth in total U.S. vehicular natural gas volume with just over 4 million GGEs or 2.15 percent. For its size, this large region lags the rest of the nation in NGV market development with none of the states among the top 10 in the country. There are bright spots, however. Oklahoma still boasts the nation's $4^{\text {th }}$ greatest number of CNG stations (54), many operated by the LDC and offering public access and the state enjoys very favorable natural gas GGE costs as compared with gasoline or diesel. Michigan's Detroit metro area has a welldeveloped network of stations that make reinvigoration of this once strong market viable without huge investments in equipment. In addition, the Indianapolis, St. Louis and Kansas City metro areas have only a few stations each but champions that are building NGV market.

PADD IV, comprising five Rocky Mountain states, accounted for the lowest volume with only 3,767,233 GGEs or 1.98 percent of the U.S total. However, as a region of relatively sparsely populated states with few major metro centers, it represents a fairly vibrant NGV marketplace with Utah and Colorado nationally ranked eighth and ninth in total volume, respectively. Vehicular natural gas use in Utah tallies a bit under 2 million GGEs and the state ranks second in total fueling locations, last estimated at nearly one hundred (only 64 were included in this report but many of the rest are fork lift operations). Colorado's tally of about 1.5 million GGEs is primarily from Denver's airport but increased throughput at the fairly extensive Denver metro network of public fueling stations could quickly add to this state's tally.

\section{National Ranking of Fuel Use by Niche Market Sector}

Using metered data, billing records or information culled from station operator interviews, fuel use was allocated into eight niche sectors. Following is a national ranking of vehicular natural gas volume by niche sector: 
Niche Sector

Transit:

Airport:

Refuse:

Government:

Short-Haul:

Utility:

Other:

School:

\section{GGEs}

129,258,390

$15,342,734$

$14,377,897$

9,224,299

$5,659,453$

$5,181,331$

4,978,136

$4,674,570$
Portion of National Total

$68.23 \%$

$8.10 \%$

$7.59 \%$

$4.87 \%$

$2.99 \%$

$2.74 \%$

$2.63 \%$

$2.47 \%$

a) Transit Sector - Definition: Includes both metro and community transportation service transit buses and all light- and medium-duty natural gas vehicles used by maintenance, route coordination and other auxiliary personnel.

Transit continues to account for the lion's share of the vehicular natural gas market with nearly 130 million GGEs, representing better than two-thirds of total U.S. volume. This is also true in five of the seven PADDs as is discussed further below. Despite continuing gains in other sectors, the transit sector will maintain its leadership position for years to come. CVEF estimates that nearly 10,000 transit buses and community shuttles are in service, each consuming relatively high fuel amounts each year. While natural gas's percentage of new orders in 2005-2006 (and thus far in 2007) is less than in the 2000-2004 timeframe, demand from Southern California transit agencies and several east coast transit authorities is still strong. In addition, several new agencies deployed their first CNG buses in 2006. Federal motor fuels excise tax credits that went into effect in October 2006 - coupled with the impact of EPA's 2007-2010 emissions requirements on diesel bus life-cycle costs, likely will spur new natural gas transit customers to emerge

b) Airport Sector - Definition: Includes airport-owned and/or contracted terminal/parking shuttles, auxiliary and ground support operations vehicles (e.g., security, maintenance, runway sweepers, baggage tugs). Also includes private fleets primarily serving or based at airports (e.g., taxis, door-to-door services and off-site parking, rental car and hotel shuttles).

CVEF estimates vehicular natural gas consumption in the airport sector at 15.3 million GGEs in 2005, representing approximately 8 percent of total U.S. volumes. This amount is expected to continue to grow as existing airport authority fleets in California, Arizona, Washington, Missouri, Massachusetts, Maryland, New York and Texas expand their operations and/or implement "special access" or "privileged access" rules that encourage private fleets to switch to natural gas. Additionally, a number of airports that began investigating NGV options in 1999-2001 but postponed action after the attacks of 9/11/2001 (due to reprioritization of staff and budget resources) are "re-engaging." The new federal vehicle and motor fuels excise tax credits are particularly well suited to the private fleets operating in and around airports.

c) Refuse Sector - Definition: Includes both publicly owned-and-operated refuse vehicles and private contractor owned-and operated vehicles including collection, recycling and transfer trucks and any other support vehicles. 
The refuse sector accounted for 14.3 million GGEs in 2005, or about 7.6 percent of total U.S. volume. Already doubling in volume since 2000, this sector accounted for about 1500 natural gas refuse trucks in service in 2005 and more have been added since. The refuse sector is projected to experience strong and steady growth over the next decade as well over half the existing inventory of refuse vehicles is ten years old or older and communities are increasingly looking to their contract haulers to reduce emissions as part of the contract evaluation and award process. As is the case with the transit sector, California has more natural gas refuse vehicles than any other state, due in large part to the South Coast AQMD Fleet Rules. Refuse truck's duty cycles, low MPG ratings and high engine operating hours translate into high yearly fuel usage. The new federal tax credits for vehicles and vehicular natural gas fuel shorten the premium payback period significantly and further improve CNG and LNG refuse truck life-cycle savings over other alternatives.

d) Government Sector - Definition: Includes light-, medium- and heavy-duty vehicles operated by a city, municipality, county, state or federal agency and which have not been accounted for elsewhere (e.g., police, parking enforcement, "fleet pool" vehicles and work trucks of all types such as public works trucks, plows, stake trucks and step vans).

Vehicular natural gas consumption in the government sector (federal, state and local) accounted for 9.2 million GGEs in 2005, representing just under 5 percent of total U.S. volume. CVEF projects this number to drop or - at best - remain flat in future years as most NGVs in government fleets are LDVs and, as noted earlier, LDV inventories in federal and state fleets are declining due to attrition. Most of the NGVs purchased by federal and state agencies were LDVs as part of the agencies' compliance with EPACT. With the exodus of General Motors, Ford and Daimler Chrysler during the 2003-2006 period and the fact that few federal or state agencies include SVM LDVs on their approved purchase lists, most of these agencies have not replaced their old NGVs with new NGVs. There are certainly exceptions to the rule and, in many California communities and in a select few cities across the nation, new CNG-powered Honda Civic GXs and retrofitted Ford and GM LDVs are being put into service. However, these new purchases are far fewer than the number of NGVs exiting service due to attrition.

e) Short-Haul Sector - Definition: Includes vehicles - usually medium- or heavyduty-commercial vehicles moving freight/product within a metro area, traveling less than 200 miles/day on regular routes/route coverage areas (e.g., mail, package delivery, snack/ bakery/beverage/grocery/restaurant provisions, linen services, newspapers and port vehicles).

Unexpectedly, the short-haul sector edged out the utility sector for fifth highest vehicular natural gas volume. Short-haul fleets accounted for 5.6 million GGEs or about 3 percent of total U.S. volume. While there are few short-haul fleets using CNG or LNG, estimated at less than two hundred accounts in 2005, these fleets' yearly fuel usage per vehicle is substantial. Examples include the U.S. Postal Service, UPS and other package delivery services, a number of grocery store chains and their suppliers, and a variety of snack and beverage distributors. Vehicular natural gas volumes in this sector are projected to grow significantly in the next five years as large-scale clean-air initiatives are undertaken at west coast 
and east coast ports.

f) Utility Sector - Definition: Includes light-, medium- and heavy-duty vehicles operated by private or public gas and electric companies or departments.

The utility sector accounted for only 5.2 million GGEs or a bit less than three percent of total U.S. vehicular natural gas consumption. Other than a handful of LDCs that still actively participate in the NGV market, this niche segment has declined steadily since the mid 1990s. Disillusionment with slower than projected market growth, losses from ill-advised station development investments and "early adopter" technical challenges prompted many LDCs to abandon their early forays into NGV deployment and marketing. EPACT compliance options, e.g. fleet decentralization, purchasing credits and or purchase of flex-fuel vehicles (despite lack of E-85 fueling infrastructure) allowed many LDCs to retire their aging NGVs and decommission stations. Lackluster LDC involvement begets lackluster customer interest and, some might argue, a self-fulfilling prophecy. Volatile gasoline and diesel prices, combined with new tax incentives for vehicles, stations and fuel may prompt some LDCs to re-evaluate and re-engage, if only in their own fleets.

g) School Sector - Definition: Includes public and private school and university buses and auxiliary services vehicles (e.g., school buses, driver training cars, shuttles and administrative, security and maintenance staff cars and trucks).

The school sector accounted for about 4.7 million GGEs of vehicular natural gas in 2005, representing a bit less than 2.5 percent of the U.S. total volume. Despite slow but steady growth in this sector since the first ten units were field-tested in 1989, CVEF estimates that there were approximately 2800-3000 natural gas school buses on the road in 150 school districts in 2005. Natural gas throughput to this sector is not expected to break out of its last place position vis-à-vis other niche sectors. That is because the average school bus only uses between 2,0002,500 GGEs a year depending on duty-cycle (urban, suburban, rural routes). Even if the new federal tax credits and grant incentives were to spur the market to double or triple its current sluggish net market growth of 400-600 school buses per year, vehicular natural gas volume will remain relatively low as compared to the other major sectors. Despite the low volume associated with each bus, this sector is still important because of the public visibility of school buses

h) Other - Definition: Includes all personal vehicles, miscellaneous small business fleets or others not specifically delineated above including off-road vehicles such as forklifts and ice arena resurfacing machines.

This "catch-all” category accounted for nearly 5 million GGEs in 2005, or about 2.6 percent of the U.S. total. Most notable were PADDs IV and V, which accounted for more than 3.6 million GGEs or seventy percent of the national total allocated to "other." In California (PADD V), CVEF estimates that there are nearly 7,500 LDVs owned and operated by individuals (not used primarily in a business) and in Utah (PADD IV), there is a burgeoning - albeit smaller - LDV market among consumers. This is reflected in the success of co-location of CNG stations at traditional petroleum-retailer locations and the thriving used-CNG vehicle marketplace. California and Utah also both have a considerable base of 
small private businesses that use NGVs and are able to rely on the well established network of stations in these states

7. PADD Ranking By Niche Sector

Niche Sector

PADD IA (New England)

Transit:

Airport:

Government

Other:

Utility

Short-Haul

Refuse

School:

PADD IB (Central Atlantic)

Transit:

Utility

Government

Airport:

Other:

School:

Refuse

Short-Haul

PADD IC (Lower Atlantic)

Transit:

Government

Other

Utility

School

Refuse

Short-Haul

Airport

PADD II (Midwest)

Utility

Transit:

Airport

Other

School

Government

Short-Haul

Refuse
GGEs

4,801,035

500,801

476,193

274,186

178,490

35,000

32,051

8,873
Portion of Region Total

$$
\begin{array}{r}
75.97 \% \\
7.92 \% \\
7.54 \% \\
4.34 \% \\
2.82 \% \\
.55 \% \\
.51 \% \\
.14 \%
\end{array}
$$

$$
\begin{array}{r}
89.15 \% \\
4.14 \% \\
2.80 \% \\
1.53 \% \\
1.04 \% \\
1.02 \% \\
.24 \% \\
.03 \%
\end{array}
$$

$\begin{array}{rr}8,008,493 & 94.25 \% \\ 188,642 & 2.22 \% \\ 121,108 & 1.43 \% \\ 115,723 & 1.36 \% \\ 34,372 & .40 \% \\ 17,653 & .21 \% \\ 4,500 & .05 \% \\ -0- & -\end{array}$

$1,585,140$

$38.86 \%$

$31.55 \%$

$10.12 \%$

$8.28 \%$

$5.64 \%$

$4.24 \%$

$.99 \%$

$.31 \%$

PADD III (Gulf Coast)

Transit:

Airport
9,389,492

$68.12 \%$

$1,980,054$
$14.37 \%$ 
Government

Short-Haul

School

Other

Utility

Refuse

\section{PADD IV (Rocky Mountain)}

Airport

Other

Transit

School

Government

Utility

Short-Haul

Refuse

\section{PADD V (West Coast)}

Transit

Refuse

Airport

Government

Short-Haul

School

Other

Utility
771,296

626,681

371,027

338,353

94,811

91,000

$1,404,165$

585,317

512,469

266,953

190,003

146,706

97,000

- 0 -
$5.60 \%$

$4.55 \%$

$2.69 \%$

$2.45 \%$

$.69 \%$

$.66 \%$

$37.27 \%$

$15.53 \%$

$13.60 \%$

$7.09 \%$

$5.04 \%$

$3.89 \%$

$2.57 \%$

-

$63.99 \%$

$11.44 \%$

$8.56 \%$

$5.34 \%$

$3.92 \%$

$2.80 \%$

$2.44 \%$

$1.49 \%$

Transit accounts played an extremely important role in five of the seven PADDs. This is most evident in the three eastern seaboard PADDs where transit agency natural gas use accounted for 88.2 percent or 38.8 million of the total 44 million GGEs dispensed. Transit was also the dominant sector in PADD V, where there are over 100 agencies in California, Arizona, Oregon, Washington and Nevada operating CNG and/or LNG buses. There are few transit agencies in the Midwest using CNG-powered (and none using LNG-powered) buses. Therefore, transit played a lesser role in PADD II. This is also true for the Rocky Mountain region where transit accounts play a limited role and, relative to the rest of the PADD, the airport sector is the biggest player. This is due to the substantial programs at the airports in Denver and Salt Lake City.

The refuse sector, while expanding into new market areas, is still a west coast - and more specifically - a California phenomenon. Of the 14.4 million GGEs dispensed into refuse trucks, nearly 14.2 million or 98 percent occurred in California. Otherwise, this sector ranks last or near last in all other PADDs. Given the very favorable economics, this would suggest that all PADDs should see a significant up-tick in refuse sector vehicular natural gas volumes in the coming decade.

The school sector had an above national average showing (7.1\%) in the Rocky Mountain PADD, primarily due to a number of districts and universities in Utah - most notably the sizeable fleet operated by Jordan School District in Sandy, Utah - and several smaller fleets in Colorado. In PADD IB (Central Atlantic), the large fleet at Lower Merion School District in suburban Philadelphia and the Long Beach Public Schools account on Long Island are notable but their overall impact on the total PADD IB tally is negligible 
and, thus, the lower than national average showing (1.2 percent). Otherwise, the school sector - like so many others - is strongest in California where there are over 125 school districts operating school buses.

\section{F. Recommendations For Future Vehicular Natural Gas Data Collection and Tracking}

The impact of transportation energy use on our national economy, its implications to our national security and the role of alternative fuels regularly receives national press attention almost daily and is prominent on state and national legislative agendas. For the U.S. DOE to provide Congress and the President actionable intelligence about alternative fuel use in the transportation sector and the effects of existing and proposed energy policy, it is imperative that accurate and timely alternative fuel use tracking mechanisms be established.

While this report provides a snapshot of the NGV fueling infrastructure and fuel consumption for 2005, the data collection process used to compile it is not easily repeatable. It is resource intensive, inefficient and lends itself to errors of omission and/or variances due to methods of extrapolation. For the U.S. DOE to implement a repeatable process requires changes in the tracking and reporting of vehicular natural gas use at the utility or market level, or at very least, at the state level.

For reasons stated above, estimating fuel use by tracking registered NGVs via state motor vehicle records or fuel tax records is not likely to achieve the desired result. Following are potential ways for U.S. DOE and the NGV industry to achieve this goal:

\section{Strengthen Current Vehicle and Fuel Reporting Mechanisms}

Vehicular natural gas consumption data is already requested by EIA via Form 176 (“Annual Report of Natural and Supplemental Gas Supply and Disposition”) but, as noted earlier, LDCs' tracking mechanisms are often inadequate. Tightening the reporting and back-up documentation requirements for this form may be the best way to track future vehicular natural gas use. It may prove useful for U.S. DOE and its AFDC contractor, NREL, to engage NGV and natural gas utility associations to communicate to their respective members the importance of more accurate tracking mechanisms and to help establish protocols for data collection and evaluate data submitted. Working with national NGV industry groups may also prove useful in tabulating their members' sales of new compressor station equipment and crosschecking it against the AFDC database. Currently, no "new station” reporting mechanism exists other than voluntary submittals by vendors and/or Clean Cities Coordinators.

\section{Enlist PUC Participation in Mandatory Vehicle and Fuel Reporting Mechanisms}

State utility regulatory authorities have a vested interest in obtaining accurate vehicular natural gas fuel use data for use in measuring the societal and economic benefits of existing and/or proposed NGV fuel tariffs. Ultimately, the data collected would originate from the utilities (as suggested in item \#1 above) but U.S. DOE liaison with NARUC may prove productive in identifying the most effective and least burdensome ways for state utility regulatory authorities to capture this information.

\section{CONCLUSIONS}


Vehicular natural gas consumption is on the rise, totaling nearly 200 million GGEs in 2005, despite declines in total NGV inventory in recent years. This may be attributed to greater deployment of higher fuel use medium- and heavy-duty NGVs as compared to the low fuel use of the natural gas-powered LDVs that exited the market through attrition, many of which were bifuel.

Natural gas station counts are down to about 1100 from their peak of about 1300. Many of the stations that closed were under-utilized or not used at all while most new stations were developed with greater attention to critical business fundamentals such as site selection, projected customer counts, peak and off-peak fueling capacity needs and total station throughput. Essentially, the nation's NGV fueling infrastructure has been - and will continue - going through a "market correction.”

While current economic fundamentals have shortened payback and improved life-cycle savings for investment in NGVs and fueling infrastructure, a combination of grants and other financial incentives will still be needed to overcome general fleet market inertia to maintain status quo. Also imperative to the market's adoption of NGVs and other alternative fueled vehicle and fueling technologies is a clear statement of long-term federal government commitment to diversifying our nation's transportation fuel use portfolio and, more specifically, the role of natural gas in that policy.

Based on the current NGV market there, and the continued promulgation of clean air and transportation policies, the Western Region is - and will continue to be - the dominant region for vehicular natural gas use and growth. In other regions, especially the Northeast, Mid-Atlantic states and Texas, increased awareness and attention to air quality and energy security concerns by the public and - more important, elected officials - are spurring policies and programs that facilitate deployment of NGVs and fueling infrastructure.

Because of their high per-vehicle fuel use, central fueling and sensitivity to fuel costs, fleets will continue to be the primary target for NGV deployment and station development efforts. The transit sector is projected to continue to account for the greatest vehicular natural gas use and for new volume growth. New tax incentives and improved life-cycle economics also create opportunities to deploy additional vehicles and install related vehicular natural gas fueling infrastructure in the refuse, airport and short-haul sectors.

Focusing on fleets generates the highest vehicular natural gas throughout but it doesn't necessarily facilitate public fueling infrastructure because, generally, fleet operators prefer not to allow public access due to liability concerns and revenue and tax administrative burdens. While there are ways to overcome this reluctance, including "outside the fence" retail dispensers and/or co-location of public and "anchor" fleet dispensing capability at a mutually convenient existing or new retail location, each has challenges that complicate an already complex business transaction. Partnering with independent retail fuel station companies, especially operators of large "truck stops" on the major interstates, to include natural gas at their facilities may build public fueling infrastructure and demand enough to entice the major oil companies to once again engage. Garnering national mass media coverage of success in California and Utah where vehicular natural gas fueling infrastructure is more established will help pave the way for similar consumer market growth and inclusion of public accessibility at stations in other regions.

There isn’t one “right” business model for growing the nation’s NGV inventory and fueling infrastructure. Different types of station development and ownership-operation strategies will continue to be warranted for different customers in different markets. Factors affecting NGV 
deployment and station development include: regional air quality compliance status and the state and/or local political climate regarding mandates and/or incentives; fuel price differentials between natural gas, diesel and gasoline; existence of NGV fleets and fueling infrastructure; prospective customers' financial resources; local real estate availability, cost and traffic access; regional construction labor rates; code compliance and permitting issues; local gas utility and PSC posture regarding NGV market support; and existence of a sufficient number of vehicle dealers to assure competitive pricing and technical support capability.

Lack of "feet on the street" is curbing the potential for NGV deployment and expanded NGV fueling infrastructure. Enhanced partnerships with Clean Cities Coalitions and other transportation energy allies, as well as re-engagement of natural gas utilities in the NGV market whether they take the lead or act in a supporting role to independent station developers - is critical to creating more market exposure and identifying fleets that can best take advantage of NGVs and NGV fueling infrastructure. Additionally, commercial fleet lease-finance companies and municipal lease-finance companies should be engaged as they have significant fleet customer contacts and are well positioned to take advantage of NGV's economic benefits.

Better NGV inventory and vehicular natural gas data collection systems are needed in order for U.S. DOE and NGV industry groups to accurately track market development for use in policy and program design and implementation. Strengthening of existing utility data reporting and documentation mechanisms is likely the best way to achieve this goal. U.S. DOE and its contractors should liaise with NARUC and gas utility and NGV organizations to develop data reporting protocols that are most useful and least burdensome. 


\section{Appendix A}

\section{Summary of NGV Market and Fueling Infrastructure Development}

\section{1965-1990: Gas Utilities Slowly Build An NGV Market From the Ground Up}

A. Pioneering Utilities Demonstrate The Technology's Potential

While there is historical record of one-of-a-kind NGVs as early as the 1930s, this review begins with the "modern" NGV market beginning in the late 1960s, when a handful of utilities began experimenting with conversions of their light-duty vehicles (LDV) such as sedans and pick-ups. Most vehicles ran on compressed natural gas and fueled at time-fill stations located on gas company property. The exception was Atlanta Gas Light, which focused its earliest efforts on vehicles fueled by LNG produced at the company's peakshaving LNG liquefaction plant. While these utilities' early vehicle development efforts were initially driven by interest in demonstrating the clean properties of NGVs, the crippling OPEC oil embargo of 1972 prompted them to accelerate their programs and spurred additional utilities to initiate programs in response to the nation's first "energy crisis.”

B. Utility Interest Grows and An Industry is Spawned

Throughout the 1970s and into the mid-1980s, interest in NGVs grew and momentum built, albeit slowly, as additional LDCs embraced the technology, primarily for their own fleets and, in several utility service territories, marketing vehicles and stations to local private businesses and governments. The burgeoning NGV market also spurred emergence of numerous NGV retrofit-conversion component and system manufacturers and installers, CNG station packagers and independent station developer-operators, many who partnered with and thrived on the business generated by utilities' marketing efforts. Several utilities spun off unregulated companies to handle vehicle conversions and build and, in some cases, operate NGV stations. Examples include Dual Fuel California - a SoCal Gas Company and Natural Fuels Corp - an offshoot of Public Service Company of Colorado.

\section{Maturing NGV Industry Focuses on Technology Improvement}

The pioneering "early adopter" utilities gleaned valuable insights into natural gas engine, fuel storage and fuel station technology, identifying areas for improvement, establishing codes and standards and setting short- and long-term research and development (R\&D) goals necessary to achieve broader market acceptance and penetration. Primary areas of R\&D focused on cylinders (e.g. reducing tank weight, accommodating higher pressures safely for greater storage capacity and vehicle range, standardization of fueling receptacles, nozzles and pressure relief devices); engine performance, fuel efficiency and reliability; and station design.

Most of the earliest NGV technology development and experimentation work was done by utilities who shared their experiences under the auspices of the American Gas 
Association's (A.G.A.) Technical Committee (TC), which included fleet management, gas technology R\&D and marketing representatives from utilities and fuel station equipment and services suppliers. Eventually, with establishment of the Gas Research Institute (GRI) in 1976, a concerted industry-wide NGV market assessment and technology R\&D program was implemented with A.G.A.’s TC and GRI collaborating closely on R\&D needs, priorities and funding. By 1988, utility interest in NGV market development had grown enough that a group of A.G.A. members voted to create and underwrite the independent Natural Gas Vehicle Coalition (NGVC). A collaborative of NGV industry groups including NGVC, GRI and others worked closely with codes and standards organizations in the next several years to develop NFPA 52, NGV 2 and other standards applicable to cylinders, stations and vehicles.

\section{Market Dominated by LDVs Operated by Few Early Adopter Utilities}

In 1990, NGVC and GRI initiated yearly surveys of utilities to track market trends for use in assessing future R\&D needs. A 1991 survey of natural gas utilities found that approximately 10,000 NGVs on the road in 1990 consumed about eight million gasoline gallon equivalents (GGEs) of vehicular natural gas fuel, an average fuel consumption per vehicle of 800 GGEs. A few were dedicated vehicles and most were bi-fuel vehicles that operated on natural gas most of the time. Nearly ninety-five percent of these vehicles were LDVs and most of them were operated by utilities. The other five percent - heavyduty vehicles (HDVs) - comprised a mix of utility crew trucks, private delivery trucks, school buses and a growing transit bus sector. In the next several years, transit would emerge as the most successful niche market for heavy-duty NGVs, as is discussed further below.

At this point, all LDVs were retrofit-conversions, as the major automotive OEMs did not introduce their first models until the mid-to-late 1990s. About thirty retrofit-conversion component and systems companies served the market. As there were no federal standards covering NGVs and the supplier base was essentially "home grown," the quality and consistency of LDV retrofit-conversion systems varied widely as did the performance and reliability of these systems. This is important because the market's expectations were based on the high level of technology reliability, service and support provided by the major OEMs for petroleum-powered vehicles.

Survey data shows that there were less than 500 HDVs on the road in 1990, nearly all of which had been converted to run on natural gas by the local gas companies as part of field demonstration projects. These early demos attracted the interest of several heavyduty engine manufacturers. After several years of collaborative work with leading utilities, Cummins introduced the first of three versions of its L10 in 1990. Detroit Diesel began demo tests of its Series 50G engine, which would eventually be sold commercially in 1994. John Deere, which began experimenting with school bus retrofits in 1989, would eventually offer its 8.1L engine by 1996. Several smaller, lesser-known start-ups, for example Tecogen, had attempted to introduce natural gas engines with mixed results.

According to the 1990 survey, over eighty-five percent of the NGVs on the road operated in just ten LDC territories. About thirty-five other utilities located throughout the U.S served the remaining fifteen percent of NGVs in operation.

E. Early NGV Infrastructure Development and Operations 
Information presented here about fuel station counts, flow rates, fuel storage and dispensing capability comes from interviews with utility representatives, equipment suppliers and industry consultants, as there is little statistical data available prior to 1996. Based on these interviews, CVEF estimates that there were slightly less than four hundred CNG stations in operation in 1990 with all but a few dozen operated by LDCs or their affiliates. The rest were owned and operated by non-utility fleets or, in a very limited number of cases, by local/regional independent station operators. While compression, storage, dispensing and related control technologies were improving and the industry was moving toward standardization, the overall state of the CNG fueling infrastructure at this point was a disorganized mix. The industry had not yet developed the NGV1 fuel connector standard so different stations operated using different systems. Depending on the age of the vehicle, the CNG cylinder might have a maximum pressure of 2400 pounds per square inch (psi) or 3000 psi as the fuel storage technology had improved. There were only a limited number of 3600 psi cylinders in test at this time, although 3600 psi would become the industry standard by 1994.

Note: Although they are few, there are still stations operating at 2400 psi today and many still offer both 3000psi and 3600psi.

Nearly all stations in operation in 1990 were time-fill locations for onsite fleets, although the concept of public fueling at so-called "fast-fill" stations was being tested with limited success by a few utilities. The fast-fill stations of 1990 bear little resemblance to the fastfill stations of today. Most had very little capacity, usually took far longer to fuel than today's fast fill stations and could not always guarantee a full fill. Furthermore, nearly all required that customers have pre-approved gas fuel card accounts and access was often restricted to specific business hours. Despite the different pressures, nozzle/receptacle technologies and the lack of individual market saturation, it is important to note that it was possible to navigate large sections of the U.S. without being "stranded" by moving from one utility network to the next, as long as you had the appropriate adaptors and gas cards for each utility.

\section{F. Snapshot 1990: The NGV Market After First Quarter Century}

By 1990, a group that started out as little more than a "club” of interested utility technicians in the mid-1960s had nurtured development of the NGV market from an interesting curiosity to a fledgling industry whose members included a growing number of utilities and a collection of compressor packagers and retrofit-conversion system companies supplying a miscellaneous array of non-standardized components and fueling services. While the market was still in its infancy, these pioneering utilities and suppliers proved that the concept was viable and attracted the attention of mainstream engine and vehicle suppliers. Sensing the national potential for natural gas as a vehicular fuel, interested stakeholders had developed enough critical mass to form their own technical, codes and standards and marketing organizations, setting the stage for the period of unprecedented growth to follow.

II. 1990-1996: Boom Times For NGV Market Development

A. Government Policy Energizes the Alt Fuel Vehicle Market

Natural gas vehicle market development accelerated considerably in the 1990s, catalyzed by several key factors. In 1990, Congress passed the Clean Air Act Amendments 
(CAAA), which set in motion a series of benchmarks and a timeline for the nation's major metro markets to improve their air quality. Fleet emission reduction measures, especially those targeting government and quasi-government fleets like transit, were to become a critical component of those market strategies. Furthering the goal of the CAAA was passage of the Intermodal Surface Transportation Efficiency Act (ISTEA) of 1991, which included the Congestion Mitigation Air Quality (CMAQ) program that supports local state initiatives to improve air quality as part of local transportation planning activities. In early 1991, the Gulf War heightened awareness of U.S. energy dependency on Middle-East oil supplies. Partially in response to the Gulf War, Congress passed the Energy Policy Act (EPACT) of 1992. It included alternative fuel vehicle purchase requirements for federal, state and fuel provider fleets, effective 1994, and it also provided tax deductions for station investment. Also authorized by EPACT, but not initially included in DOE's promulgation of regulations, were private fleet alternative fuel vehicle purchase requirements that would take effect in 1997 if alternative fuels had not displaced thirty percent of the nation's petroleum-based transportation fuel use. In the following several years, the U.S. DOE provided nearly \$20 million per year to help federal agencies offset the incremental cost of AFVs purchases. The NGV industry was the primary benefactor of these program funds as few other AFV options were available.

Some states' governments, most notably California and Texas, also played an important role in spurring NGV market interest and development by initiating or expanding programs aimed at reducing emissions and increasing use of alternative fuels. This included a mix of mandates, tax incentives, grants and other spending programs targeting school districts, local government, and transit agencies, among others.

\section{B. Major Vehicle OEMs Finally Engage, Market Takes Notice_}

The early 1990s also saw several automobile original equipment manufacturers (OEM) begin to allocate resources into NGV platform development in earnest. In 1990, Ford, which had already participated in NGV industry technical forums since the late 1970s, committed to developing a dedicated Crown Victoria for projected market introduction by mid-decade with other vehicles expected to follow shortly thereafter. General Motors, Chrysler and, later, Toyota and American Honda also joined in, each launching their own NGV platform development programs. The natural gas industry co-funded much of this $\mathrm{R} \& \mathrm{D}$, either directly from the larger utilities and/or through GRI. While these vehicles would not be ready for market until the second half of the decade, most industry pundits viewed this engagement by the LDV OEMs as a critical step because it created confidence in the eventual development of a consumer market.

The combination of increased public attention to energy security and air quality issues, new federal and state mandates, positive movement by the automobile OEMs and favorable fuel price differentials between CNG and petroleum fuels set the stage for what the natural gas utility industry thought would be a boom in NGV market growth. Illustrative of this outlook is a 1992 projection prepared for NGVC, which estimated that vehicular natural gas fuel use would grow from about eight million GGEs in 1990 to more than 400 million GGEs by 1998 and 1.6 billion GGEs by 2004. Across the nation, natural gas utilities that previously had been only lukewarm to the NGV market now embraced it with fervor.

The positive signs didn't just catch the attention of the LDCs. In 1992, Amoco Oil Company executives saw great potential for the NGV market. NGVs were already 
gaining a foothold in foreign markets, and the expected EPACT mandates on private fleets, due to be in place by 1997, would generate tremendous demand. Amoco management was further encouraged by the OEM commitments to bring CNG product to market. By 1995, Amoco Oil had put together a business plan and created alliances with station equipment and installation companies to roll-out CNG stations at their retail locations, focusing first on the top 15 U.S. markets, then adding stations in secondary markets until the top 50 metro areas were covered. They worked closely with Atlanta Gas Light, a leading NGV utility at the time to launch the first stations there in time for the 1996 Olympics and plans were already in place to install nearly 50 more CNG stations in the Atlanta, Denver, Chicago and Miami metro areas.

Note: An update of the original Amoco market development plan was prepared in late 2005and is included as Appendix B of this report.

\section{Early LNG Market Developments}

By 1993, several utilities already had implemented small LNG projects with heavy-duty fleet customers. For example, using funding from parent company Consolidated Natural Gas, East Ohio Gas (EOG) installed a small LNG fueling station in Akron, Ohio to serve two Roadway LNG trucks operating in their service territory. Other LNG-powered vehicle projects were underway in San Diego and Atlanta. In 1994, Liquid Carbonics built a dedicated LNG plant in Willits, Texas to supply the Houston Metro transit agency, the first transit fleet to use LNG. Amoco realized that LNG had several operational advantages over CNG for HDV fleets and could potentially deliver life-cycle savings as long as an inexpensive LNG supply could be established. Dedicated LNG plants can be an expensive proposition unless operating at or near capacity, so Amoco sought and identified several lower-cost LNG supply options. These included retrofitting existing petrochemical plants, oil-gas exploration field re-gasification sites, purchase from LDC liquefaction plants and LNG import terminals. They quickly entered the market with supplies based in Texas and Wyoming, capturing existing transit accounts and developing new ones in Texas, Arizona and California within the next three years.

Amoco Oil Company's entry into vehicular CNG and LNG created a lot of excitement in the natural gas and financial markets. Many NGV industry analysts believed then - and still do - that it will take the financial and marketing resources of the traditional petroleum retailers' for the NGV market to achieve its full potential. Amoco's early enthusiasm was dampened however, when the expected EPACT mandates governing private fleets never materialized, as is discussed further below. The company's CNG station development program continued for several years but fuel sales did not meet expectations and, when the BP acquired the company in 1999, both the CNG and LNG programs were discontinued.

D. NGV Market Experiences Sustained Double-Digit Vehicle Sales Growth Various analyses prepared for NGVC between 1990 and 1996 disagree about the exact number of NGVs on the road or fuel stations in operation or total vehicular natural gas fuel consumption, but all indicate double-digit yearly growth. Despite purchase price premiums for natural gas vehicles and less-than-optimal fueling infrastructure, the number of vehicles on the road more than quadrupled in less than five years. Yearly utility surveys show that the nation's NGV inventory hit nearly 38,000 in 1994 and about 47,000 by 1995. The 1997 survey (1996 data), to which 139 utilities now responded as 
directly or indirectly fueling NGVs, tallied almost 55,000 NGVs. LDVs represented eighty-four percent of the total inventory, most of which were still retrofit-conversions as OEM sales were just underway. Continued improvements in heavy-duty engine performance and reliability were increasing fleet operators' confidence in the technology. Sales growth in the transit sector was especially strong because air quality plans frequently targeted transit fleets and because transit fleets were allocated significant ISTEA-CMAQ funding to move to cleaner fuels.

Local and state governments, especially California and Texas, were playing an ever more important role in the growth of the NGV market. According to the 1996 data, government fleets surpassed utilities in the number of NGVs on the road for the first time. Private fleets still ran a distant third. Survey data also shows that average vehicular natural gas consumption continued to climb. This is likely due to the fact that utility demand for LDVs was waning and government and transit agency use of medium- and heavy-duty vehicles was increasing.

E. Market Growth Leads to Station Development Frenzy, Trips and Pitfalls

An R\&D Needs Assessment prepared in 1996 for GRI and NGVC indicates that there were 1222 CNG stations dispensing almost 43 million GGEs in 1995, a three-fold increase in stations and a five-fold increase in volume as compared to 1990. Installed fueling capacity in 1995 was estimated at 125,000-150,000 scfm and analysts projected double- and triple-digit growth over the next decade, largely due to expected growth of medium- and heavy-duty market segments. The outlook for NGVs was very positive. Collectively, the utilities indicated that another net 10,000 vehicles would be added by year-end 1997 for a total of 65,000 NGVs consuming 54 million GGEs.

The frenzy of NGV fueling station installations by utilities, while generally positive, had its drawbacks. Of the 1222 stations in place or under construction by year-end 1995, some were poorly planned and/or executed and destined to fail. For example, while most utilities developed their station networks methodically, selecting locations that would meet their own needs and incrementally adding capacity to meet the needs of new customers, others built expensive oversized stations based on optimistic projections of market growth and a "if we build it, they will come" mentality. For these oversized stations, throughput would never justify the investment. Some stations were installed at undesirable locations based on proximity to the utilities' own gas lines or convenience to their own fleet operations instead of being driven by customers' needs. Again, less than expected sales would eventually sour many utilities' managements concerning these investments and their commitment to the NGV market. Some stations were just poorly engineered and constructed as utilities navigated the learning curve of designing and constructing high-pressure gas vehicle fueling systems. Persistent maintenance and operations problems doomed these locations from the start and eroded public confidence in the technology. Many of these poorly planned and/or executed stations would never achieve the necessary economics to be viable and eventually close years later - as described further below - as the market "self-corrected."

\section{F. Snapshot 1996: A Market Positioned For Continued Expansion}

In 1996, nearly all the pieces were in place for the NGV market to flourish. The federal government and several states had begun implementing AFV friendly clean air and clean transportation policies. The major automotive OEMs were well on their way to introducing LDVs. Utilities all across North America were energized and eager to 
promote the market. Overall growth in the number of NGVs on the road, stations and fuel throughput all indicated that the NGV industry was well on its way to building a sound, sustainable foundation.

\section{1997-2005: Utility Deregulation, Unfulfilled Expectations Derail NGV Momentum}

In the 1997-2005 timeframe, the total NGV market expanded but not nearly to the level that industry analysts had projected. In addition, growth was very niche specific and limited to just a few regions.

\section{A. Deregulation Leads Many Formerly Active Utilities To Disengage From NGVs}

From the 1960s through the mid-1990s, natural gas utilities were the primary driving force behind NGV market growth. Areas with active, supportive LDCs enjoyed the greatest growth in NGV inventories, fuel stations and throughput - a fact that remains true today. Unfortunately, as the gas utility industry transitioned to a deregulated market in the late 1990s and into the early-2000s, mergers and acquisitions side-tracked or derailed many NGV programs as new management teams focused on cost-cutting and reverting back to their core competency - delivery of utility services. Across the nation, utilities that had once been at the forefront of marketing NGVs and other new natural gas technology suspended their marketing programs and, in some cases, reassigned or let go their marketing personnel.

During deregulation, a few utilities were directed by their Public Utilities Commission (PUC) to divest their NGV business investments. For example, in 1996, California's PUC directed SoCal Gas Company to sell most of its CNG stations. Those located at private fleet yards were sold to the NGV customers they served. Most of the rest were sold to Pickens Fuel Corporation but SoCal was able to retain some locations located on their own property if their primary purpose was to refuel SoCal vehicles. Even though the company divested most of its CNG stations, they continued to promote NGVs to customers. Some utilities chose to voluntarily divest their NGV business interests. For example, when Texas Gas purchased Lone Star Gas Company (TX), it sold off non-core business units including the unregulated NGV station development and vehicle conversion businesses that Lone Star had established in 1986. Blue Energy, a private company, purchased the businesses and also purchased Natural Fuels Corp from Public Service Company of Colorado at about the same time. ENRG (later renamed Clean Energy), the successor company to Pickens Fuel Corporation, would eventually acquire Blue Energy. In all, about a dozen small independent station-development and/or operations companies emerged during this period of utility deregulation. Most were - and still are - local or regional and many did not last more than a few years, either closing operations or selling to others in the business.

Many utilities tried unsuccessfully to sell their NGV business assets. Nationally, the number of utility NGV assets available for sale far exceeded market capital. Further complicating the situation, utilities generally rate-based their investments over extended periods, e.g. up to 20 years, like other gas company assets. The market value of much of the station equipment available for sale was far below the value listed on utility corporate asset sheets. The result is that stations were left in place and, without active NGV marketing programs to generate new customers and load, these stations went largely underutilized for years before finally being decommissioned. 
There were certainly exceptions to this general utility trend to back away from NGV market development, most notably the three investor-owned utilities in California, which maintained active NGV programs, and about a dozen other utilities spread out across the U.S. Overall, however, nearly four out of every five U.S. utilities active in marketing NGVs in 1996 discontinued their programs altogether by 2005. An additional thirty to forty utilities maintained and operated CNG stations during this timeframe for their dwindling NGV fleets and/or occasional transient customers but they no longer actively marketed NGVs or fuel stations to customers. As is noted below, there would be more attrition in LDC marketing programs and fueling infrastructure during the 2006-2007 timeframe.

Increasingly, NGV market development relied on the resources of the half-dozen nonutility companies engaged in NGV station development and operations, compressor equipment manufacturers and the vehicle OEMs and SVMs. Also of growing importance in educating the public and generating leads were clean-air and clean-transportation allyadvocates such as Clean Cities Coordinators and their stakeholders.

\section{B. OEMs’ Vehicles Arrive as Many Utilities Exit, Price Premiums Are An Obstacle}

The process of utility industry deregulation and disengagement from the NGV market by some began just as the major automobile OEMs were introducing their long-awaited NGVs. Ford introduced the Crown Victoria in model year (MY) 1996, and by MY1998, brought the Contour, the F250 and E-series Econoline vans to market. GM launched the 1500 series pick-up truck in 1998, the same year that American Honda rolled out its first Civic GX. After an initial unsuccessful stab at introducing a Chrysler Minivan in 199798, the company regrouped and offered the Dodge Ram van and wagon in MY2000. That same year, GM expanded its CNG line to include the bi-fuel Cavalier and in 2001, the Express and Savana vans. Toyota, which had several times announced - then postponed - introduction of the Camry, eventually offered the vehicle in limited quantities to fleets located in California in 2000 and 2001.

Generally, entry of the major OEMs created enthusiasm in the marketplace and built credibility that NGV technology was viable. Significant price premiums were an obstacle that was overcome by grants and incentives - where they were available. NGV industry efforts to secure federal tax credits for vehicles, considered essential for market penetration, were not successful until nearly eight years later.

\section{SVM Network and Vehicle Choices Dwindle as Regulation Takes its Toll}

Prior to entry of the major OEMs, Small Volume Manufacturers (SVMs) of retrofitconversion systems had been the sole source for engines and vehicles. SVMs would continue to play an important role and still do today but, beginning in 1994, these companies faced their own new set of technical and regulatory challenges. That's when the major automobile OEMs began introduction of electronic control modules (ECM), which were designed to greatly improve engine operational efficiency and reduce emissions to meet EPA requirements. In September 1994, EPA issued the first rulemaking governing certification of CNG vehicles, effective MY1997. Under an option known as Memorandum 1A, Option 3, which EPA extended several times up to April 2002, retrofit-conversion system SVMs had the option of avoiding the more costly certification requirements as long as they had reasonable basis to believe - and could document - that their systems did not degrade vehicle emissions. Over the next several years, most of the "kit" manufacturers that did not have the engineering expertise, 
sophisticated testing equipment or financial resources to meet this higher-level technical challenge exited the market. Of the companies that did remain, several more left the market in 2002 when Option 3a phased out and costly full certification was required. Finally, in 2005, implementation of phase two On-Board Diagnostics (OBDII) requirements for LDVs forced all but two LDV retrofit-conversion systems manufacturers out of the U.S. market. The effect of the more costly and complicated certification process is that SVMs were forced to pass on higher prices to customers and, due to limited resources, offer fewer engine/vehicle choices.

\section{Unfulfilled Expectations Lead All But One LDV OEM to Exit Market}

Sales of OEM light-duty NGVs and retrofit-conversion systems during the 1997-2005 time frame were not as robust as most OEMs and SVMs had projected. Fleet managers and NGV industry stakeholders interviewed for this report cite a variety of reasons for this less-than-projected sales performance.

The late 1995 Clinton Administration decision to not mandate that private fleets' purchase alt fuel vehicles, as allowed and expected under EPACT 92, eliminated one of the major market drivers OEMs had planned on when investing in their NGV development programs. NGV industry stakeholders cite lack of promulgation of the private fleet rule as a major setback then and continue to express that view today. Exacerbating the situation, federal agencies fell far short of their target goals for purchases of AFVs of all types between 1994-2003. By the time these shortfalls were given greater scrutiny and addressed, Flex-Fuel vehicles priced on par with standard gasoline vehicles and able to run on regular gasoline while still qualifying for compliance credit were available. In addition, EPACT program credit banking and trading provisions, especially those related to B100 fuel use, created an overabundance of credits that effectively swamped the market and eliminated the need to purchase AFVs. At the same time, utilities' demand for NGVs steadily waned between 1997-2005. Decentralization of fleets and, later, availability of Flex-Fuel vehicles prompted many utilities to scale back or eliminate their usual NGV orders.

While there were exceptions to this general declining sales trend, most notably in California, Texas and New York, where several utilities' and state and local governments' purchase of LDVs helped sustain OEMs' presence in the market, sluggish sales eventually took their toll. Toyota's short-lived foray into the NGV market with the Camry in 2000-2001 never got traction and the limited market entry was pulled. By 2003, Daimler-Chrysler discontinued production of the Ram series and exited the market completely. Ford scaled back it's offering to just the Crown Victoria and the F150 and GM still offered the Cavalier, 1500 series pick-ups and Express-Savana vans but, given the financial condition of both companies, both sent signals they would have to discontinue models if sales performance didn’t increase considerably. In 2004, Ford pulled out of the market completely, GM dropped the Cavalier from its line-up and late in the year announced discontinuance of its Express and Savana CNG van option for 2005. Only American Honda's Civic GX and GM's 1500 Series pick-ups remained for MY2006. GM announced in late 2005 that it would discontinue the CNG pick-ups in April 2006, leaving American Honda as the only remaining LDV OEM.

Fortunately, several SVMs stayed engaged, offering a fairly broad selection of GM and Ford retrofit-conversion systems for light-, medium- and heavy-duty vehicles. Selling through the SVM channel was far more difficult however as they did not have the same market presence and enjoy the same market confidence as the major OEMs. In addition, 
conversion costs were high as the SVMs had to amortize their certification investment across a smaller sales base.

\section{E. As LDV Sales Falter, Steady Gains in HDV Niche Sectors Sustain Market}

Despite the exit - or pending exit - of several OEMs in the light duty sector and the culling out of SVMs not able to meet tougher EPA and CARB emission certification requirements, there were positive trends in regards to NGV inventory, most notably gains in sales of MDVs and HDVs. This is due, in large part, to the strength of the high fuel use sector accounts, e.g. transit agencies and also to gains in sales of buses to the airport and school sectors and trucks to the refuse and other vocational work truck markets. These sales gains may be attributed primarily to three market drivers: significant improvements to natural gas engine performance, reliability and service infrastructure; implementation by California's South Coast AQMD of its NGV-friendly "1100 Series" heavy-duty fleet rules, which required local governments and/or their contracted vendors to purchase AFVs; and improving life-cycle economic advantages of natural gas-powered buses and trucks as compared to diesel-powered units as EPA heavy-duty engine emission requirements phased in, beginning in late 2002.

\section{F. Fueling Infrastructure Experiences Market Correction For Excesses of 1990s}

The station development boom that started in the early-to-mid 1990s peaked at about 1300 in 1998 and, by year-end 2005, the net number of CNG stations in the U.S. declined to about 1100 as the number of new stations opening lagged the number closing or decommissioning. This attrition in the fueling infrastructure is widely viewed by knowledgeable industry analysts as a market correction. Most of the stations closed or decommissioned were older utility-owned-and-operated stations that were underutilized for years and/or completely inactive. In collecting data for Part III of this report, CVEF identified dozens of recently closed or soon-to-be-closed stations that had throughput of less than 1000 GGEs per year. The customer base at these underperforming stations usually comprised only the utilities' own few remaining vehicles (often bi-fuel) as NGV marketing to customers discontinued long ago. For the most part, these stations languished without proper service or investment (e.g. upgrade to higher operating pressure) and provided little value to the NGV fueling infrastructure anyway.

On the other hand, most of the new stations installed during the 1998-2005 timeframe were predicated on sound economic fundamentals, whether they were small-capacity (less than 50scfm) stations installed for local school districts and municipal governments (e.g., Ingersoll-Rand or FuelMaker units) or high fuel use stations installed at transit agencies, airports or refuse operations. By far, the greatest investment in fueling infrastructure during the 1998-2005 period occurred in California, Texas and New York with isolated highlights in other major metro areas including Atlanta, Washington D.C., Boston, Seattle and Denver, among others. Capacity added during this period came in the form of upgrades to existing infrastructure for current CNG customers and new installations for both private-access-only and public-access locations.

\section{G. As NGV Inventory Peaks, Then Declines, Vehicular Natural Gas Use Climbs}

The net effect of the LDV, MDV and HDV sales performance was a leveling off and eventual decline in the number of NGVs on the road, yet - due to MDV and HDV sales steady growth in fuel throughput. CVEF estimates that between 1997-2005, about 48,000 natural gas LDVs were sold. When sales of MDVs and HDVs are added and attrition of 
older units taken out of service is factored in, the estimated peak in NGVs was between 105,000 and 110,000 in 2003. By 2005, CVEF estimates that due to attrition in the LDV market and retiring of older HDVs, especially those in the transit sector, the total NGV inventory had dropped to about 92,000 vehicles. This tally comprised $12,000-14,000$ HDVs, another 10,000-12,000 MDVs and 66,000-70,000 LDVs. Of that inventory, most - about ninety-seven percent - operated on CNG with the remaining vehicles running on LNG. As is presented in more detail in Part III of this report, total fuel vehicular natural gas throughput was approximately just shy of 200 million GGEs.

In 2005, the heavy-duty fleet comprised 8,500-9,000 transit buses in operation, with nearly one in four new transit buses on order - between 1000 and 1300 units per year specified to run on natural gas. Steady sales growth, albeit in relatively small numbers, had increased the nation's natural gas refuse fleet to just short of 1300 units and the school bus fleet to around 2300. Another 1800-2300 HDVs operated in a variety of applications in the utility, grocery-beverage, freight, airport and local and state government sectors. The nation's MDV fleet comprised a mix of airport-based shuttles, community transport shuttles, smaller package and freight delivery step vans and trucks, and a wide assortment of HD pick-up trucks and Class 2-4 cab-and-chassis work trucks

\section{H. Snapshot 2005: Amid Mixed Market Signals, Industry Prepares to Redouble Efforts}

The close of 2005 presented multiple opportunities and challenges. As noted above, the number of stations in operation was down a bit from its 1998 peak but vehicular natural gas fuel use was climbing, due to successes in the high fuel use heavy-duty niche markets, especially transit, airports and refuse.

Of the major automotive OEMs that had entered the market with a limited number of vehicle models, Toyota, Daimler-Chrysler and Ford had already exited and, of those that remained, only American Honda gave clear signs that it was committed to staying the course. The other, GM, had already pulled some vehicles due to lower than expected sales and indicated that it would pull its remaining pick-up at the close of its MY2006 production runs in early 2006. Of the four remaining SVMs offering LDVs, two would likely exit in 2006 because of OBDII certification requirements but the remaining two Baytech Corporation and BAF Technologies - demonstrated their ability to meet these requirements and their intention to bring GM- and Ford-based engine family platforms to market (respectively).

In the heavy-duty engine market, Clean Air Power stopped offering its Caterpillar-based Dual-Fuel engine in January 2003, Mack Truck announced in late 2005 it’s E7G gas engine would not remain after MY2006 and Detroit Diesel announced it was discontinuing its only natural gas engine. On the positive side, two suppliers of heavyduty engines, Cummins Westport Inc and John Deere Power Systems, were increasing their market share and building truck and bus chassis OEM relationships and two additional engine suppliers, Westport Innovations and Emission Solutions were on the verge of certifying additional engines.

Less than a dozen natural gas utilities still had active NGV marketing programs in place. In limited regions and markets, a few independent station development-operations companies supplemented these efforts. For much of the country, there was no NGV market development program at all so what remained of the dwindling existing customer base was declining through attrition. 
The favorable price differential between vehicular natural gas and gasoline or diesel continued to get better and better, improving NGVs' simple payback and life-cycle savings edge. A particularly tough hurricane season disrupted both gas production and oil refinery operations in fall 2005 (Katrina, Rita), causing spikes in fuel costs and further heightening public awareness of the nation's delicate balance between supplies, demand and pricing.

Last, and certainly not least in importance, was passage of two critical pieces of federal legislation in August 2005 - the Energy Policy Act of 2005 ("EPACT") and the SAFETY-LU ("Transportation Act"). EPACT 2005 included vehicle and station tax credits effective January 1, 2006 and SAFETY-LU included a motor fuels excise tax credit of \$.50 per LNG gallon or GGE of CNG, effective October 1, 2006.

\section{2006-2007: Tax Credits, Emissions Advantages, Petroleum Prices Energize NGV Market}

Passage of the Energy and Transportation bills in late 2005, the impending 2007 phase-in of EPA heavy-duty emissions requirements and the growing differential between natural gas and petroleum fuels all combined to substantially brighten the outlook for NGV and fueling infrastructure investment in 2006.

\section{A. Federal Tax Credits}

Of the three new long-sought-after federal tax credits, the combined effect of the vehicle tax credits and the federal motor fuels excise tax credit improved NGVs' economic advantage and was widely expected to spur sales to the public and private sector. The station tax credit, while welcome, was expected to have less of an impact. Unfortunate delays in IRS guidance concerning how to file for the vehicle tax credits, which was finally issued in June 2006, dampened the initial impact of this measure as most of the order deadlines for CNG vehicle production runs expired by April and many fleet managers were hesitant to move forward without knowing the specifics. Further delayed still were the details on how to get the additional thirty percent "bonus" credit for vehicles that met stricter emissions requirements. Honda finally received notice in late 2006 that its Civic GX qualified for the full eighty percent credit, which in this case was worth $\$ 4000$. The heavy-duty engine manufacturers would continue to have difficulty getting IRS clarification and guidance on this issue until well into 2007. IRS guidance on the motor fuels excise tax was finally issued two days prior to its effective date (October 1, 2006). Again, the IRS delay in clarification of issues regarding who qualified to take the credit created confusion but, generally, did not slow projects from moving forward. IRS guidance concerning the station equipment tax credits was not issued until early 2007; its impact, if any, cannot be assessed yet.

\section{B. EPA Heavy-Duty Engine Emissions Requirements Take Effect}

Another positive market driver was the impending phase in of the EPA heavy-duty engine emissions requirements. By early 2006, several natural gas engines had met the 2007 PM and NOx requirements and were confident that 2010-compliant engines could be ready for market introduction by early-mid 2007. Diesel engine manufacturers, on the other hand, had far more difficulty but were able to meet the 2007 standard using a mix of engine modifications and exhaust after-treatment devices. However, these solutions pushed truck purchase prices up and operating costs higher. Wanting to avoid price increases and uncertain about the performance and maintenance implications of the new 
diesel systems, fleet managers engaged in a substantial "pre-buy" similar to the one that occurred in mid-late 2002. The differential in truck life-cycle costs now clearly was in favor of natural gas; heavy-duty natural gas engine sales of the major OEM suppliers and SVMs continued to do well in 2006 and into 2007.

One disappointment, announced at year-end 2006, was John Deere Power System's decision to discontinue production of its popular 8.1L natural gas engine effective yearend 2007. The decision was based on the company's need to focus engineering resources on getting its diesel farm and construction equipment engines to meet the next phase of EPA emissions requirements in time for the 2010 deadline. Deere's departure left several heavy-duty school bus and truck chassis OEMs looking for a new engine and sent the wrong message to the market. As of this writing, several suppliers have stepped in to offer viable options and the availability of vehicles from these manufacturers appears to be uninterrupted going into MY2008.

\section{Current LDV Options Are Limited But Remaining OEM, SVMs Are Optimistic}

On the light duty side, Honda continued to make market strides with its Civic GX, achieving its sales goals for 2006 and well on track for 2007. The two remaining SVMs with EPA and CARB-certified LDV product, Baytech Corporation and BAF Technologies, both certified several fully OBDII-compliant engine families covering a variety of vehicle models. Continued resistance to buying through the SVM channel, especially by federal and many state government fleets, reigned-in the full potential for these vehicles but sales were characterized by both as "good" and the future outlook appears promising.

D. Price Differential Between Natural Gas and Petroleum Fuels Grows

While oil and gas prices constantly fluctuate, the 2006-2007 time frame saw the differential between natural gas and diesel remain the same and/or grow. The causes were many: the lingering effect of the fall hurricanes of late 2005 well into 2006; world crude oil prices remaining at or above $\$ 60$ per barrel (and as high as $\$ 78$ per barrel); the strain on U.S refining capacities due to EPA's 15ppm sulfur content requirement and several refinery outages. When coupled with the new federal motor fuels excise tax (effective October 2006), the differential in cost per GGE ranged from twenty to fifty percent less than petroleum fuels.

E. Vehicle Counts Drop, Fueling Infrastructure Remains Flat, Throughput Continues to Grow

Based on extrapolation of trends documented in its 2005 survey process supplemented by proprietary information gleaned from interviews with engine and vehicle suppliers, CVEF estimates that there were 85,000-90,000 NGVs on the road at the close of 2006. This number includes new OEM- and SVM-supplied LDVs, MDVs and HDVs entering the market, offset by vehicles exiting the market due to age. Although there is no tracking mechanism in place, CVEF's inventory estimates assume that approximately one-half of the light-duty CNG vehicles being disposed of by utility and government fleets are being resold to consumers and small businesses. The remaining vehicles are being scrapped or converted back to gasoline powered vehicles before being sold at auction.

Regarding fueling infrastructure, 2006 and 2007 (to date) saw consolidation in the LNG supplier market with Clean Energy's purchase of Apollo Resouces/ALT's Willis, Texas plant, and the addition or re-launching of 50-65 new CNG fueling stations including 
small packages serving just a few vehicles to large high-profile stations in the transit, refuse, airport and school niche markets. While new stations in California grabbed the lion's share of market growth and attention, there were additional CNG stations newly installed or re-invigorated in several northeast states, Texas, Arizona, Utah and Virginia. The Midwest continued to lag the rest of the nation in new CNG station installations although there were a few, most notably in St. Louis and the Detroit metro area. There also were CNG station closings, as a number of utilities (e.g., Consolidated in PA, OH and WV and CenterPoint in TX) and local and state governments (e.g., in FL and VA) finally decommissioned underutilized stations. In several cases, independent fuel retailers purchased, upgraded and re-launched previously utility- and municipally-owned CNG stations in conjunction with landing new anchor fleet accounts.

CVEF estimates that the net affect on total CNG station counts was minimal and that the current inventory remains approximately at 1100 sites.

Again, based on trends observed in the 2005 data and supplemented by press announcements of new fleet sales and station installations, CVEF estimates that total vehicular natural gas throughput at year-end 2006 was 205 million GGEs and it continues to climb, despite the drop in total vehicle inventory and relatively flat net station counts. This estimate is based on the fact that most of the used LDVs sold to the general public will use as much as - if not more fuel than - the fleets from which they came. It is assumed that new LDV sales are driven by the operator's interest in utilizing the fuel. Furthermore, many of the new high-profile successes (e.g., in the transit, airport and refuse sectors) are high-fuel use vehicles (e.g., buses, taxis, shuttles), that use more net fuel then the vehicles being taken out of service.

\section{Appendix B}

\section{NGV Refueling Infrastructure Strategy Establishing a Self-Sufficient NGV Refueling Infrastructure}


Study conducted for the Clean Vehicle Education Foundation (CVEF) and it's National Energy Technology Laboratory's contract entitled

“NGV Road Map and Data Collection Effort” (DE-FC26-05NT42609)

\section{Bruce Cotterman}

The BAS Group

4435 Northside Pkwy, Suite 248

Atlanta, Georgia 30327 U.S.A.

404-580-2918 404-816-7519 fax

www.thebasgroup.com

April 17, 2006 


\section{EXECUTIVE SUMMARY}

Amoco in the 1990s demonstrated in the Metro Atlanta market that a NGV market could grow when supported by an area wide public CNG (Compressed Natural Gas) refueling infrastructure. Amoco's strategy and approach is documented in this study sponsored by the Clean Air Vehicle Foundation and the Department of Energy's National Energy Technology Laboratory.

Amoco's NGV infrastructure strategy was to:

Provide CNG area wide coverage for NGVs in its existing retail refueling stations, focus on major metropolitan markets, then expand into smaller markets, and interconnect all markets for regional refueling coverage.

Amoco's strategy at the time differed from most across the nation with its area wide coverage approach, focus on customer needs and satisfaction and providing transparent CNG and LNG refueling experiences at public retail stations. Amoco was successful in establishing LNG and LCNG stations as part of its strategy serving all vehicle types light, medium and heavy duty. Important to its success was recognizing that a refueling infrastructure had to be in place to attract NGVs.

From Amoco's NGV experience, presented in this study is a modified NGV refueling infrastructure strategy more aligned with present government regulatory conditions and incentives that was developed but not implemented. Its goals were to maximize area coverage and refueling transparency while minimizing capital and operating costs. It follows basic principles identified as matching supply to demand, matching infrastructure

growth with NGV growth, starting with central refueling or public refueling if convenient to fleets, adding public or card lock refueling to extend NGV operational areas, managing infrastructure costs, focusing on customer needs, and considering options with CNG, LNG and LCNG.

Note from the Author

Amoco represented the only major effort by a national transportation fuel provider in the United States to implement CNG refueling and possibly any alternative fuel on a basis equivalent to traditional fuels. When Amoco exited the NGV market, it lost the institutional knowledge it had gained in the NGV industry. The Clean Air Vehicle Foundation and its support for this contract from the Department of Energy are thanked for supporting the retrieval and documentation of the remaining knowledge base. 


\section{TABLE OF CONTENTS}

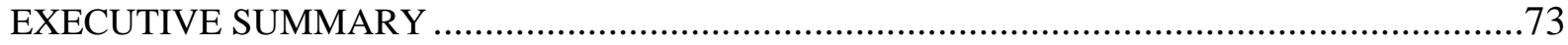

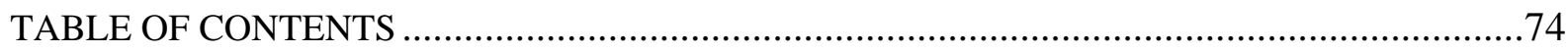

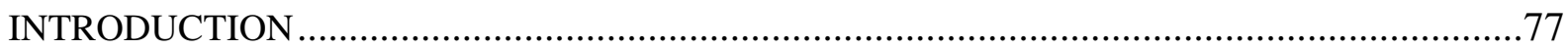

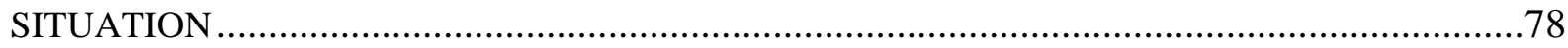

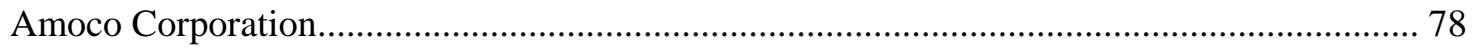

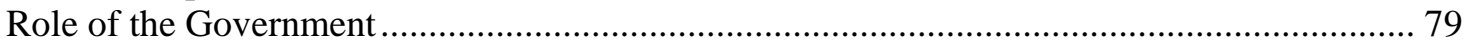

Part III of this study provides suggestions on how to continue building a CNG refueling infrastructure in today's environment with limited government support............................................80

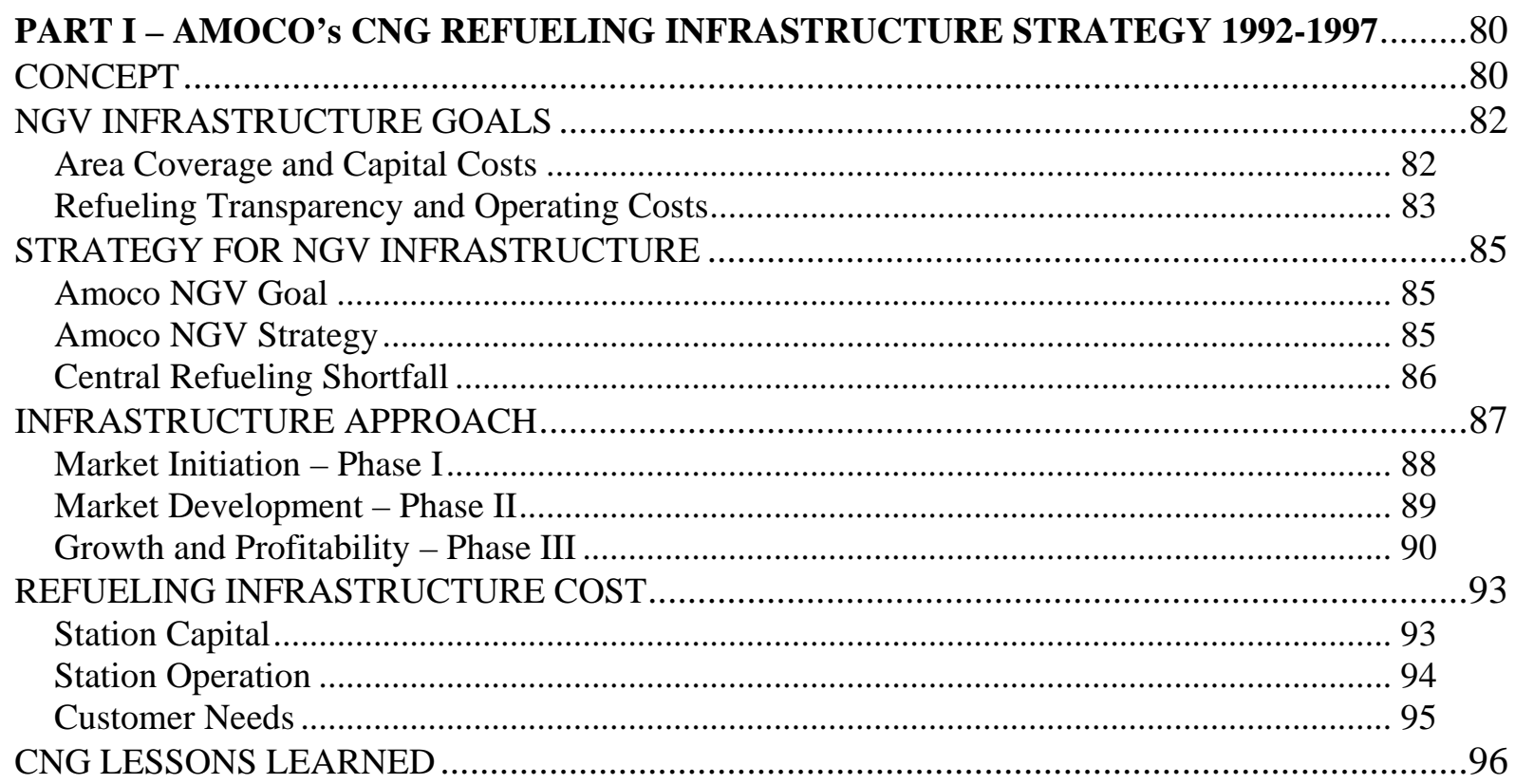

PART II - IMPLEMENTING LNG REFUELING INTO THE INFRASTRUCTURE

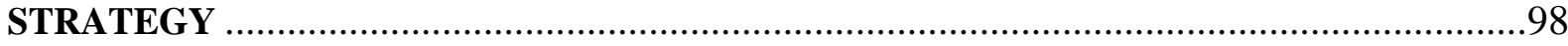

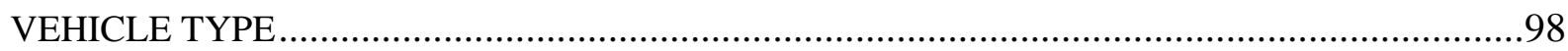

LNG IN THE CNG REFUELING INFRASTRUCTURE ..........................................................99

PART III - STARTING OVER and BUILDING A NGV REFUELING

INFRASTRUCTURE TODAY ………........................................................................101

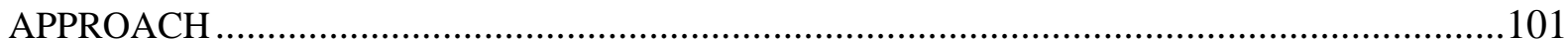

CONCEPT - REFUELING OPTIONS \& STATIONS LOCATIONS ……………………............102

NGV REFUELING INFRASTRUCTURE PLANNING …………………………….................103

Step 1 - Identify customer fleet fuel requirements................................................................ 103

Step 2 - Identify Customer Fleet Operating Area …………………………………………... 104

Step 3 - Identify Refueling Demand ................................................................................. 105

Step 4 - Match supply with demand...………………………………………………………. 105

Step 5 - Match infrastructure development with NGV growth .............................................. 107 


\section{Figures}

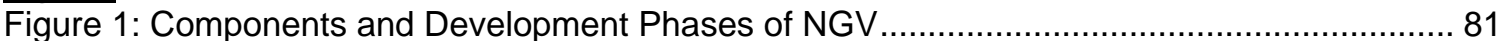

Figure 2: NGV Refueling Infrastructure Approach...................................................... 87

Figure 3: Phase I Market Initiation - Amoco Refueling Infrastructure in Metropolitan Atlanta,

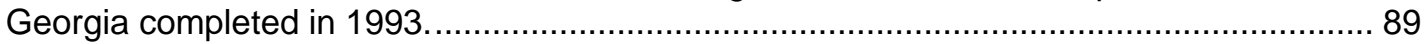

Figure 4: Phase II Market Development - Amoco Refueling Infrastructure in Metropolitan Atlanta,

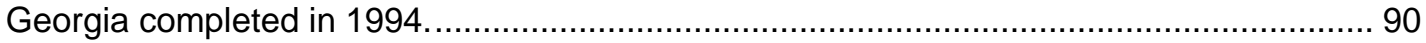

Figure 5: Phase III Growth \& Profitability - Amoco Refueling Infrastructure in Metropolitan

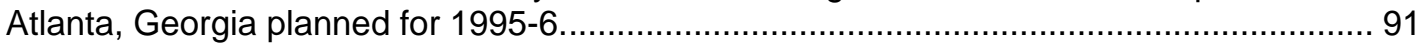

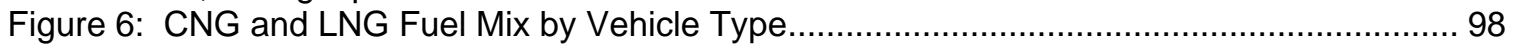

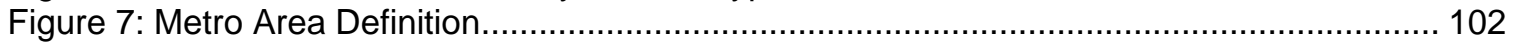

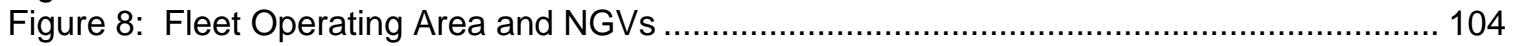

Figure 9: Defining Central Refueling from Area Wide Refueling in Terms of Distance from a

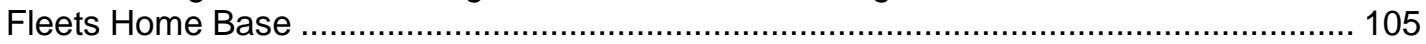

Figure 10 : Allocating CNG Stations matching Supply with Demand ................................... 107 Figure 11: Match Infrastructure Development with NGV Growth and Marketing Phases .......... 108

Figure 12: Match Infrastructure Development with Overlapping NGV Growth .................... 108

\section{Tables}

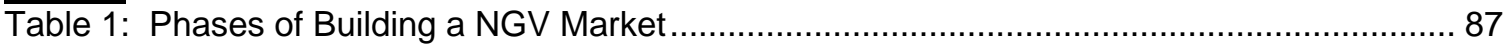

Table 2: NGV Refueling Station Comparison - CNG, LNG, LCNG ................................... 99

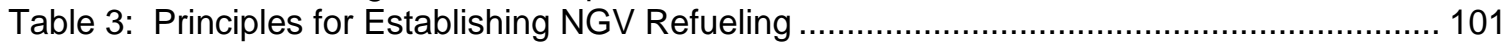

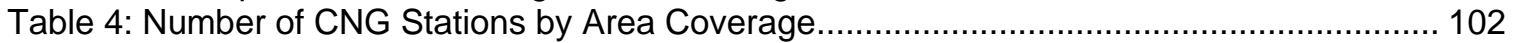

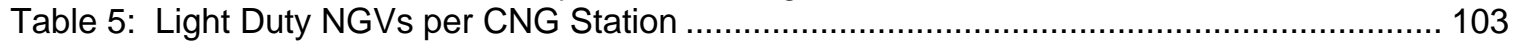

Table 6: NGV Fuel Demand Based on Daily Distances Traveled ................................ 103

Table 7: Number and Density of NGVs from One Fleet Location ................................... 104

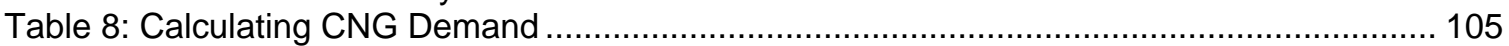

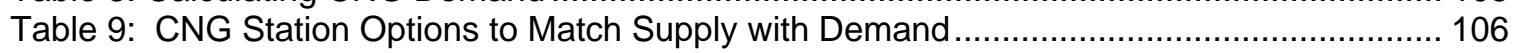

Table 10: Allocating CNG Stations Matching Supply with Demand .................................. 107

\section{Bio on Author}

Bruce Cotterman has been involved with CNG, LNG, LPG and other alternative fuels since 1990. From 1992 to 1998 when Amoco was an alternative fuels market leader, he was the Regional Business Manager for its CNG and Marketing Operations in the Southeastern U.S. and later the General Manager for Amoco's LNG Alternative Energy. In Metro Atlanta he had 14 public stations operational and 7 more being installed covering over 1600 square miles and was awarded the Chairman's Amoco Torch Award for performance. During this period he assisted in establishing another 24 CNG retail stations in other cities; LPG at Canadian central refueling sites; LNG refueling for rail yards, public transit systems and tractor-trailer fleets; and was Amoco's Alternative Fuels representative to the Department of Energy, the 1996 Olympics and the Southeastern Governor's Council. The "Clean Air City"' alliance he co-founded in Atlanta with utility partner Atlanta Gas Light Company, now Atlanta Gas Resources, was adopted and implemented nationally by the Department of Energy.

He can be contacted at: bcotterman@thebasgroup.com or 404-580-2918. 


\section{INTRODUCTION}

A retail area wide CNG infrastructure strategy for Natural Gas Vehicles (NGVs) was developed and successfully implemented in the Metropolitan Atlanta, Georgia area from 1992 thru 1996 by Amoco Corporation, now British Petroleum (BP). This effort was part of a large scale trial planned to be expanded nationally. Implementation was cancelled when the Clinton administration did not implement the mandates for NGVs provided in the Energy Act of 1992.

The alternative fuel knowledge base and experience within Amoco was lost in 1998 when it merged into BP, but still resided with its ex-employees. The strategic approach developed by Amoco for a national retail area wide CNG infrastructure was documented for the Clean Vehicle Education Foundation (CVEF) as part of its National Energy Technology Laboratory's contract with CVEF entitled "NGV Road Map and Data Collection Effort" (DE-FC26-05NT42609).

The scope of the strategy encompassed the infrastructure concept, station capital, operating factors, customer needs, general criteria for fuel type (CNG, LNG or LCNG), infrastructure planning steps and a qualitative CNG versus LNG comparison for refueling stations. Part I reviews the Amoco CNG strategy in the 1990s. Part II provides a brief overview of LNG for NGV refueling. Part III provides a modified model for building a NGV refueling infrastructure in the present economic environment.

Implementing NGVs successfully requires having concurrently an area wide infrastructure providing a supply of NGVs, demand for NGVs and NGV refueling. Previous attempts have proven to be difficult creating all three concurrently which has been a major reason inhibiting natural gas from becoming a viable transportation alternative fuel. It's the classical "egg versus chicken" which comes first dilemma - NGVs or NGV refueling. A viable and robust NGV strategy must address all three aspects. This study addresses the NGV refueling strategy needed to grow the NGV industry.

NOTE: In this study, NGV (natural gas vehicles) refueling refers to refueling of NGVs using either CNG (compressed natural gas), LNG (liquid natural gas) or LCNG (CNG produced from LNG). CNG refueling refers specifically to refueling NGVs with CNG. Where LNG is not emphasized, the reader could interchangeably use NGV refueling with CNG refueling. 


\section{SITUATION}

Economics drives business and consumer decisions. Historically the federal government builds transportation infrastructures and industry supports it with vehicles and refueling capabilities. In the case of highways and road infrastructures, gasoline and diesel vehicles are the norm that society has developed around. To change this, there has to be a compelling economic reason that will positively impact a business or consumer. For light to medium duty NGVs using CNG, the economic advantages even with tax incentives have proven inadequate to promote growth. For heavy duty vehicles using LNG, the economics can be better than diesel and are expected to improve as additional LNG port facilities come on line in the United States.

The solution for NGVs has been and continues to be driven by utilities and small refueling companies focusing on light to medium duty vehicles fueled by CNG. Efforts have been local and limited in state wide efforts. Only one major transportation fuel provider had actively participated in the NGV industry, and that was Amoco, presently part of British Petroleum (BP).

\section{Amoco Corporation}

The Energy Act of 1992 passed by the first Bush administration provided the economic incentives and mandates for industry to make the investments in both NGVs and NGV refueling facilities. Based on this, Amoco Corporation as a leading transportation fuel provider recognized Amoco the NGV opportunity and began investing in CNG refueling facilities as an integral part of its retail refueling business. Its NGV industry partners continued in a growth mode with Amoco focusing on the area wide refueling infrastructure strategy into 1996. Amoco reevaluated the NGV opportunity soon after the Clinton Administration decided in 1995 to not adopt the optional mandates provided in the Energy Act of 1992. Without these mandates, the economics of natural gas refueling changed from a mid term (3-5 years) ROI (Return On Investment) to a long term (10+ years) ROI. Fleets without the mandates or economic incentives quickly abandon plans for using NGVs. Automakers in turn reduced their NGV efforts and Amoco exited the CNG refueling business. 
A major study in 1995 by Booz Allen for Amoco recommended that Amoco stay active with its then successful Metro-Atlanta area wide retail refueling even without the Energy Act mandates. It was in Atlanta that Amoco developed its area wide refueling retail strategy with 14 stations in place and 7 more in progress being built. ${ }^{1}$ Amoco by 1996 was financially focused on other strategic businesses offering higher near term ROIs. Its CNG Refueling business with only a long term ROI was cancelled.

Amoco in 1995 began to invest in LNG for heavy duty NGVs where economic incentives and acceptable ROls were demonstrated for all aspects of the infrastructure - fleets, equipment and engine supplies and fuel providers.

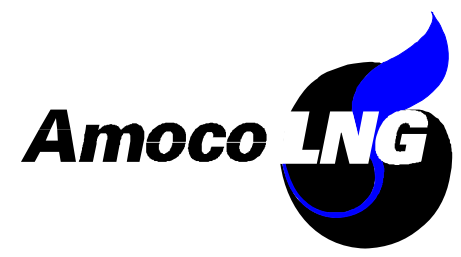

Recognized was the value that a LNG refueling infrastructure could have providing LCNG (CNG produced from LNG) to light and medium duty vehicles. Amoco exited in 1999 the heavy duty NGV market when it was merged into British Petroleum (BP) whose industry strategy did not encompass alternative transportation fuels.

Had Amoco maintained its Metro Atlanta CNG business and had BP stayed in the heavy duty NGV business with LNG refueling, its believed by some BP (ex-Amoco) insiders that these two businesses would be viable and possibly profitable in 2006 even with the high natural gas costs. But without federal economic incentives or any strong U.S. energy policy supporting alternative fuels with immediate and economically viable applications, there is no incentive for BP or any major transportation fuel provider to change their strategy from traditional fuels.

\section{Role of the Government}

To change an infrastructure that has become a norm for both industry and society requires compelling economic incentives. For practical reasons, only the federal government can change a national transportation infrastructure. The Energy Act of 1992 passed by the first Bush administration provided mandates with economic incentives for industry to make the investments in both NGVs and NGV refueling facilities. At the time it impacted fleets operating in over 150 cites in the U.S., focused on light duty vehicles, and would mandate fleets to begin purchasing alternative fuel vehicles beginning in 1996. Had the Energy Act of 1992 mandates been implemented, a national NGV infrastructure would likely have evolved.

\footnotetext{
${ }^{1}$ The General Manager for Amoco's Metro-Atlanta CNG Business who developed Amoco's area wide retail refueling strategy was Bruce Cotterman, author of this study.
} 
Building a successful infrastructure requires private enterprise to make long term financial investments in an environment demanding near term results. This has prevented the growth of any nation wide alternative fuel infrastructure to date. With no foreseen solution providing an economical or compelling reason to change, only government policy backed by funding, mandates, regulatory support and economic incentives can implement a new infrastructure on the scale needed to have an impact on energy security.

Part III of this study provides suggestions on how to continue building a NGV refueling infrastructure in today's environment with limited government support.

PART I - AMOCO'S CNG REFUELING INFRASTRUCTURE STRATEGY 1992-1997

With the Energy Act of 1992 and the Clean Air Act of 1990, Amoco had a viable strategy to be the market leader in CNG refueling as a first mover in the 33 states it operated in with over 12,000 public access retail stations. This same situation does not exist in 2006 and consequently the same strategy may not work today.

Proposed later in Part III is a NGV refueling strategy based on the lessons learned by Amoco for present times to build a robust area wide CNG refueling infrastructure. In some aspects, this proposed strategy is being pursued today. At the same time, it is not achieving the NGV growth needed and may benefit from the Amoco experience.

To understand and implement the proposed NGV refueling infrastructure strategy presented in Part III, the reader needs to first understand the Amoco strategy pursued, and the lessons learned and where it differs from other NGV strategies.

\section{CONCEPT}

To many in the NGV industry, building a successful infrastructure is having concurrently a supply of NGVs, demand for NGVs and NGV refueling to support it. From a transportation fuel provider's perspective, the components were the same but are defined differently as:

INFRASTRUCTURE NGV refueling and support such as maintenance for both NGVs and refueling stations. 
SALES

ACCEPTANCE
Demand from fleets and consumers combined with availability of NGVs.

Acknowledging NGVs and natural gas fuels (CNG and LNG) as cost effective, transparent, safe and reliable alternatives to traditional gasoline and diesel fuels.

Figure 1: Components and Development Phases of NGV

With each NGV market such as the Metro Atlanta market, developing the NGV infrastructure was in a three phase approach referred to as Market Initiation, Market Development, and Growth and Profitability.

The Goals and Strategy are built around the three phases to concurrently achieve the three components of Infrastructure, Sales

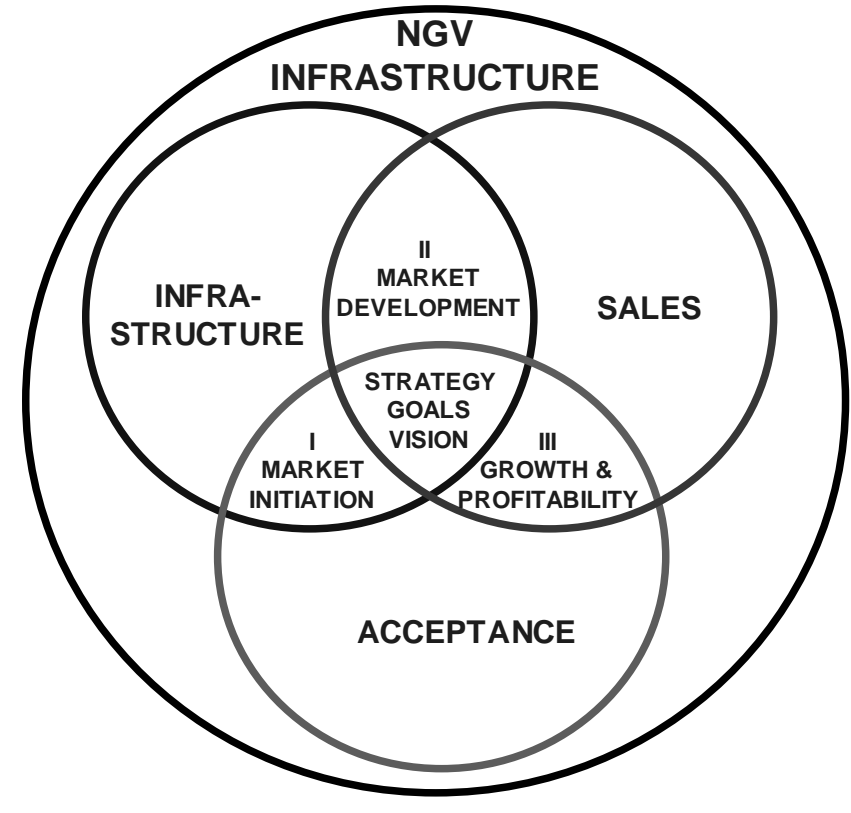
and Acceptance.

I Market Initiation

II Market Development

III Growth \& Profitability
Build the start-up refueling infrastructure and initiate pilot NGV programs and acceptance by fleets, local government agencies, communities and consumers.

Expand usage of NGVs to generate CNG fuel demand and expand the refueling infrastructure.

Grow demand of NGVs and CNG fuel to establish reinvestment quality profitability. 


\section{NGV INFRASTRUCTURE GOALS}

As a transportation fuel company, Amoco understood fleets, consumers and their transportation refueling needs. It identified from its experience a set of goals to establish a successful NGV refueling business as:

- Maximize area coverage and refueling transparency

- Minimize capital costs and operating costs

These goals are counter to each other and required a balanced and phased approach to achieve concurrently.

\section{Area Coverage and Capital Costs}

Maximizing area coverage means to provide the ability for any driver whose CNG fuel gauge is near empty to find a relatively close CNG refueling station. This is how fleets and motorists presently refuel. With CNG, the choice was to either change 100 years of refueling habits which have become the norm or adapt CNG refueling to the norm. To not would limit the number of fleet vehicles using CNG to small scale fleet projects which often is the case rather than building a true NGV infrastructure. Adapt was chosen.

Building an area wide refueling infrastructure requires large capital investments. To balance cost versus coverage requires starting with area wide refueling coverage to effectively service multiple fleet refueling needs, yet in a phased approach expanding area coverage as NGVs and fleets are added. It also requires starting with small but adequate CNG stations having the flexibility to adjust each station's volume upwards to meet growing demand.

In another perspective, provide adequate coverage means avoiding point coverage, minimizing central refueling and going straight to area wide coverage with multiple stations. In time multiple area coverage would either overlap or gaps would be filled to provide regional coverage. 
This can be accomplished using the existing public refueling sites (where Amoco had an advantage) or the more difficult approach providing public access to private stations. For creating regional coverage, stations are needed along interstates and intrastate highways.

\section{Refueling Transparency and Operating Costs}

Maximizing refueling transparency means the driver's CNG or LNG refueling experience closely resembles a traditional refueling experience with gasoline or diesel with:

- Easy access to and from all major highways

- Locations near fleets

- Covering all quadrants of operational areas

- Easy entrance and exit during rush hours

- Extended hours of operation

- Fast fill

- Dispensers and hoses similar to gasoline or diesel

- Measurements in equivalent gallons

- Safety

- Convenient locations

- Self-service

- Honoring most forms of payment

- Fleet cards

- 24 hour service

- Oil, gasoline, diesel, water, air, etc. available

- Emergency refueling

- Conveniences such as restrooms, food and drinks

Transparency is critical to have acceptance. Without acceptance, alternative fuels will not grow. Forcing drivers to use alternative fuels or lacking transparency has been shown to not work. It must be wanted and accepted. This is an area where many nontraditional fuel providers such as utilities have struggled.

To balance cost versus transparency requires planning in fuel transparency from the beginning to include site selection. Fleet drivers and motorists have many refueling options. This includes which fuel - CNG or gasoline - to use as well as which CNG station to use. Providing transparency encourages and assures the successful use of CNG. 
Amoco had many examples where any deviation from transparency even with traditional fuels had resulted in motorists and fleet drivers avoiding use. A classic example was the overnight drop in gasoline sales when Amoco stations converted from gallons to metric liters. Customers went to competitors simply because of reduced transparency to traditional refueling measurements. The remedy was to quickly return to consumer expectations by reverting back to gallons. Another example was the reluctance of motorists to adopt diesel vehicles requiring refueling at diesel pumps on separate islands. The remedy was to establish refueling transparency by mixing diesel dispensers with the gasoline dispensers, then later designing in diesel as an option on gasoline dispensers. 


\title{
STRATEGY FOR NGV INFRASTRUCTURE
}

\author{
Amoco NGV Goal
}

For Amoco, the NGV goal was to:

Develop a NGV refueling business with profitable growth within 5 years and achieving within 10 years $\$ 500$ million in revenues, $\$ 50$ million operating profit and $15 \%$ return on investment.

A goal of this magnitude was realistic for a national transportation fuel provider entering a new market. Based on the opportunity presented in 1992 with the Energy Act, NGVs vehicles were either going to become part of the national transportation infrastructure or remain a small technical experiment supported by small niche businesses.

\section{Amoco NGV Strategy}

The NGV infrastructure strategy to accomplish the goal was to:

Provide CNG area wide coverage for NGVs in its existing retail refueling stations, focus on major metropolitan markets, then expand into smaller markets, and interconnect those markets for regional refueling coverage.

Analysis of market drivers leading into the strategy indicated that using central refueling would limit development of the NGV infrastructure. Additionally, there were trends that indicated a move for many fleets back to using public access retail stations. Increasing environmental costs for underground storage tanks and the capital costs to build above ground in the 1990s was driving this. Lastly, the strategy was consistent with Amoco's strengths and capabilities with over 12,000 public access retail stations in 33 states.

Its noted that of the four major metropolitan areas targeted by Amoco - Metro Chicago, Northern Virginia/Baltimore/Washington, DC, Metro Atlanta and the Florida Gold Coast only the Metro Atlanta area followed the Amoco NGV Infrastructure strategy. The explanation was the difficulties in implementing the strategy based on issues with either 
the local utility, local and state government agencies, the general fiscal and risk taking conservatism of the Amoco managers or all of these.

The Atlanta Market was successful based on several preconditions identified as:

(1) Cooperative utility - Atlanta Natural Gas and Light Company,

(2) Pro-alternative fuel local and state governments,

(3) Management with a business development background experienced in entering new markets, and

(4) Strategic focus on area wide refueling coverage.

Yet success was achieved within Metro Atlanta in a highly competitive environment consisting of low gasoline prices compared to across the country, three CNG fuel providers and multiple alternative fuels including LPG (propane), electric and ethanol (E85) competing for the same fleet customers.

The lesson learned from this were the pre-conditions listed above are critical to successfully develop a NGV infrastructure or enter any market with NGVs.

\section{Central Refueling Shortfall}

Area wide coverage was chosen by Amoco over central refueling, yet central refueling is seen as the optimal solution balancing the economics of bringing supply and demand together. Central refueling is popular due to the lower investment, lower operating costs and physical control of fleets who start and return to the same location daily. Central refueling sites are located in industrial areas and at the convenience of the on site fleet it serves. Therefore it would seem the obvious approach for meeting refueling needs.

Except in a few sites, this approach, though found attractive by fleets and utilities providing the refueling, was not producing the demand expected or needed for developing the NGV refueling infrastructure.

Shortfalls in central refueling for developing the NGV infrastructure were identified as: 
- Not functional for other commercial refueling if utilizing slow filled refueling, lacking a metered refueling pump, having inadequate CNG storage capability or undersize compression capability for fast filling or lacking capabilities for recording and crediting fleet and vehicle accounts.

- Limited in the area served based on location or metro area traffic patterns

- Limited access, availability or convenience to other fleets.

- Non functional design for public use.

- No incentive for public transportation refuel providers to participate.

- Motorists in personal cars unlikely to use fleet facilities as demonstrated with diesel.

- Higher capital and operating costs to provide public access.

- Small stations often could not meet the fast fill or peak load requirements

Amoco was able to overcome the issues involving central refueling with its experience, capabilities, capital and existing retail sites. A major challenge to building any NGV infrastructure is how to overcome these issues without the cooperation and support of public access retail stations or how to get their cooperation, support and capital. This issue is beyond the scope of this study, but is one that needs addressed for NGVs to grow beyond localized areas and become a major source of transportation.

\section{INFRASTRUCTURE APPROACH}

With each NGV market such as the Metro Atlanta market, developing the NGV infrastructure was in the three phase approach described earlier as Initiation, Market Development and Growth and Profitability. The timing and goals of each phase are shown in Figure 2 and Table 1 respectively.

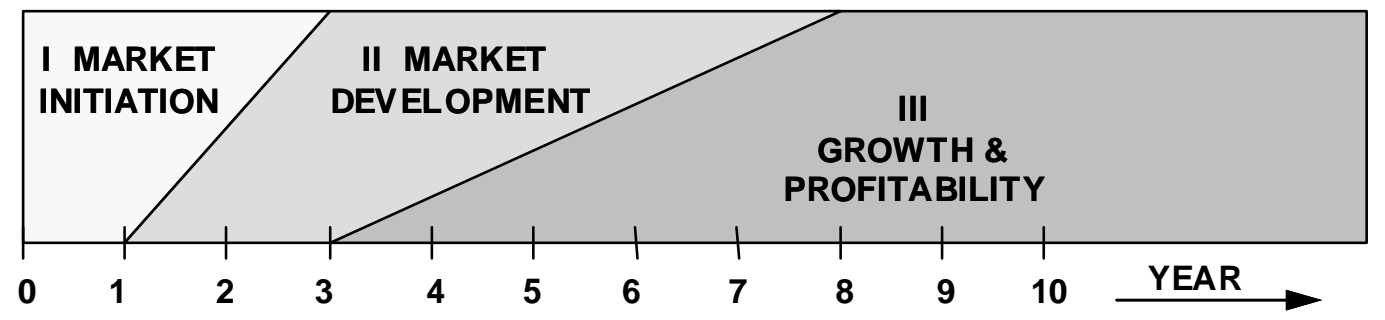

Figure 2: NGV Refueling Infrastructure Approach

Table 1: Phases of Building a NGV Market

I Market Initiation

Develop initial "Skeleton" infrastructure 


\begin{tabular}{|l|l|}
\hline & Initiate new customer test programs \\
\hline II Market Development & $\begin{array}{l}\text { Focus on meeting customer needs } \\
\text { Expand refueling infrastructures based on market demand } \\
\text { Focus on reducing fixed and variable refueling costs }\end{array}$ \\
\hline III Growth \& Profitability & $\begin{array}{l}\text { Expand refueling infrastructures based on market demand } \\
\text { Develop intrastate and interstate refueling infrastructures }\end{array}$ \\
\hline
\end{tabular}

The time periods are relevant. As with any program with high capital costs and operating costs, entering a market has to start achieving a positive impact within a one year time period. A "toe in water" approach seldom works. At the same time this approach demands in depth research and planning before committing. As with any project, the phases will overlap. By year 3, growth and profitability, or at least break even status, should be achieved. Though new market entry effort usually has a 5 year scenario, few companies have the cash flow luxury or management patience to go beyond 3 years. This is especially true for the fleets and the motorist. If they can't see the financial payback within 2 to 3 years for a vehicle with a 5 year life, then the program will seldom succeed or be supported.

The exception is with heavy duty vehicles that operate based on life cycle costs versus the light to medium duty vehicles that budget based on annual operating costs. This subtle point will be discussed later and is what differentiated the LNG refueling market from CNG.

\section{Market Initiation - Phase I}

Market initiation begins after all the market research and planning is completed. It includes adding the first refueling station(s) as a "skeleton" infrastructure for a major metropolitan area. This provides a value proposition to fleets that encourages pilot NGV programs to test the concept. They can then budget for the following year to begin converting the remaining fleet upon completion of a successful pilot program. With this comes creditability, attention as a "real" fuel to take seriously, support from NGV converters and

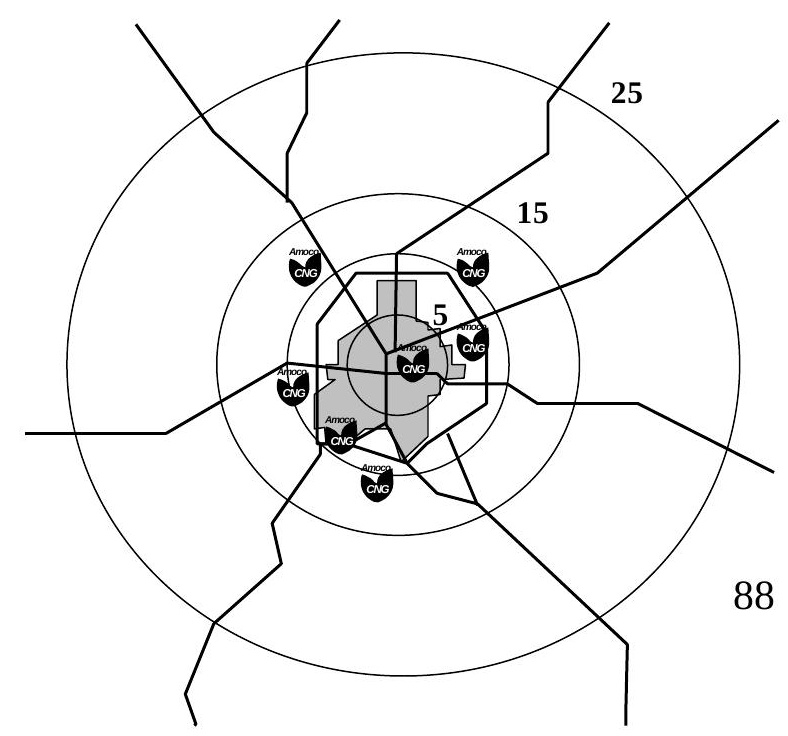


OEMs, faster acceptance and a steep learning curve.

Figure 3: Phase I Market Initiation - Amoco Refueling Infrastructure in Metropolitan Atlanta, Georgia completed in 1993.

The plan was for one station every 25 square miles or 5 miles apart. In the case of Atlanta, 7 stations were added establishing instant area wide coverage though limited. Station sites were based on earlier NGV adopters identified during the pre-Phase I market research and planning. Each station was over designed in capacity to assure a successful fast fill experience for any NGV and fleets, especially during peak times. Based on all the unknowns in establishing area wide coverage and gaining acceptance, starting off with smaller refueling stations was not an option. The stations located five miles apart in a dense urban area with heavy traffic patterns provided marginal coverage which limited NGV growth. Four miles apart or closer would have encouraged greater NGV growth.

\section{Market Development - Phase II}

The Market Development phase focused on growing demand by transitioning pilot NGV programs into fleet conversions and initiating new customer fleet pilot programs with a wider area refueling coverage. Gaining acceptance was a key goal.

This was accomplished through improved meeting of customer needs, expanded refueling infrastructures based on market demand and reducing fixed and variable refueling costs. The Market Development phase was heavily dependent on lessons learned during the Market Initiation phase and adjusting the business and market plans accordingly. Focusing on reducing costs was an important effort during this phase in preparation for achieving sustainable profit growth.

In Atlanta, an additional 7 stations were added for a total of 14 . Most of the new stations were located near fleets in high density industrial areas and federal, state and local government fleets that were converting to NGVs. Several stations were added beyond the 15 miles radius of metro Atlanta to provide the area coverage needed to convert a larger percentage of fleets.

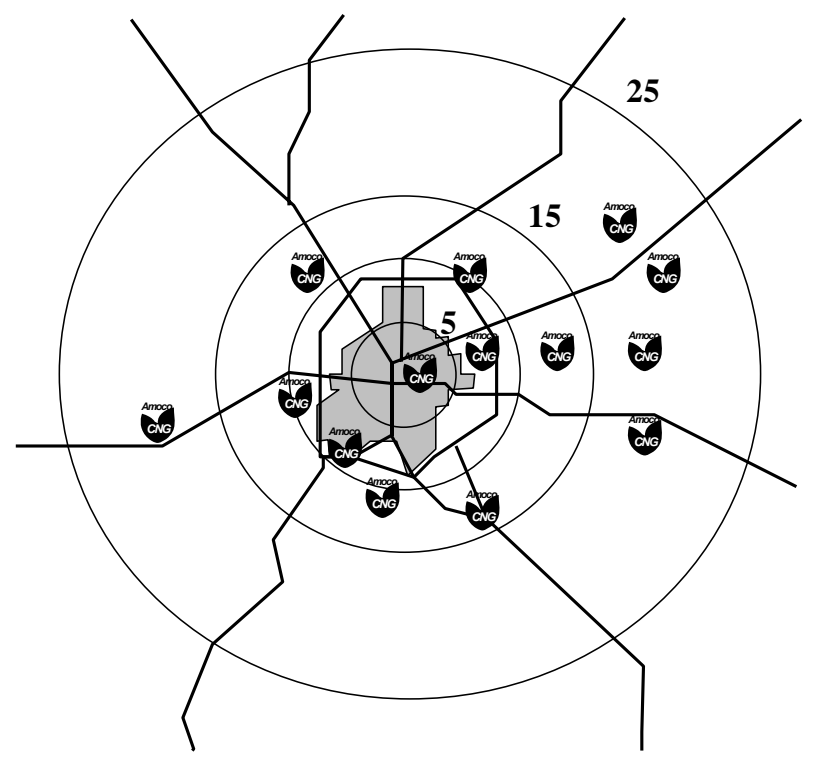


Figure 4: Phase II Market Development - Amoco Refueling Infrastructure in Metropolitan Atlanta, Georgia completed in 1994.

The second set of 7 stations added were designed and installed based on lessons learned the first year. Factors involved lower operation costs, higher automated monitoring capabilities, higher reliability, greater peak load capability, faster fill times, greater capacity for stations with higher demand potential and positioning within retail stations to improve through put and refueling times for commercial fleets. Greater emphasis was placed on NGVs with high mileage than numbers of NGVs to increase CNG demand.

Once again oversized stations were introduced as in Phase I to assure continual acceptance and support growth during the Market Development phase. With hindsight, the stations placed to extend driving distances and area coverage should have had smaller capacity with lower capital and operating costs.

Growth and Profitability - Phase III

Achieving profitable growth is an absolute requirement. Its possible to rationalize negative financials based on pulling through additional natural gas sales. But this does not build a NGV infrastructure nor encourage businesses to enter the industry or markets. During this phase, aggressive Market Development from Phase II continues.

The refueling infrastructure continues to be expanded but only when justified based on market demand. Concurrently, intrastate and interstate refueling stations are planned and added to begin regional coverage and encourage NGV travel between major markets.

Expanding into heavy duty NGVs with LNG is evaluated in this phase. Though dependent on the cost effectiveness and availability, LNG offers range and fuel density advantages that could greatly open up demand and establish regional coverage with interstate and intrastate travels. With LNG refueling, CNG can be made available with LCNG facilities.

This is the phase were CNG stations have their refueling capabilities matched with demand to optimized capital and operating costs. 
Figure 5: Phase III Growth \& Profitability Amoco Refueling Infrastructure in Metropolitan Atlanta, Georgia planned for 1995-6.

Planned for Metro Atlanta was a third set of 7 stations for expanding the area coverage bringing the total to 21 stations plus one LNG truck stop. This CNG set included newer and improved designs with higher reliability, lower operating costs and smaller stations for balancing capacity with demand. Once demand was understood at each site, the stations were to be moved around to balance capacity with demand as part of the refueling infrastructure expansion.

The Metro Atlanta market with 21 stations of varying capacity would have completed the area coverage providing CNG refueling to over $80 \%$ of the fleets and motorists.

Motorists began to be emphasized and marketed to during Phase III. Their shear numbers and fuel usage for commuting would easily provide Amoco the means to meet and exceed its financial goals.

The LNG station was planned for local heavy duty vehicles such as waste haulers and local delivery medium duty trucks. The same LNG station would allow interstate travel when eventually liked with another LNG station either in South Florida, going west through Alabama, Mississippi, Louisiana and Texas, or north toward Virginia and Maryland. The U.S. Postal Services and Amoco tractor trailers based in Georgia were the initial target interstate fleets. CNG produced from the LNG would support the light and medium duty vehicles in the area as an additional CNG station.

While phase III and the addition of stations 15 through 21 were in progress, Amoco decided to exit the market in 1996 as previously discussed. Had Amoco stayed in the Atlanta market and fully implemented phase III, indications were that the financial goals as originally planned in 1993 with the Atlanta market would have been met in 1996-7 with profitable growth achieved as new fleets continued to convert to NGVs. This 
statement of profitability does not factor in the unforeseen high rise in natural gas prices caused by deregulation and other events around 1998 on. 


\section{REFUELING INFRASTRUCTURE COST}

One of the main inhibitors to the development of the NGV market is the cost of installing and then operating a refueling station until there is adequate CNG demand to cover operating costs and provide an acceptable ROI on the capital. The refueling infrastructure costs has three components - station capital, operating costs and the cost to meet customer needs. The latter is important for gaining acceptance and growth.

Infrastructure Cost $=$ Station Capital + Station Operating Costs + Customer Needs

Amoco as a national transportation fuel provider understood the needs and psychology that motivates and creates a successful refueling experience for motorists and fleet operators. It translated this knowledge to its CNG refueling approach and was successful in growing volume at its stations by increasing the participating fleets, numbers of vehicles per fleet and CNG usage per vehicle. Though many of the points to be listed may seem obvious, several continue to not be applied by some CNG providers. Reasons range from the cost to simple lack of understanding of the needs and motivations of vehicle operators.

\section{Station Capital}

The components of station capital are listed below. Since the 1990s, refueling equipment's performance and reliability has improved considerably. The costs identified in the 1990s may differ by today's standards. Land availability and site preparation can be a significant portion of station capital.

$\begin{array}{rll}\text { Station Capital }= & \text { Compressor size (CNG) or pump size (LNG /LCNG) } \\ + & \text { Compressor motor (gas or electric) } \\ + & \text { Storage (Volume and pressure) } \\ + & \text { Dispenser (s) } \\ + & \text { Automation } \\ + & \text { Land acquisition or lease } \\ + & \text { Site prep } \\ + & \text { Building/Brick and Mortar }\end{array}$

Minimizing refueling time is important to a cost effective and efficient fleet operation. Storage offers assurance for quick fast refills and meeting peak or unexpected demand, yet is often undersized. Amoco choose to use 5000 psi cylinders plus extra storage to assure the customers achieved that fastest fill possible. 
Dispensers are important to acceptance and need to be transparent. That is similar to traditional gasoline and diesel dispensers in appearance and function. Attractive and flashy designs are acceptable as marketing tools as long as they do not deviate from transparency. With high pressure CNG, they could have a menacing look. This was found to actually discourage the use of CNG, generate apprehension on safety and cause unqualified rumors to spread within fleets.

Metering in equivalent gallons was found to be a necessity, otherwise there was confusion and suspicion that the value per energy unit was not there. Fleet managers also found that without equivalent gallons they lost control of operating costs per vehicle and sometimes discouraged or stopped the use of CNG. ${ }^{2}$

Dual dispensers were utilized by Amoco in every situation for two reasons even if demand did not warrant it. First, as a back up. There were multiple things that could go wrong. Dispensers occasionally failed and operator error sometimes caused failure to refill even with the most standard and automated of dispensers, hoses and nozzles. Simply observing any retail gasoline refueling station for 20 minutes emphasizes this point. Without a functioning dispenser, a refueling site is out of business. Secondly, for those times a second vehicle pulls in to refill, waiting for an available dispenser creates an inconvenience that will discourage acceptance and prevent growth. Operators tend to avoid sites where quick access is an issue, even if only a one time situation. Having dual dispensers at every retail refueling site regardless of its capacity proved from Amoco's perspective to be the correct decision.

\section{Station Operation}

Along with site location, the operation and maintenance of a refueling station are important to acceptance of CNG or LNG by vehicle operators. The components are identified below.

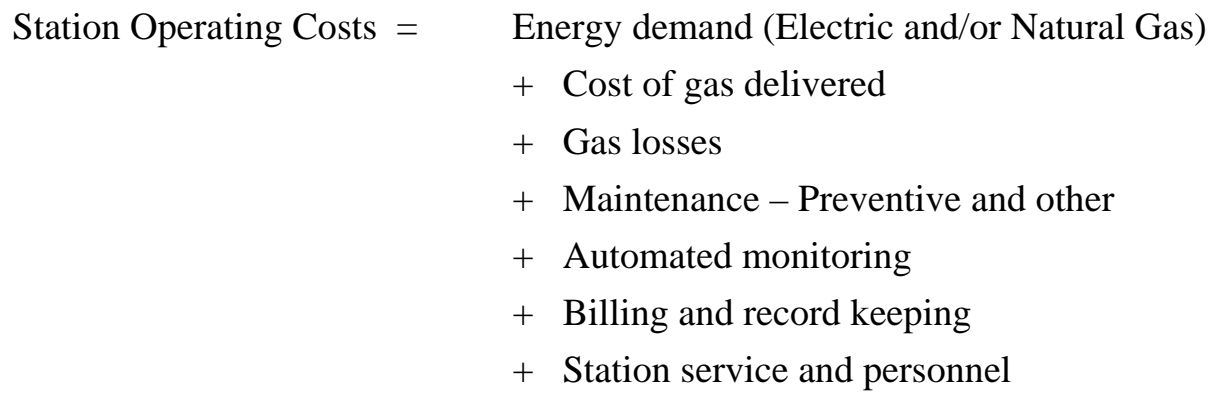

\footnotetext{
${ }^{2}$ The use of equivalent gallons is mentioned based on the rigid stand Amoco took within the NGV community and the present trend for hydrogen fuels away from equivalent gallons.
} 
+ Third party margins

The station has to work the first time and every time a vehicle operator uses it. If not, then operators have no choice but to seek alternatives. Then they will avoid, as many motorists would, coming back to a dysfunctional or inconvenient refueling site and inform others of their difficulties. The reverse is true for a refueling station that operates well and is convenient.

Maintenance needs to be proactive and preventive, but is too often a reactive repair situation. Having continuous maintenance capability is expensive but necessary to the successful operation of any refueling station regardless of the fuel type. This was observed as an issue with some stations and an area where Amoco excelled.

Observed by Amoco was the need for automated monitoring of performance. Even with the retail sites having on site personnel, mechanical problems were seldom reported in a timely manner. Continuous monitoring was an evolving technology and added expense in the 1990s but less an issue today. Critical is assuring that storage cylinders are full and the station is fully functional prior to peak refueling times. The result in assuring a reliable and fast refueling experience was acceptance by NGV operators to using CNG, especially in bi-fuel vehicles, and operators switching from slower or less reliable stations to refuel at Amoco's CNG dispensers in its retail stations.

Billing with detailed vehicle and operator information for fleets is readily available and easy to implement. Though an added cost, it provides valuable information for both fleet managers and fuel providers to understand refueling patterns. It should be a standard offering.

Energy demand is a hidden cost that can generate significant operating costs if not planned from the design forward. This is an area that deserves management attention.

Energy demand $=$ Function (Compressor size, peak demand, continuous demand, storage requirements, lighting and ancillary equipment)

\section{Customer Needs}

There is another component often overlooked. It is the cost of meeting the customer's needs. This is an area where many non-traditional transportation fuel providers struggle. Its an area where the customer is "king" or "queen" and always right. Its what drives the highly competitive retail stations and differentiates the successful ones from the others. CNG should be treated no less to achieve acceptance and drive growth. 
Though many customers' refueling needs are covered in the station capital or operating costs, there may incur added incremental costs to meet customer needs.

Customer Refueling Needs $\quad=\quad$ Easy access to and from all major highways
Near fleets
Covers all quadrants of operational area
Easy entrance and exit during rush hours
Extended hours of operation
Fast fill
Safe
Convenient locations
Self-service
Honor most forms of payment
Fleet cards
24 hour service
Oil, gasoline, diesel, water, air, etc. available
Emergency refueling

\section{CNG LESSONS LEARNED}

The lessons learned by Amoco from its efforts in building both area wide public CNG and central CNG stations are basic to transportation refueling.

- Pre-conditions of cooperative utilities, pro alternative fuel local and state governments, management talent with business development background and an area wide refueling strategy need to be in place to successfully develop the NGV infrastructure in a new market.

- A refueling infrastructure needs to be in place to create NGV demand.

- Utilize smaller capacity stations where demand is low, yet still providing fast fill capabilities.

- Central refueling limits NGV growth whereas public refueling promotes NGV growth.

- Without government incentives to assure rapid growth of NGVs, the return on investment (ROI) for an area wide NGV refueling infrastructure is too long term for industry participation as demonstrated by the limited number of participants today.

- For NGV growth, CNG refueling needs to be transparent to traditional gasoline and diesel refueling.

- Each time a NGV fuels with CNG , it must be successful requiring back up dispenser hoses, reliable compressor stations and alternate refueling sites in close proximity, i.e. an area wide refueling infrastructure similar to traditional fuels. 
- Public refueling stations offer many advantages with their added services which attracts fleet refueling, though fleet managers prefer central refueling to avoid driver distractions.

- Driver refueling satisfaction is paramount to the successful growth of NGVs.

- NGV trials by fleet managers were typically successful with a well maintained vehicle and good driver with a positive attitude, whereas they almost always failed when the pilot test used a poor driver and poorly maintained vehicle.

- Fleet economics based on operational costs for light to medium duty fleets ultimately dictate the growth of NGVs assuming reasonable incremental acquisition costs for the NGVs.

- Life cycle costs apply only to heavy duty fleets.

- Stations located five miles apart in a dense urban area with heavy traffic patterns provided marginal coverage which limited NGV growth. Four miles apart is recommended (reduces travel time by $20 \%$ and area coverage by one third from approximately 25 sq. mi. to 16 sq. mi.). 
PART II - IMPLEMENTING LNG REFUELING INTO THE INFRASTRUCTURE STRATEGY

Liquid Natural Gas (LNG) as a source of natural gas fuel provides higher density storage and distance advantages than CNG. This is especially important for heavy duty and select medium duty vehicles who consume large volumes of fuel and/or travel long distances. The disadvantage to LNG was its limited supply, need to be distributed by truck and the special handling and safety aspect as a cryogenic liquid. LNG could easily be converted into CNG referring to it as LCNG for its source offering a dual refueling capability as either LNG or CNG.

\section{VEHICLE TYPE}

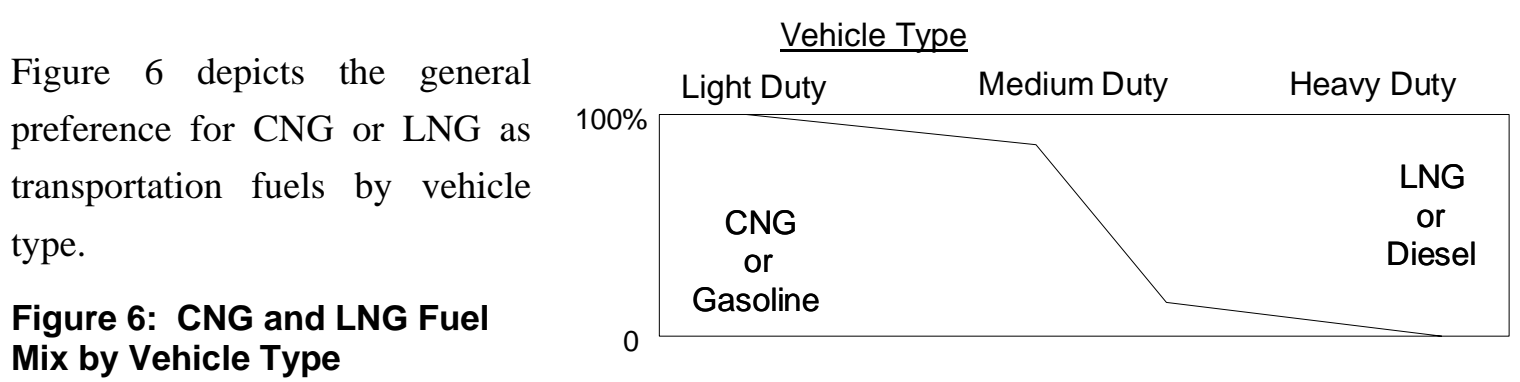

Light - Medium Duty Vehicles needs were best served by CNG as a substitute for gasoline refueling with:

- Self service refueling

- Emphasis on operating costs

- Range and space limitations

- 4-10 gals per minute fueling

The physics of refueling for cryogenic LNG were found to not be practical for small tank sizes commonly found in light duty vehicles. Therefore, LNG was best used in medium and heavy duty vehicle with large tanks of 20 liquid gallons and larger.

Medium - Heavy Duty Vehicles needs were best served by LNG as a substitute for diesel refueling with:

- Serviced or trained operator refueling for safety

- Emphasis on life cycle economics

- Range, weight and space limitations

- 20-50 gallons per minute fueling

Amoco found three key advantages with LNG for heavy duty and select medium duty vehicles. The first was in how their ROI was calculated. With light to medium duty vehicles, the ROI for switching to CNG was based on operating costs and short term vehicle life. Therefore the incremental conversion cost had to be low for a payback. For medium to heavy duty vehicles, the ROI was measured based on life cycle costs. Heavy and select medium duty vehicles have the vehicle and engines specified separately allowing for a cost effective natural gas engine substitution. The engine life advantage using LNG combined with the lower particulate emissions and lower equivalent gallon cost in the mid 1990s provided a competitive life cycle cost advantage to LNG. 
The second advantage for Amoco at the time was its low cost sources of LNG where it was produced as a secondary product without the high acquisition, operation and overhead costs of dedicated LNG plants. This could be duplicated where there are abundant sources of lower cost natural gas such as found in the western United States or as low priced LNG imports become available as new LNG terminals are opened.

The third advantage was in the psychology of refueling. Heavy duty operators are use to refueling and safety issues not found in public or gasoline refueling stations. Amoco found the operators had no issues or safety concerns using another liquid, LNG, even though it was cryogenic, whereas they did with compressed natural gas, CNG. The acceptance among operators of heavy duty trains, construction equipment and tractor trailers was immediate.

In summary, LNG with its 3.5 times greater energy density compared to CNG was found to:

- Be acceptable to operators

- Use same diesel tank locations without frame modifications

- Have fast fueling rates of 30-50 gpm regardless of outdoor temperature

- Vapor is delivered to engine (same engines for CNG and LNG)

- Be a safe, simple, reliable refueling system

- $\quad$ Generate acceptable ROIs for heavy duty and many medium duty vehicles

- Be an alternative fuel to diesel as LNG and gasoline as LCNG

\section{LNG IN THE CNG REFUELING INFRASTRUCTURE}

LNG provides many advantages with its high density and ability to be used in areas where no natural gas pipelines service an area. With the technology of cryogenic storage tanks, LNG has several weeks life with minimal off gassing. As LCNG it reduced the compression pump and storage costs for a CNG refueling station. It has the potential to be a cost effective refueling source along the interstate highways and truck stops and where high volume demand is needed to service medium and heavy duty vehicles.

Fast fill LNG stations can be integrated into the NGV refueling infrastructure with the following capabilities.

- Designed to serve 50 vehicles or more per day

- 30 - 40 gpm. fueling rate with fills not affected by ambient temp.

- 6,000 gal. storage, instant-on service

- 10-13,000 gal. storage add on capability

- Dispenser with card-lock capability

- Designed for CNG alone as LCNG

Comparing station and refueling economics (based on costs from 1994-1998), the advantage of LNG assuming equal costs of natural gas supply are seen in Table 2 .

Table 2: NGV Refueling Station Comparison - CNG, LNG, LCNG

\begin{tabular}{llll} 
Economic & Station & Typical Vol & \# NGVs \\
Station Size & Cost & per NGV & per Station \\
\hline
\end{tabular}




\begin{tabular}{|c|c|c|c|}
\hline CNG & $\begin{array}{l}\text { 8-10,000 } \\
\text { gal/month }\end{array}$ & $\begin{array}{l}\$ 250,000 \\
-\$ 350,000\end{array}$ & $\begin{array}{l}1-20 \mathrm{gal} / \text { day } \quad 40-500 \\
20-500 \mathrm{gal} / \mathrm{month} / \mathrm{NGV}\end{array}$ \\
\hline LNG & $\begin{array}{l}80-100,000 \\
\text { gal/month }\end{array}$ & $\begin{array}{l}\$ 300,000 \\
-\$ 400,000\end{array}$ & $\begin{array}{lr}50-200 \mathrm{gal} / \mathrm{day} \quad 16-100 \\
1000-5000 \mathrm{gal} / \mathrm{month} / \mathrm{NGV}\end{array}$ \\
\hline L/CNG & $\begin{array}{l}\text { 8-10,000 } \\
\text { gal/month }\end{array}$ & $\begin{array}{l}\$ 150,000 \\
-\$ 200,000 * *\end{array}$ & $\begin{array}{l}\text { 1-20 gal/day } 40-500 \\
20-500 \mathrm{gal} / \mathrm{month} / \mathrm{NGV}\end{array}$ \\
\hline
\end{tabular}

With LNG, it can be simpler to grow a positive cash flow business based on central refueling with:

- 1 station per fleet or 1 station servicing several fleets

- Typical customer tests using 2-5 trucks utilizing 40-80,000 gal/yr/truck or 80-400,000 gallons per year per fleet of 10 heavy duty vehicles

- 3 -12 Fleet Customers per 1,000,000 gal/year station

The approach for LNG is:

- Central refueling

- Add full size stations only and then based on demand

- Match economics with diesel to start

- Grow based on LNG economic advantage over diesel

- Develop area coverage: Based on demand

With government assistance

Combination of both

- Add truck stop refueling as Intrastate and interstate NGV travel occurs 
PART III - STARTING OVER and BUILDING A NGV REFUELING INFRASTRUCTURE TODAY

Many lessons were learned by Amoco from developing the CNG and LNG refueling infrastructures from 1992 to 1998. For building a NGV refueling infrastructure in 2006, presented is a different approach based on Amoco's experience.

Motorists still represent the ultimate goal for NGV growth. Yet, it's the fleets who will drive the development of the NGV infrastructure. Though none of the issues with central refueling have changed, economics and practicality dictate that central refueling be a major part of any viable NGV Refueling Infrastructure today. The only scenario that would change this is the active participation by a major transportation fuel providers' with their retail stations similar to Amoco's involvement in the 1990s.

\section{APPROACH}

The overall three phase approach used by Amoco - Market Initiation, Market Development, and Growth \& Profitability - is recommended keeping the same goals to maximize area coverage and fuel transparency while minimizing capital and operating costs.

Principles were identified to follow for establishing NGV refueling from Amoco's experience that reflect today's economic environment.

\section{Table 3: Principles for Establishing NGV Refueling}

- Provide area wide coverage

- Start with central refueling or public refueling if convenient to fleet

- Match supply to demand

- Match infrastructure growth with NGV growth

- Add public and/or card lock refueling to extend NGV operation area

- Manage aggressively on infrastructure costs

- Focus religiously on customer needs

- Consider options: CNG, LNG, LCNG 
This strategy differs from Amoco's earlier one by starting with point coverage using central refueling or key lock stations where public access stations are unavailable for high volume fleet customers. Area wide coverage will follow with key lock stations or public access stations for multiple customers. In time multiple area coverage will either overlap or gaps will be filled to provide regional coverage.

This approach is necessary with profitable economics being harder to achieve having fewer government driven incentives for both fleets owning NGVs and refueling stations, higher natural gas prices and slower growth projected.

All other recommendations on station capital, operations and meeting customer needs are still applicable. A lesson learned from the Amoco strategy that may differ from other strategies is to still provide area wide coverage utilizing smaller capacity stations where demand will be low, yet still providing fast fill capabilities.

\section{CONCEPT - REFUELING OPTIONS \& STATIONS LOCATIONS}

The first step is to define the target metropolitan area and its high traffic areas and size. The next step is to define the CNG station type, area coverage and number of stations needed.

Figure 7: Metro Area Definition

Table 4: Number of CNG Stations by Area Coverage

$\begin{array}{llll}\text { Radius } & & \text { Area } & \text { Station } \\ 5 \mathrm{mi} & & 80 \text { sq. mi. } & 3 \\ 10 \mathrm{mi} & & 300 \text { sq. mi. } & 12 \\ 15 \mathrm{mi} & & 700 \text { sq. mi. } & 28 \\ 25 \mathrm{mi} & & 2000 \text { sq. mi. } & 80\end{array}$

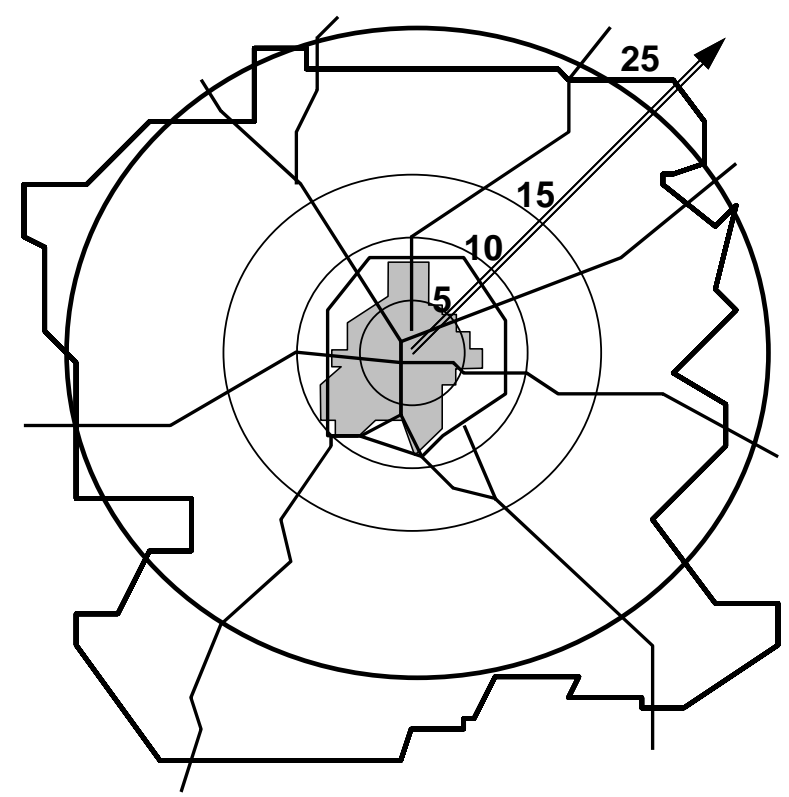


For estimating the number of CNG stations needed, Amoco's original plan of one station every 25 square miles or 5 miles apart was used. Theoretically, the Metro Atlanta area as defined in 1992 and shown in Figure 7 requires 80 stations to adequately provide CNG refueling coverage. Since areas within the metro area differ in traffic density, and not all areas can justify supporting a NGV infrastructure, stations would be added in phases to match the growth and density of NGVs. Amoco had found that 21 stations would provide initial area wide refueling within the 25 mile radius circle area considered metro Atlanta.

The focus remains on area wide coverage. Where there are central CNG stations, the area wide CNG refueling coverage could support those NGVs who need to refuel before returning to their home base. With this concept, a more exact approach is provided for a NGV refueling infrastructure that meets the goals and principles defined earlier.

NGV REFUELING INFRASTRUCTURE PLANNING

Step 1 - Identify customer fleet fuel requirements

The first step is to identify the fleets for converting to NGVs and their refueling volumes. The focus is on high volume fleets to base load the CNG stations.

Table 5: Light Duty NGVs per CNG Station

$\left.\begin{array}{lccc}\multicolumn{3}{l}{\text { Gallons per Vehicle per }} & \text { No. NGVs per } \\ \underline{\text { Day }} & \underline{\text { Week }} & \underline{\text { Month }} & \underline{10,000 \text { gal/month station }} \\ 1 & 5 & 20 & 500 \\ 2 & 10 & 40 & 250 \\ 5 & 25 & 100 & 100 \\ 10 & 50 & 200 & 50\end{array}\right\}$ Target high volume fleets

Few fleets have homogeneous refueling needs among all of its vehicles. The example for light duty NGVs shown in Table 6 uses the average gallons per month which typically varies greatly among fleet vehicles.

Table 6: NGV Fuel Demand Based on Daily Distances Traveled

\begin{tabular}{llll} 
Operating\# NGVs & $\begin{array}{l}\text { Distance } \\
\text { Gal/month }\end{array}$ & \multicolumn{2}{c}{ Average } \\
5 & 200 & 40 \\
10 & 200 & 60 \\
15 & 200 & 80 \\
25 & 200 & $\underline{100}$
\end{tabular}


Step 2 - Identify Customer Fleet Operating Area

In Figure 8 and Table 7 Areas I through IV are defined as between the area of two radii of circles. For example, Area III is between the circles formed by the 10 and 15 mile radii. Its area is then $700-300=400$ square miles (See Table 7 ).

For the fleet in this example, it services the area with 200 vehicles for every 5 miles from its fleet location. ${ }^{3}$ With a 15 mile operating distance covering about 700 square miles that include Areas I, II and III, 600 fleet vehicles are required averaging one per 0.9 square miles. Within Area III itself, 200 fleet vehicles operate averaging one per 0.5 square miles as shown in Figure 8 and Table 7. This needs to be done for each fleet.

Figure 8: Fleet Operating Area and NGVs

Table 7: Number and Density of NGVs from One Fleet Location

\begin{tabular}{|c|c|c|c|c|c|c|c|}
\hline \multirow[b]{2}{*}{ Area } & \multirow{2}{*}{$\begin{array}{l}\text { Operating } \\
\text { Distance }\end{array}$} & \multicolumn{2}{|c|}{ Sq. Mi. within } & \multicolumn{2}{|c|}{ Total \# NGVs } & \multicolumn{2}{|c|}{ \# NGVs per } \\
\hline & & $\underline{\text { Circle }}$ & Area & $\underline{\text { Circle }}$ & Area & Circle & Area \\
\hline 1 & 5 & 80 & 80 & 200 & 200 & 2.5 & 2.5 \\
\hline II & 10 & 300 & 220 & 400 & 200 & 1.3 & 0.9 \\
\hline III & 15 & 700 & 400 & 600 & 200 & 0.9 & 0.5 \\
\hline IV & 25 & 2000 & 1300 & 800 & 200 & 0.4 & 0.2 \\
\hline
\end{tabular}

\footnotetext{
${ }^{3}$ Assumes that a fleet's NGVs customer base decreases away from its fleet's central location.
} 


\section{Step 3 - Identify Refueling Demand}

Central refueling typically meets a vehicle's needs within a 5-10 radius from the fleets location. Area coverage is often required to add NGVs requiring refueling outside the fleet's location as depicted in Figure 9. From this, the number of NGVs requiring area wide refueling and their estimated fuel demand can be determined as reflected in Table 8.

\section{Figure 9: Defining Central Refueling from Area Wide Refueling in Terms of Distance from a Fleets Home Base}

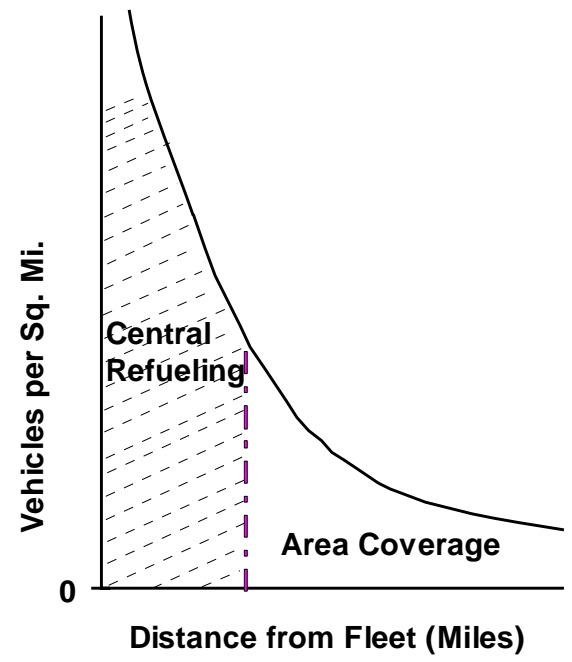

The NGVs serving each area are surveyed or assumptions are made determining where they refuel as shown in Table 8 . For example, the 200 NGVs in Area III refill 40\% of the time in Area I, 40\% in Area II where they travel through and $20 \%$ in Area III as they travel about. CNG demand is then calculated as shown in Table 8. For example, the:

Total Monthly Fuel Consumption in Area I within the 5 mile radius $=$

$200 * 40 * 100 \%+200 * 60 * 60 \%+200 * 80 * 40 \%+200 * 100 * 40 \%=29,600$ gallons

The total CNG demand within the 25 mile radius is 56,000 gallons.

Table 8: Calculating CNG Demand

\begin{tabular}{|c|c|c|c|c|c|c|c|c|}
\hline & Distance & \# Vehicles & Gal. per & \multicolumn{5}{|c|}{ Percent refueling from fleet location } \\
\hline Area & Operating & in Area & Month & $\underline{5 \mathrm{mi}}$ & $\underline{10 \mathrm{mi}}$ & $15 \mathrm{mi}$ & \multicolumn{2}{|c|}{$\underline{25 \mathrm{mi}}$} \\
\hline I & 5 & 200 & 40 & $100 \%$ & $0 \%$ & $0 \%$ & \multicolumn{2}{|l|}{$0 \%$} \\
\hline II & 10 & 200 & 60 & $60 \%$ & $40 \%$ & $0 \%$ & \multicolumn{2}{|l|}{$0 \%$} \\
\hline III & 15 & 200 & 80 & $40 \%$ & $40 \%$ & $20 \%$ & \multicolumn{2}{|l|}{$0 \%$} \\
\hline IV & 25 & 200 & 100 & $40 \%$ & $30 \%$ & $20 \%$ & \multicolumn{2}{|l|}{$10 \%$} \\
\hline & & ----- & & ----- & ----- & ----- & ----- & TOTAL \\
\hline & & 800 & & 29.6 & 17.2 & 7.2 & 2.0 & 56.0 \\
\hline
\end{tabular}

\section{Step 4 - Match supply with demand}

The principles in Table 3 dictate this step. That is providing area wide coverage, matching supply to demand, matching infrastructure growth with NGV growth, starting with central refueling or public refueling if convenient to fleet, adding public 
and/or card lock refueling to extend NGV operation area and managing on infrastructure costs. This is accomplished by establishing four types of CNG stations identified in Table 9. The costs are updated 2006 estimates.

Based on Table 8, stations from Table 9 are allocated to each area as shown in Table 10. The actual station size in gallons per month and area coverage can vary based on the metro area. As shown in Figure 10 the large central or public refueling Anchor Stations are in the center or Area I where the fleet is located. In the next ring between 5 and 10 miles out or Area II are the Growth Stations. In Area III further out are the Satellite Stations with their smaller volume for occasional refueling needs. In Area IV are Emergency Stations that allow fleet vehicles to return to their base or nearest refueling stations closer in. Billing from the Emergency Station could be either by dispenser or determined as storage containers are refilled combined with an ID card-lock system to keep cost down.

Table 9: CNG Station Options to Match Supply with Demand

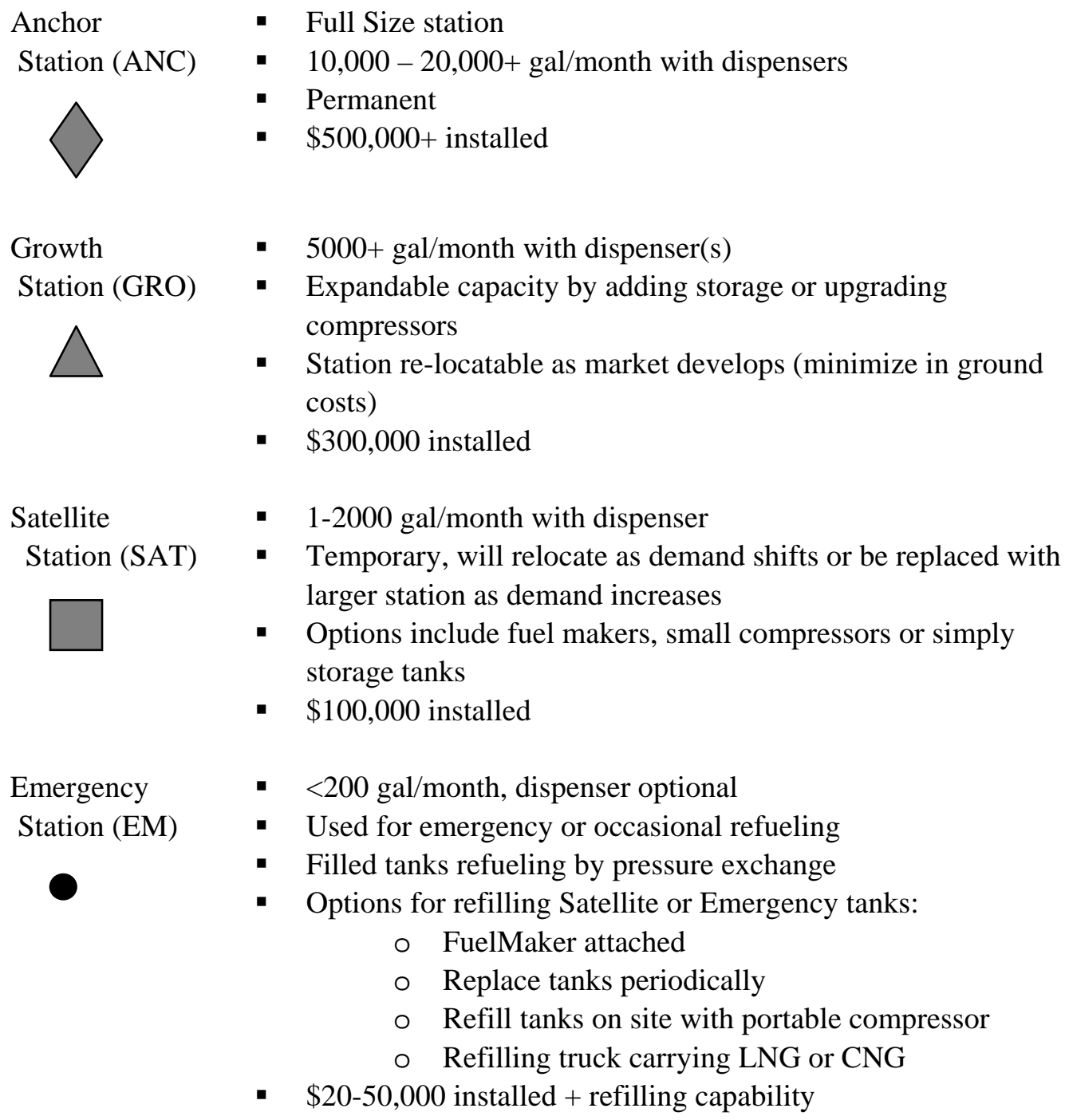

- Options include fuel makers, small compressors or simply storage tanks

- $\$ 100,000$ installed

Emergency $\quad$ - $\quad<200 \mathrm{gal} / \mathrm{month}$, dispenser optional

Station (EM) - Used for emergency or occasional refueling

- Filled tanks refueling by pressure exchange

- Options for refilling Satellite or Emergency tanks:

o FuelMaker attached

o Replace tanks periodically

o Refill tanks on site with portable compressor

o Refilling truck carrying LNG or CNG

- $\$ 20-50,000$ installed + refilling capability 
Table 10: Allocating CNG Stations Matching Supply with Demand

\begin{tabular}{|c|c|c|c|c|c|}
\hline & Operating & Monthly & \multicolumn{3}{|c|}{ No. Stations by Type } \\
\hline$\underline{\text { Area }}$ & Distance & $\underline{\text { Volume }} \underline{\mathrm{ANC}}$ & $\underline{\mathrm{GRO}}$ & $\underline{\text { SAT }}$ & $\underline{\mathrm{EM}}$ \\
\hline I & 5 & 29600 & 2 & & \\
\hline II & 10 & 21200 & & 3 & \\
\hline III & 15 & 7200 & & & 4 \\
\hline IV & 25 & 2000 & & & \\
\hline
\end{tabular}

The stations are located along the highway infrastructure and routes that best service the fleet vehicles while concurrently allowing new NGV fleets to conveniently use the CNG refueling infrastructure.

Figure 10 : Allocating CNG Stations matching Supply with Demand

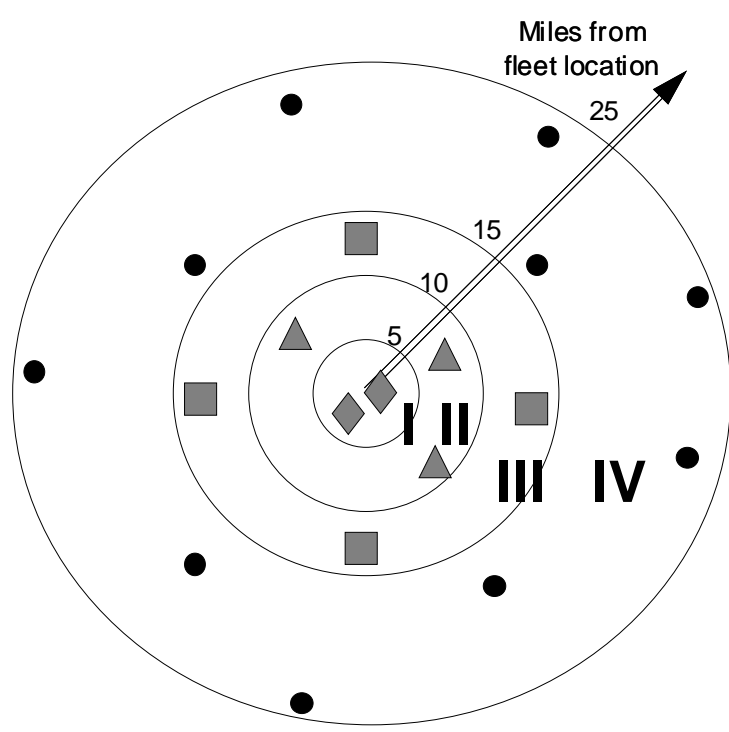

Step 5 - Match infrastructure development with NGV growth

CNG stations would be added as NGV demand grew. Figure 11 shows how they can be phased in matching the market growth. Stations are added, adjusted in size and type and moved around to match the NGV demand and forecasted growth. Ideally all the CNG stations are added as early as possible from year 1 on to promote NGV growth with an area wide refueling infrastructure.

With multiple fleets and as the NGV market grows, the CNG refueling infrastructures will overlap. This could occur during any phase of market growth. Overlapping areas are needed to foster NGV growth and a true area wide infrastructure. 
Figure 11: Match Infrastructure Development with NGV Growth and Marketing Phases

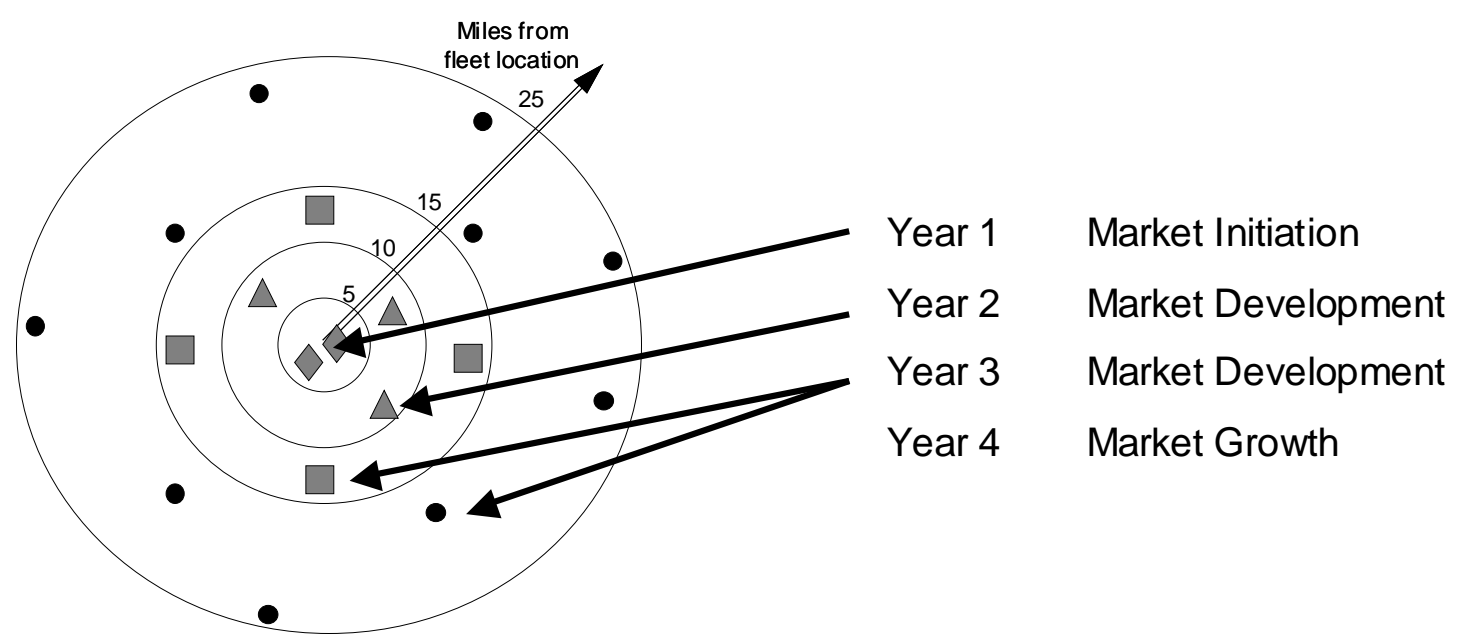

Figure 12: Match Infrastructure Development with Overlapping NGV Growth

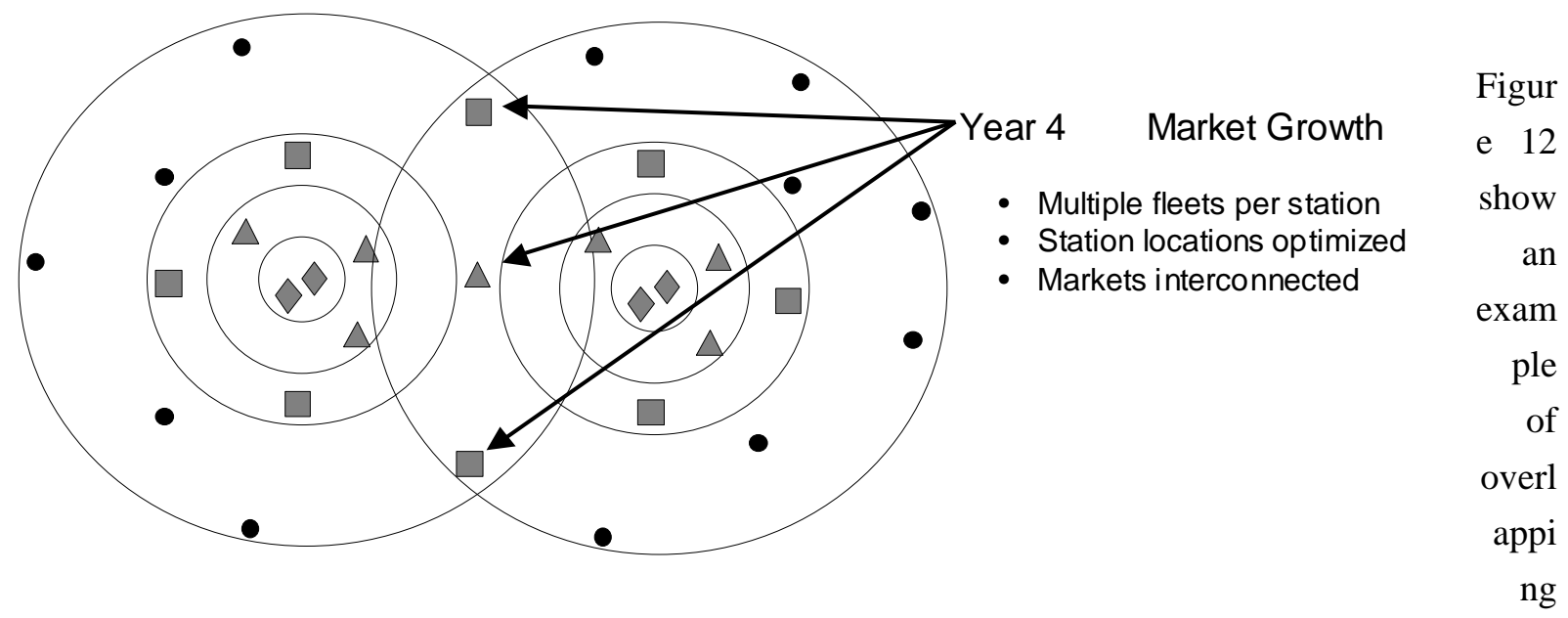

areas where larger Growth and Satellite stations are located to service both areas. Eventually permanent Anchor stations could go in as NGV demand rises and more areas overlap. In time LNG with LCNG can be added at truck stops and CNG or LCNG stations added along interstate and intrastate highways to connect metro and other NGV areas. Then a true regional NGV area wide infrastructure has been developed.

\section{SUMMARY}

Amoco in the 1990s demonstrated in the Metro Atlanta market that a NGV market could grow when supported by an area wide public CNG (Compressed Natural Gas) refueling infrastructure. 
The NGV infrastructure strategy was to:

Provide CNG area wide coverage for NGVs in its existing retail refueling stations, focus on major metropolitan markets, then expand into smaller markets, and interconnect all markets for regional refueling coverage.

Amoco's strategy differed from most across the nation at the time with its area wide coverage approach, focus on customer needs and satisfaction and providing transparent CNG and LNG refueling experiences. Amoco was successful in establishing LNG and LCNG stations as part of its strategy serving all vehicle types - light, medium and heavy duty. Key to its success was recognizing that a refueling infrastructure had to be in place to attract NGVs.

From Amoco's NGV experience, presented in Part III of this study is a modified NGV refueling infrastructure strategy more aligned with present government regulatory conditions and incentives. This updated strategy was developed but not implemented. Its goals are to maximize area coverage and refueling transparency while minimizing capital costs and operating costs. It follows basic principles identified as matching supply to demand, matching infrastructure growth with NGV growth, starting with central refueling or public refueling if convenient to fleets, adding public and/or card lock refueling to extend NGV operational areas, managing infrastructure costs, focusing on customer needs, and considering options with CNG, LNG and LCNG.

Following the Clinton Administration's decision to not adopt the optional mandate incentives in the Energy Act of 1992, Amoco exited CNG refueling for light and medium duty NGVs and refocused its efforts on the heavy duty NGVs fueled with LNG. When Amoco merged into British Petroleum (BP) in 1999, it exited the NGV industry entirely.

To change an infrastructure that has become a norm for both industry and society requires compelling economic incentives. For practical reasons, only the federal government can change a national transportation infrastructure. Had the Energy Act of 1992 mandates been implemented in 1996, Amoco would have continued its strategy attracting additional national fuel providers and support from auto OEMS. From this a national NGV infrastructure would likely have evolved with BP maintaining the Amoco NGV strategy. 


\section{REFERENCES}

Public Service CNG Station Budget Analysis, courtesy of ANGI International , ATTN: Chuck

Nelson, 15 Plumb St., Milton WI 53563. PH \# 608-868-4626 ext. 213, Fax \# 608-868-2723, email cnelson@angiinternational.com.

Domestic Vehicular Natural Gas Fuels Business, Strategic Planning, Alternative Transportation Fuels Business Unit (ATFBU), Amoco Oil Company, May 9, 1995.

Liquid Natural Gas (LNG) Vehicular Fuel Strategy Expansion, Amoco Corp, 1995.

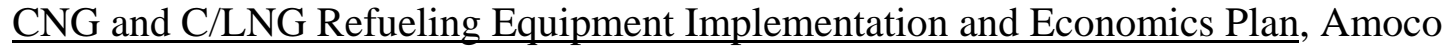

Corp, 1995.

Domestic Vehicular Natural Gas CNG Fuels Business Strategy Update and War Gaming

Exercise, Amoco Corp, 1995.

LNG and CNG Transportation Fuel, Proposal to Idaho National Engineering and Environmental Laboratory (INEEL), Amoco Corp, 1993.

Metro Atlanta Area Business and Market Plan (CNG), Amoco Corp, 1992.

Developing the Necessary Refueling Infrastructure to Support Natural Gas Fleets, Amoco Corp,

Department of Energy Northeast Regional Conference, 1997.

LNG as a Vehicle for Growth, Amoco Corp Strategic Planning Committee, 1997.

CNG, A Retailer's View, Amoco Corp, Southeastern Gas Association, 1995.

CNG Economics of On-Site versus Off-Site Refueling, Amoco Corp, U.S. NGV Conference, 1995.

CNG Fill'er Up Refueling Convenience, Amoco Corp, 6th Annual Alternative Vehicle Fuel Market

Fair \& Symposium, Texas, 1995.

Building a Compressed Natural Gas (CNG) Refueling Infrastructure in the United States, Amoco Corp, International NGV Conference, 1994.

Introducing Natural Gas Retailing into Major Metropolitan Areas, Amoco Corp, U.S. NGV

Conference, 1993. 